\title{
The 2020 report of The Lancet Countdown on health and climate change: responding to converging crises
}

Article

Accepted Version

Creative Commons: Attribution-Noncommercial-No Derivative Works 4.0

Watts, N., Amann, M., Arnell, N., Ayeb-Karlsson, S., Beagley, J., Belesova, K., Boykoff, M., Byass, P., Cai, W., CampbellLendrum, D., Capstick, S., Chambers, J., Coleman, S., Dalin, C., Daly, M., Dasandi, N., Dasgupta, S., Davies, M., Di Napoli, C., Dominguez-Salas, P., Drummond, P., Dubrow, R., Ebi, K. L., Eckelman, M., Ekins, P., Escobar, L. E., Georgeson, L., Golder, S., Grace, D., Graham, H., Haggar, P., Hamilton, I., Hartinger, S., Hess, J., Hsu, S.-C., Hughes, N., Jankin Mikhaylov, S., Jimenez, M. P., Kelman, I., Kennard, H., Kiesewetter, G., Kinney, P. L., Kjellstrom, T., Kniveton, D., Lampard, P., Lemke, B., Liu, Y., Liu, Z., Lott, M., Lowe, R., Martinez-Urtaza, J., Maslin, M., McAllister, L., McGushin, A., McMichael, C., Milner, J., Moradi-Lakeh, M., Morrissey, K., Munzert, S., Murray, K. A., Neville, T., Nilsson, M., Sewe, M. O., Oreszczyn, T., Otto, M., Owfi, F., Pearman, O., Pencheon, D., Quinn, R., Rabbaniha, M., Robinson, E. ORCID: https://orcid.org/0000-0002-4950-0183, Rocklöv, J., Romanello, M., Semenza, J. C., Sherman, J., Shi, L., Springmann, M., Tabatabaei, M., Taylor, J., Triñanes, J., Shumake-Guillemot, J., Vu, B., Wilkinson, P., Winning, M., Gong, P., Montgomery, H. and Costello, A. (2021) The 2020 report of The Lancet Countdown on health and climate 
change: responding to converging crises. Lancet, 397 (10269). pp. 129-170. ISSN 0140-6736 doi:

https://doi.org/10.1016/S0140-6736(20)32290-X Available at https://centaur.reading.ac.uk/94739/

It is advisable to refer to the publisher's version if you intend to cite from the work. See Guidance on citing.

Published version at: http://dx.doi.org/10.1016/S0140-6736(20)32290-X

To link to this article DOI: http://dx.doi.org/10.1016/S0140-6736(20)32290-X

Publisher: Elsevier

All outputs in CentAUR are protected by Intellectual Property Rights law, including copyright law. Copyright and IPR is retained by the creators or other copyright holders. Terms and conditions for use of this material are defined in the End User Agreement.

\section{$\underline{\text { www.reading.ac.uk/centaur }}$}

\section{CentAUR}

Central Archive at the University of Reading

Reading's research outputs online 
Nick Watts, Markus Amann, Nigel Arnell, Sonja Ayeb-Karlsson, Jessica Beagley, Kristine Belesova, Maxwell Boykoff, Peter Byass, Wenjia Cai, Diarmid Campbell-Lendrum, Stuart Capstick, Jonathan Chambers, Samantha Coleman, Carole Dalin, Meaghan Daly, Niheer Dasandi, Shouro Dasgupta, Michael Davies, Claudia Di Napoli, Paula Dominguez-Salas, Paul Drummond, Robert Dubrow, Kristie L. Ebi, Matthew Eckelman, Paul Ekins, Luis E. Escobar, Lucien Georgeson, Su Golder, Delia Grace, Hilary Graham, Paul Haggar, Ian Hamilton, Stella Hartinger, Jeremy Hess, Shih-Che Hsu, Nick Hughes, Slava Jankin Mikhaylov, Marcia P. Jimenez, Ilan Kelman, Harry Kennard, Gregor Kiesewetter, Patrick Kinney, Tord Kjellstrom, Dominic Kniveton, Pete Lampard, Bruno Lemke, Yang Liu, Zhao Liu, Melissa Lott, Rachel

Lowe, Jaime Martinez-Urtaza, Mark Maslin, Lucy McAllister, Alice McGushin, Celia McMichael, James Milner, Maziar Moradi-Lakeh, Karyn Morrissey, Simon Munzert, Kris A. Murray, Tara Neville, Maria Nilsson, Maquins Odhiambo Sewe, Tadj Oreszczyn, Matthias Otto, Fereidoon Owfi, Olivia Pearman, David Pencheon, Ruth Quinn, Mahnaz Rabbaniha, Elizabeth Robinson, Joacim Rocklöv, Marina Romanello, Jan C. Semenza, Jodi Sherman, Liuhua Shi, Marco Springmann, Meisam Tabatabaei, Jonathon Taylor, Joaquin Trinanes, Joy Shumake-Guillemot, Bryan Vu, Paul Wilkinson, Matthew Winning, Peng Gong*, Hugh Montgomery*, Anthony Costello*

* Denotes Co-Chair

Word Count: 18,002 


\section{Table of Contents}

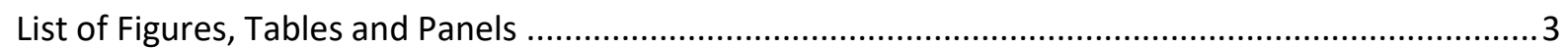

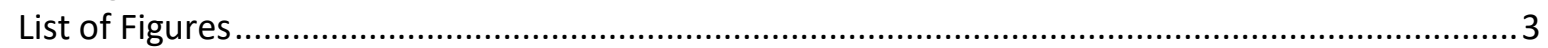

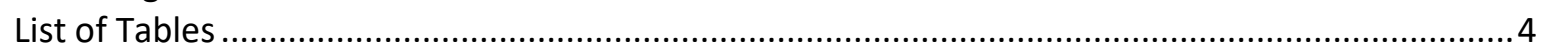

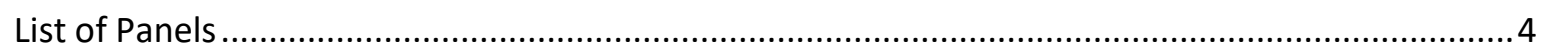

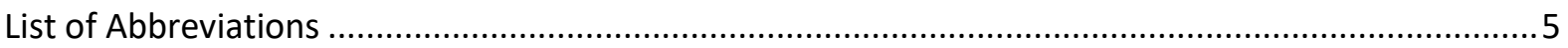

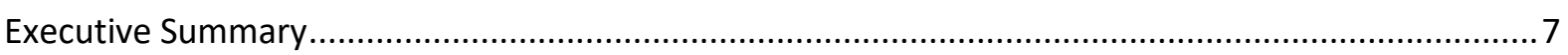

The Emerging Health Profile of the Changing Climate ................................................................ 7

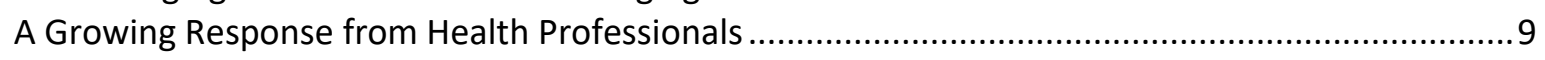

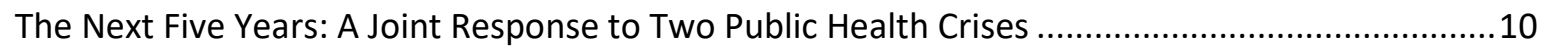

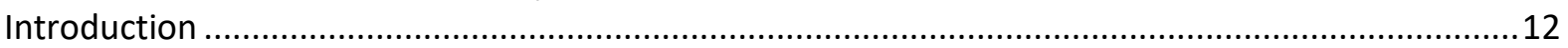

Expanding and strengthening a global monitoring system for health and climate change .............13

Section 1: Climate Change Impacts, Exposures, and Vulnerability ....................................................17

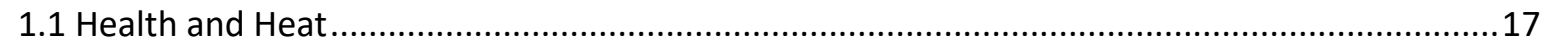

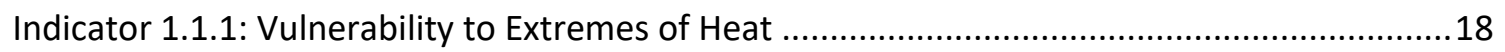

Indicator 1.1.2: Exposure of Vulnerable Populations to Heatwaves............................................ 18

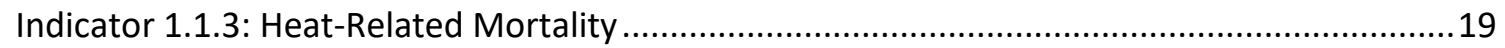

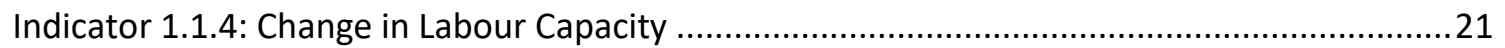

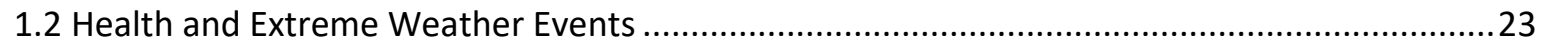

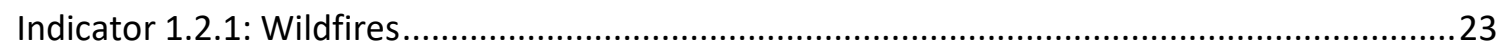

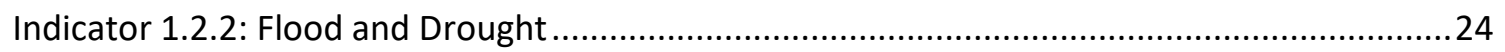

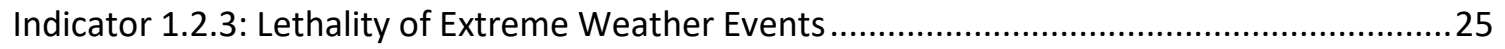

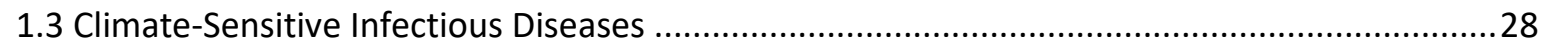
Indicator 1.3.1: Climate Suitability for Infectious Disease Transmission ....................................28

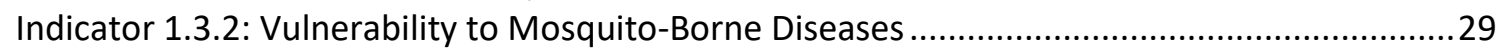

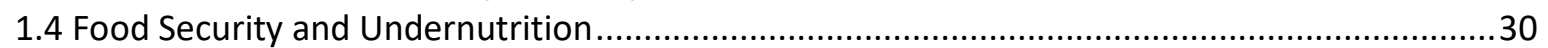

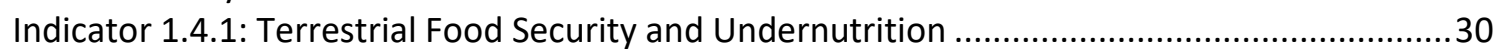

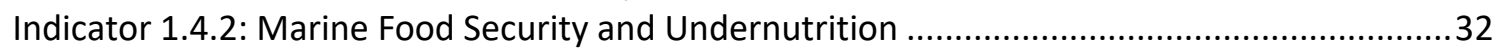

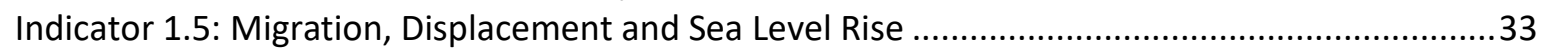

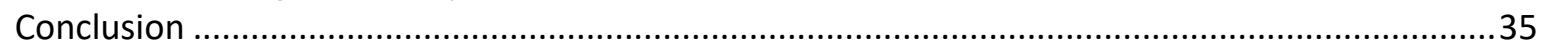

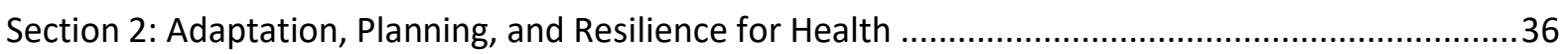

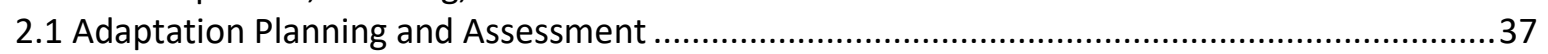

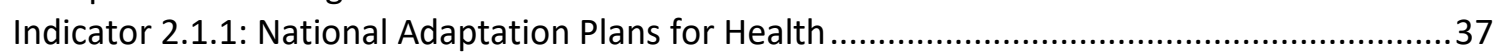

Indicator 2.1.2: National Assessments of Climate Change Impacts, Vulnerabilities, and

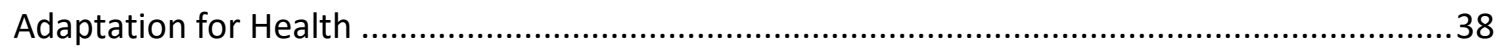

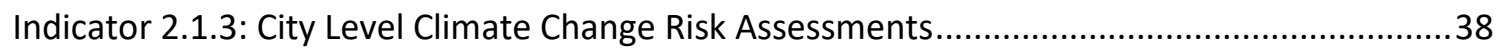

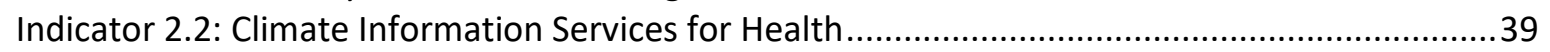

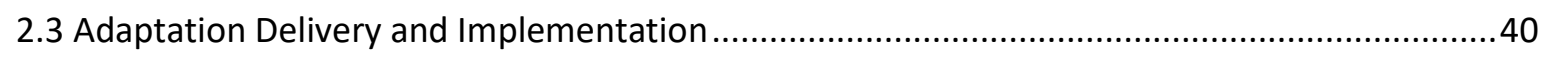

Indicator 2.3.1: Detection, Preparedness and Response to Health Emergencies ........................40

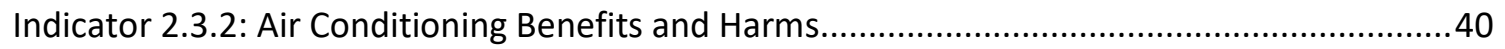

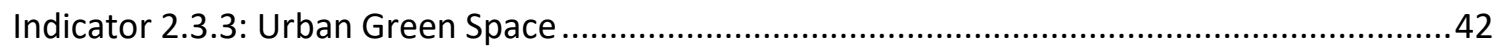

Indicator 2.4: Spending on Adaptation for Health and Health-Related Activities ..........................43

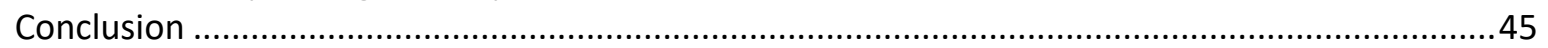

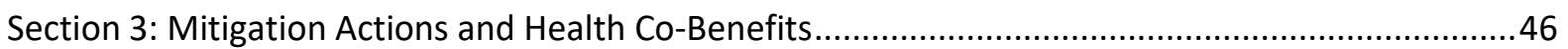

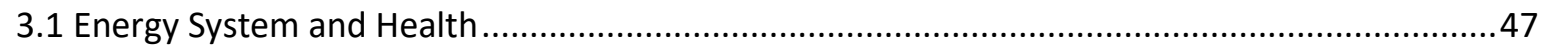

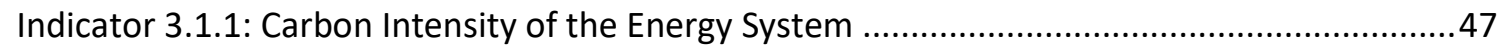

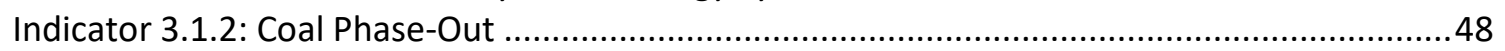

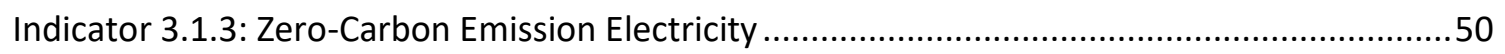


Indicator 3.2: Clean Household Energy 50 Indicator 3.3: Premature mortality from ambient air pollution by sector ..................................53 Indicator 3.4: Sustainable and Healthy Transport...............................................................5

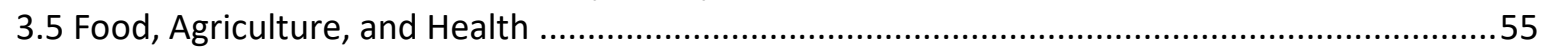
Indicator 3.5.1: Emissions from Agricultural Production and Consumption..............................55

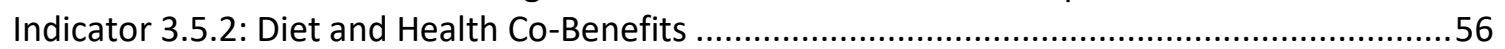

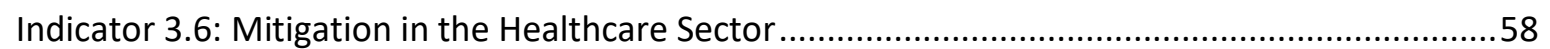

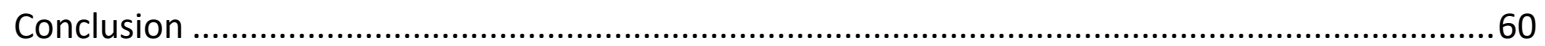

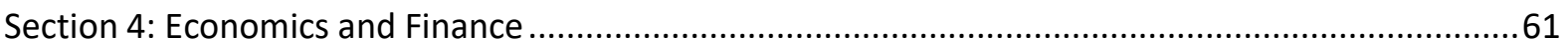

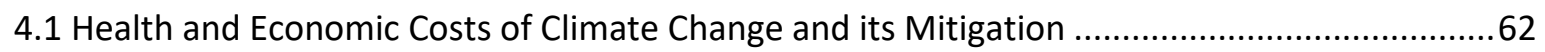
Indicator 4.1.1: Economic Losses due to Climate-Related Extreme Events .............................62 Indicator 4.1.2: Costs of Heat-Related Mortality ...............................................................62 Indicator 4.1.3: Loss of Earnings from Heat-Related Labour Capacity Reduction .....................63 Indicator 4.1.4: Economics of the Health Impacts of Air Pollution .........................................64

4.2 The Economics of the Transition to Zero-Carbon Economies ..............................................66 Indicator 4.2.1: Investment in New Coal Capacity ...........................................................66 Indicator 4.2.2: Investments in Zero-Carbon Energy and Energy Efficiency.............................67 Indicator 4.2.3: Employment in Renewable and Fossil Fuel Energy Industries .........................68 Indicator 4.2.4: Funds Divested from Fossil Fuels .....................................................69 Indicator 4.2.5: Net Value of Fossil Fuel Subsidies and Carbon Prices......................................70

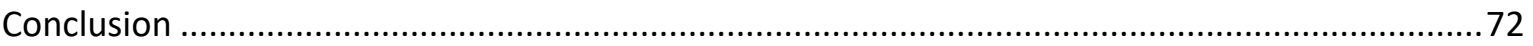

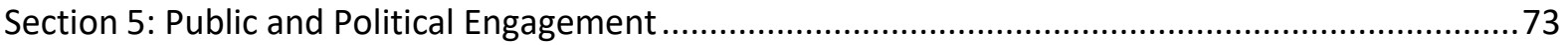
Indicator 5.1 Media Coverage of Health and Climate Change .................................................. 74 Indicator 5.2: Individual Engagement in Health and Climate Change .......................................... 76 Indicator 5.3: Coverage of Health and Climate Change in Scientific Journals ..............................77 Indicator 5.4: Government Engagement in Health and Climate Change ....................................78 Indicator 5.5: Corporate Sector Engagement in Health and Climate change ...............................81

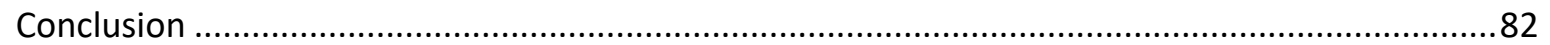

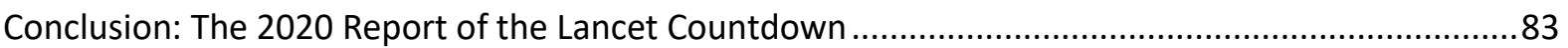

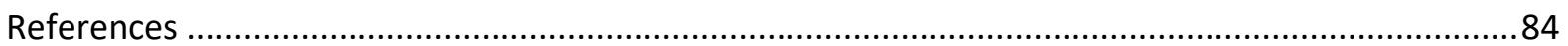

\section{List of Figures, Tables and Panels}

\section{List of Figures}

Figure 1: Change in days of heatwave exposure relative to the 1986-2005 baseline in the over 65 population............................................................................................................ 19 Figure 2: Global heat-related mortality for populations over the age of 65 , from $2000-2018$..........20 Figure 3: Annual heat-related mortality in the over 65 population, averaged from 2014 to 2018 ....21 Figure 4: Population-weighted mean changes in extremely high and very high fire danger days in 2016-2019 compared with 2001-2004

Figure 5: Change in climate suitability for infectious diseases ...............................................29 Figure 6: Change in crop growth duration for maize, soybean, spring wheat, winter wheat, and rice, relative to the $1981-2010$ global average................................................................................3 Figure 7: Number of people exposed to $1 \mathrm{~m}$ and $5 \mathrm{~m}$ of global mean sea level rise by country..........34 
127 Figure 8: Global proportion of households with air conditioning

128 Figure 9: Urban greenness in capital cities $>1$ million inhabitants in 2019.

129 Figure 10: Adaptation and Resilience to Climate Change (A\&RCC) spending for financial years

$1302015 / 16$ to 2018/19 by WHO Region Figure 11: Carbon intensity of Total Primary Energy Supply (TPES) for selected regions and countries, and global $\mathrm{CO}_{2}$ emissions by fuel type, 1971-2019.

Figure 12: Share of electricity generation coal in selected countries and regions, and global coal

Figure 14: Estimated net effect of housing design and indoor fuel burning on premature mortality due to air pollution in 2018.

Figure 15: Premature deaths attributable to exposure to ambient fine particulate matter $\left(\mathrm{PM}_{2.5}\right)$ in

Figure 18: Deaths attributable to high red meat consumption 1990-2017 by WHO region.

Figure 19: National per capita healthcare GHG emissions against the Healthcare Access and Quality Index for 2015. Figure 20: Monetised value of heat-related mortality represented as the number of people to whose income this value is equivalent, on average, for each WHO region...

Figure 21: Annual monetised value of YLLs due to anthropogenic PM2.5 exposure ...........................65

Figure 22: Annual investment in coal-fired capacity 2006-2019. national health expenditure, across 75 countries, 2016 and 2017 Figure 26: Average monthly coverage of (a) health and climate change and (b) climate change in 61 newspapers (36 countries), 2007-2019.

\section{List of Panels}

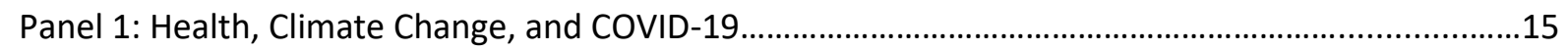

Panel 2: The Lancet Countdown Indicators.

Panel 3: Quantifying the Links between Climate Change, Human Health, and Extreme 
172 A\&RCC - Adaptation \& Resilience to Climate Change

173 CDP - Carbon Disclosure Project

174 CFU - Climate Funds Update

$175 \mathrm{CO}_{2}-$ Carbon Dioxide

$176 \mathrm{CO}_{2} \mathrm{e}-$ Carbon Dioxide Equivalent

177 COP - Conference of the Parties

178 ECMWF - European Centre for Medium-Range Weather Forecasts

179 EE MRIO - Environmentally-Extended Multi-Region Input-Output

180 EJ-Exajoule

181 EM-DAT - Emergency Events Database

182 ERA - European Research Area

183 ETS - Emissions Trading System

184 EU - European Union

185 EU28 - 28 European Union Member States

186 FAO - Food and Agriculture Organization of the United Nations

187 GBD - Global Burden of Disease

188 GDP - Gross Domestic Product

189 GHG - Greenhouse Gas

190 GNI - Gross National Income

$191 \mathrm{GtCO}_{2}-$ Gigatons of Carbon Dioxide

192 GW - Gigawatt

193 GWP - Gross World Product

194 HIC - High Income Countries

195 IEA - International Energy Agency

196 IHR - International Health Regulations

197 IPC - Infection Prevention and Control

198 IPCC - Intergovernmental Panel on Climate Change

199 IRENA - International Renewable Energy Agency

200 LMICs - Low- and Middle-Income Countries

201 LPG - Liquefied Petroleum Gas

202 Mt - Metric Megaton

$203 \mathrm{MtCO}_{2} \mathrm{e}-$ Metric Megatons of Carbon Dioxide Equivalent

204 MODIS - Moderate Resolution Imaging Spectroradiometer

205 MRIO - Multi-Region Input-Output

206 NAP - National Adaptation Plan

207 NASA - National Aeronautics and Space Administration

208 NDCs - Nationally Determined Contributions

209 NHS - National Health Service

$210 \mathrm{NO}_{\mathrm{x}}$ - Nitrogen Oxide

211 NDVI - Normalised Difference Vegetation Index

212 OECD - Organization for Economic Cooperation and Development

$213 \mathrm{PM}_{2.5}$ - Fine Particulate Matter

214 PV - Photovoltaic 
215 SDG - Sustainable Development Goal

216 SIDS - Small Island Developing State

217 SDU - Sustainable Development Unit

218 SSS - Sea Surface Salinity

219 SST - Sea Surface Temperature

$220 \mathrm{tCO}_{2}-$ Tons of Carbon Dioxide

221 tCO2/TJ - Total Carbon Dioxide per Terajoule

222 TJ-Terajoule

223 TPES - Total Primary Energy Supply

224 TWh - Terawatt Hours

225 UN - United Nations

226 UNFCCC - United Nations Framework Convention on Climate Change

227 UNGA - United Nations General Assembly

228 UNGD - United Nations General Debate

229 VC - Vectorial Capacity

230 WHO - World Health Organization

231 WMO - World Meteorological Organization 
233 The Lancet Countdown is an international collaboration, established to provide an independent, global monitoring system dedicated to tracking the emerging health profile of the changing climate.

The 2020 report presents 43 indicators across five sections: climate change impacts, exposures, and vulnerability; adaptation, planning, and resilience for health; mitigation actions and health co-benefits; economics and finance; and public and political engagement. This report represents the findings and consensus of the 35 leading academic institutions and UN agencies that make up the Lancet Countdown, and draws on the expertise of climate scientists, geographers, and engineers; of energy, food, and transport experts; and of economists, social and political scientists, data scientists, public health professionals, and doctors.

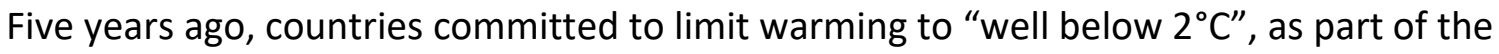
landmark Paris Agreement. Five years on, global $\mathrm{CO}_{2}$ emissions continue to rise steadily, with no convincing or sustained abatement, and a resultant $1.2^{\circ} \mathrm{C}$ of global average temperature rise. Indeed, the five hottest years on record have occurred since 2015.

250

251

252

253

254

255

256

257

258

259

260

261

262

263

264

265

266

The changing climate has already produced significant shifts in the underlying social and environmental determinants of health, at the global level. Indicators in all of the domains of impacts, exposures and vulnerabilities that the collaboration tracks are worsening. Here, concerning, and often accelerating trends are seen for each of the human symptoms of climate change monitored, with the 2020 indicators presenting the most worrying outlook reported since the Lancet Countdown was first established.

These effects are often unequal, disproportionately impacting populations who have contributed the least to the problem. This reveals a deeper question of justice, whereby climate change interacts with existing social and economic inequalities and exacerbates long-standing trends within and between countries. An examination of the causes of climate change reveals similar issues, and many carbon-intensive practices and policies lead to poor air quality, poor food quality, and poor housing quality, which disproportionately harms the health of disadvantaged populations.

Vulnerable populations experienced an additional 475 million heatwave exposure events globally, which is in turn reflected in excess morbidity and mortality, with a $53.7 \%$ increase in heat-related deaths over the last 20 years, up to a total of 296,000 deaths in 2018 (Indicators 1.1.2 and 1.1.3). The high cost in terms of human lives and suffering is associated 
with impacts on economic output, with more than 80 billion hours of potential labour capacity lost in 2019 (Indicators 1.1 .3 and 1.1.4). China, India, and Indonesia are among the worst affected countries, experiencing potential labour capacity losses equivalent to $4-6 \%$ of their annual gross domestic product (Indicator 4.1.3). In Europe, the monetised cost of heatrelated mortality was equivalent to $1.2 \%$ of its gross national income, or the average income of 11 million European citizens (Indicator 4.1.2).

273

274

275

276

277

278

279

280

281

282

283

284

285

286

287

288

289

290

291

292

293

294

295

296

297

298

299

300

301

302

303

304

Turning to extremes of weather, advancements in climate science increasingly allow for greater accuracy and certainty in attribution, with studies from 2015 to present day demonstrating the fingerprints of climate change in 76 floods, droughts, storms, and temperature anomalies (Indicator 1.2.3). Further, 114 countries experienced an increased number of days where people were exposed to very high or extremely high wildfire risk up to present day (Indicators 1.2.1). Correspondingly, 67\% of global cities surveyed expect climate change to seriously compromise their public health assets and infrastructure (Indicator 2.1.3).

The changing climate has down-stream effects, impacting broader environmental systems, which in turn harms human health. Global food security is threatened by rising temperatures and increases in the frequency of extreme events, with a 1.8-5.6\% decline in global yield potential for major crops observed from 1981 to present day (Indicator 1.4.1). The climate suitability for infectious disease transmission has been growing rapidly since the 1950 s, with a $15 \%$ increase for dengue from Aedes albopictus globally, and similar regional increases for malaria and Vibrio (Indicator 1.3.1). Projecting forward based on current populations, between 145 million and 565 million people face potential inundation from sea level rise (Indicator 1.5).

Despite these clear and escalating signs, the global response to climate change has been muted and national efforts continue to fall far short of the commitments made in the Paris Agreement. The carbon intensity of the global energy system has remained almost flat for 30 years, with global coal use increasing by $74 \%$ over this time (Indicators 3.1 .1 and 3.1.2). The reduction in global coal use that had been observed since 2013 has now reversed for the last two consecutive years as coal use rose by $1.7 \%$ from 2016 to 2018 . The health burden here is substantial - over one million deaths occur every year as a result of air pollution from coal-fired power, and some 390,000 of these as a result of particulate pollution in 2018 (Indicator 3.3). The response in the food and agricultural sector has been similarly concerning. Emissions from livestock grew by $16 \%$ from 2000 to $2017,82 \%$ of which came from cattle (Indicator 3.5.1). This mirrors increasingly unhealthy diets seen around the world, with excess red meat consumption contributing to some 990,000 deaths in 2017 (Indicator 3.5.2). Five years on from when countries reached agreement in Paris, a concerning number of indicators are showing an early, but sustained reversal of previously positive trends identified in past reports (Indicators 1.3.2, 3.1.2 and 4.2.3). 
307 Despite limited economy-wide improvement, relative gains have been made in a number of

308 key sectors, with a 21\% annual increase in renewable energy capacity from 2010 to 2017, 309 and low-carbon electricity now responsible for $28 \%$ of capacity in China (Indicator 3.1.3).

310 However, the indicators presented in the 2020 report of the Lancet Countdown suggest that 311 some of the most significant progress can be seen in the growing momentum of the health 312 profession's engagement with climate change, globally. Doctors, nurses, and the broader profession have a central role to play in health system adaptation and mitigation, in seeking 314 to understand and maximise the health benefits of any intervention, and in communicating 315 the need for an accelerated response.

316 In the case of national health system adaptation, this change is underway. Impressively, 317 health services in 86 countries are now connected with their equivalent meteorological 318 services to assist in health adaptation planning (Indicator 2.2). At least 51 countries have developed national health adaptation plans, which is coupled with a sustained $5.3 \%$ rise in health adaptation spending globally, reaching US\$18.4 billion in 2019 (Indicators 2.1.1 and 2.4).

The healthcare sector - responsible for $4.6 \%$ of global greenhouse gas emissions - is taking early but significant steps to reduce its own emissions (Indicator 3.6). In the United Kingdom, the National Health Service has declared an ambition to deliver a 'net-zero health service' as soon as possible, building on a decade of impressive progress that achieved a $57 \%$ reduction in 'delivery of care' emissions from 1990, and a $22 \%$ reduction when considering its supply chain and broader responsibilities. Elsewhere, the Western Australian Department of Health used its 2016 Public Health Act to conduct Australia's first Climate and Health Inquiry, and the German Ministry of Health has restructured to include a new department on Climate, Sustainability and Health Protection. This progress is becoming more evenly distributed around the world, with $73 \%$ of countries making explicit reference to health and wellbeing in their national commitments under the Paris Agreement, and $100 \%$ of countries in South East Asia and the East Mediterranean doing so (Indicator 5.4). Similarly, Least Developed Countries and Small Island Developing States are providing increasing global leadership within the UN General Debate on the connections between health and climate change (Indicator 5.4).

337 Individual health professionals and their associations are responding as well, with health 338 institutions committing to divest over US\$42 billion worth of assets from fossil fuels (Indicator 4.2.4). In academia, there has been a nine-fold increase in publication of original scientific articles on health and climate change from 2007 to 2019 (Indicator 5.3).

341 These shifts are being translated into the broader public discourse. From 2018 to 2019, the outpacing the increased attention in climate change overall, and reaching the highest 
observed point to-date (Indicator 5.1). Just as it did with advancements in sanitation and hygiene and with tobacco control, growing and sustained engagement from the health profession over the last five years is now beginning to fill a crucial gap in the global response to climate change.

December 12, 2020, marks the anniversary of the 2015 Paris Agreement, with countries set to update their national commitments and review them every five years. These next five years will be pivotal. In order to reach the $1.5^{\circ} \mathrm{C}$ target and maintain temperature rise "well below $2^{\circ} \mathrm{C}^{\prime \prime}$, the 56 gigatons of $\mathrm{CO}_{2} \mathrm{e}$ currently emitted annually will need to drop to $25 \mathrm{Gt}$ $\mathrm{CO}_{2} \mathrm{e}$ within only 10 years (by 2030). In effect, this requires a $7.6 \%$ reduction every year, representing a five-fold increase in current levels of national government ambition. Without further intervention over the next five years, the reductions required increase to $15.4 \%$ every year, moving the $1.5^{\circ} \mathrm{C}$ target out of reach.

358 The need for accelerated efforts to tackle climate change over the next five years will be contextualised by the impacts of, and the global response to, COVID-19. With the loss of life from the pandemic and from climate change measured in the hundreds of thousands, the potential economic costs measured in the trillions, and the broader consequences expected to continue for years to come, the measures taken to address both of these public health crises must be carefully examined, and closely linked. In May 2020, over 40 million health professionals wrote to global leaders, emphasising this point. These health professionals are well placed to act as a bridge between the two issues, and considering the clinical approach to managing a patient with COVID-19 may be useful in understanding the ways in which these challenges should be jointly addressed.

368 In an acute setting, a high priority is placed on rapidly diagnosing and comprehensively assessing the situation. Likewise, further work is required to understand the problem, including: which populations are vulnerable to both the pandemic and to climate change; how global and national economies have reacted and adapted, and the health and environmental consequences of this; and which aspects of these shifts should be retained to support longer term sustainable development. Secondly, appropriate resuscitation and treatment options are reviewed and administered, with careful consideration of any potential side-effects, the goals of care, and the life-long health of the patient. Economic recovery packages that prioritise out-dated fossil fuel-intensive forms of energy and transport will have unintended side-effects, unnecessarily adding to the seven million people that die every year from air pollution. Instead, investments in health imperatives such as renewable energy and clean air, active travel infrastructure and physical activity, and resilient and climate-smart healthcare, will ultimately be more effective. 
Thirdly, attention turns to secondary prevention and long-term recovery, seeking to minimise the permanent effects of the disease and prevent its recurrence. Many of the steps taken to prepare for unexpected shocks such as a pandemic are similar to those required to adapt to the extremes of weather and new threats expected from climate change. This includes the need to identify vulnerable populations, assess the capacity of public health systems, develop and invest in preparedness measures, and emphasise community resilience and equity. Indeed, without considering the current and future impacts of climate change, efforts to prepare for future pandemics will likely be undermined.

390 At every step and in both cases, acting with a level of urgency proportionate to the scale of 391 the threat, adhering to the best-available science, and practising clear and consistent communications is paramount. The consequences of the pandemic will contextualise governments' economic, social, and environmental policies over the next five years, a period that is crucial in determining whether temperatures will remain "well below $2^{\circ} \mathrm{C}$ ". Unless the global response to COVID-19 is aligned with the response to climate change, the world will fail to meet the target laid out in the Paris Agreement, damaging public health both in the short-term and in the long-term. 
400 The world has already warmed by over $1.2^{\circ} \mathrm{C}$ compared to pre-industrial levels, resulting in 401 profound, immediate, and rapidly worsening health impacts, and moving dangerously close 402 to the agreed limit of maintaining temperatures "well below $2^{\circ} \mathrm{C}^{\prime \prime} .{ }^{1-4}$ These are seen on 403 every continent, with the ongoing spread of dengue fever across South America; the 404 cardiovascular and respiratory effects of record heatwaves and wildfires in Australia, 405 California, and Western Europe; and the undernutrition and mental health impacts of flood 406 and drought in China, Bangladesh, Ethiopia, and South Africa. ${ }^{5-8}$ In the long-term, climate 407 change threatens the very foundations of human health and wellbeing, with the Global Risks 408 Report registering it as one of the five most damaging or likely global risks, every year, for 409 the last decade. ${ }^{9}$

410 It is clear that human and environmental systems are inextricably linked, and that any 411 response to climate change must harness, rather than damage these connections. ${ }^{10}$ Indeed, 412 a response commensurate to the size of the challenge - which prioritises health system 413 strengthening, invests in local communities, and ensures clean air, safe drinking water, and nourishing food - will provide the foundations for future generations to not only survive, but to thrive. ${ }^{11}$ Recent evidence suggests that increasing ambition from current climate policies to those which would limit warming to $1.5^{\circ} \mathrm{C}$ by 2100 would generate a net global benefit of US\$264 to $\$ 610$ trillion. ${ }^{12}$ The economic case is further strengthened when the benefits of a healthier workforce and of reduced healthcare costs are considered. ${ }^{13-15}$

419 The present-day impacts of climate change will continue to worsen without meaningful 420 intervention. These tangible, if less-visible, public health impacts have so far resulted in a 421 delayed and inadequate policy response. By contrast and on a significantly shorter timescale, COVID-19, the disease caused by severe acute respiratory syndrome coronavirus 2 (SARS-CoV-2), has rapidly developed in to a global public health emergency. Since it was first detected in December 2019, the loss of life and livelihoods has occurred with staggering speed. However, as for climate change, much of the impact is expected to unfold over the coming months and years, and is likely to disproportionately affect vulnerable populations as both the direct impacts of the virus, and the indirect effects of the response to the virus are felt throughout the world. Panel 1 takes stock of this, and draws a number of lessons and parallels between climate change and COVID-19, focusing on the response to, and 430 recovery from the two health crises.

431 The Lancet Countdown exists as an independent, multi-disciplinary collaboration dedicated to tracking the links between public health and climate change. It brings together 35 academic institutions and UN agencies from every continent, and structures its work across five key domains: climate change impacts, exposures, and vulnerability; adaptation planning and resilience for health; mitigation actions and their health co-benefits; economics and finance; and public and political engagement (Panel 2). The 43 indicators and conclusions presented in this report are the cumulative result of the last eight years of collaboration, 
and represent the consensus of its 86 climate scientists; geographers; engineers; energy, food, and transport experts; economists; social and political scientists; public health professionals; and doctors.

441 Where the pandemic has direct implications for an indicator being reported (and where accurate data exists to allow meaningful comment), these will be discussed in-text. Beyond this, the 2020 report of the Lancet Countdown will maintain its focus on the connections between public health and climate change, and the collaboration has worked hard to ensure the continued high quality of its indicators, with only minor amendments and omissions resulting from the ongoing disruptions.

\section{Expanding and strengthening a global monitoring system for health and climate change}

The Lancet Countdown's work draws on decades of underlying scientific progress and data, with the initial indicator set selected as part of an open, global consultation that sought to identify which of the connections between health and climate change could be meaningfully tracked. ${ }^{16}$ Proposals for indicators were considered and adopted based on a number of criteria, including: the existence of a credible underlying link between climate change and health that was well described in the scientific literature; the availability of reliable and regularly updated data across expanded geographical and temporal scales; the presence of acceptable methods for monitoring; and the policy relevance and availability of actionable interventions.

An iterative and adaptive approach has seen substantive improvements to the vast majority indicators. Given this approach, and the rapidly evolving nature of the scientific and data landscape, each annual update replaces the analysis from previous years. The Appendix describes the methods, data sources, and improvements for each indicator in full, and is an essential companion to the main report.

The 2020 report of the Lancet Countdown reflects an enormous amount of work refining and improving these indicators, conducted over the last 12 months, including an annual update of the data.

469 A number of key developments have occurred, including:

- The strengthening and standardisation of methods and datasets for indicators that capture heat and heatwave; flood and drought; wildfires; the climate suitability of infectious disease; food security and undernutrition; health adaptation spending; 
food and agriculture; low-carbon healthcare; the economics of air pollution; and engagement in health and climate change from the media, the scientific community, and individuals.

- Improved or expanded geographical or temporal coverage of indicators that track: heat and heatwave; labour capacity loss; flood and drought; the climate suitability of infectious disease; climate change risk assessments in cities; use of healthy household energy; and household air pollution.

- The development of new indicators, exploring: heat-related mortality; migration and population displacement; access to urban green space; the health benefits of lowcarbon diets; the economics of extremes of heat and of labour capacity loss; net carbon pricing; and the extent to which the UNFCCC's Nationally Determined Contributions (NDCs) engage with public health.

This continued progress has been supported by the Lancet Countdown's Scientific Advisory Group and the creation of a new, independent Quality Improvement Process, which provides independent expert input on the indicators prior to the formal peer review process, adding rigour and transparency to the collaboration's research. In every case, the most up-to-date data available is presented, with the precise nature and timing of these updates varying depending on the data source. This has occurred despite the impact of COVID-19, which has only impacted on the production of a small sub-set of indicators for this report.

The Lancet Countdown has also taken a number of steps to ensure that it has the expertise, data, and representation required to build a global monitoring system. Partnering with Tsinghua University and Universidad Peruana Cayetano Heredia, the collaboration launched two new regional offices for South America (in Lima), and for Asia (in Beijing), as well as the development of a new partnership to build capacity in West Africa. This expansion is coupled with ongoing work to develop national and regional Lancet Countdown reports: in Australia, in partnership with the Medical Journal of Australia; in the European Union, in partnership with the European Environment Agency; in China; and in the United States. At the same time, a new data visualisation platform has been launched, allowing health professionals and policymakers to investigate the indicators in this report. (lancetcountdown.org/data-platform).

Future work will be concentrated on supporting these regional and national efforts, on building communications and engagement capacity, on developing new indicators (with a particular interest in developing indicators related to mental health and to gender), and on further improving existing indicators. To this end, the continued growth of the Lancet Countdown depends on the dedication of each of its composite experts and partners, continued support from the Wellcome Trust, and ongoing input and offers of support from new academic institutions willing to build on the analysis published in this report. 
Panel 1: Health, Climate Change, and COVID-19

As of the $31^{\text {st }}$ of July 2020 , the COVID-19 pandemic has spread to 188 countries, with over $17,320,000$ cases confirmed, and over 673,800 deaths recorded. ${ }^{17}$ The scale and extent of the suffering, and the social and economic toll will continue to evolve over the coming months, with its effects likely felt for years to come. ${ }^{18}$ The relationship between the spread of existing and novel infectious diseases, and worsening environmental degradation, deforestation and land-use change, and animal ill-health have long been analysed and described. Equally, both climate change and COVID-19 act to exacerbate existing inequalities within and between countries. ${ }^{19-21}$

As a direct consequence of the pandemic, an $8 \%$ reduction in greenhouse gas (GHG) emissions is projected for 2020, which would be the most rapid one-year decline on record. ${ }^{22}$ Crucially, these reductions do not represent the decarbonisation of the economy required to respond to climate change, but simply the freezing of economic activity. Equally, the $1.4 \%$ reduction which followed the 2008 global financial crisis was followed by a rebound, with emissions rising by $5.9 \%$ in 2010 . Likewise, it is unlikely that the current fall in emissions will be sustained, with any reductions potentially outweighed by a shift away from otherwise ambitious climate change mitigation policies. However, this need not be the case. ${ }^{22}$ Over the next five years, considerable financial, social, and political investment will be required to continue to protect populations and health systems from the worst effects of COVID-19, to safely restart and restructure national and local economies, and to rebuild in a way that prepares for future economic and public health shocks. Harnessing the health co-benefits of climate change mitigation and adaptation will ensure the economic, social, and environmental sustainability of these efforts, while providing a framework that encourages investment in local communities and health systems, as well as synergies with existing health challenges. ${ }^{23}$

Multiple, 'ready-to-go' examples of such alignment are available, such as commonalities seen in future pandemic preparedness and effective health adaptation climate-related impacts. ${ }^{24}$ In the latter, decisionmaking under deep uncertainty necessitates the use of the principles of flexibility, robustness, economic low-regrets, and equity to guide decisions. ${ }^{25,26}$ At the broader level, poverty reduction and health system strengthening will both stimulate and restructure economies, and are among the most effective measures to enhance community resilience to climate change. ${ }^{27}$

Turning to mitigation, at a time when more and more countries are closing down the last of their coal-fired power plants and oil prices are reaching record lows, the fossil fuel sector is expected to be worse affected than renewable energy. ${ }^{22}$ If done with care and adequate protection for workers, government stimulus packages are well placed to prioritise investment in healthier, cleaner forms of energy. Finally, the response to COVID-19 has encouraged a re-thinking of the scale and pace of ambition. Health systems have restructured services practically overnight to conduct millions of general practitioner and specialist appointments online, and a sudden shift to online work and virtual conferencing has shifted investment towards communications infrastructure instead of aviation and road transport. ${ }^{28,29} \mathrm{~A}$ number of these changes should be reviewed, improved on, and retained over the coming years.

It is clear that a growing body of literature and rhetoric will be inadequate, and this work must take advantage of the moment, to combine public health and climate change policies in a way that addresses inequality directly. The UNFCCC's COP26 - postponed to 2021, in Glasgow - presents an immediate opportunity for this, to ensure the long-term effectiveness of the response to COVID-19 by linking the recovery to countries' revised commitments (Nationally Determined Contributions) under the Paris Agreement. It is essential that the solution to one economic and public health crisis does not exacerbate another, and in the long-term, the response to COVID-19 and climate change will be most successful when they are closely aligned. 


\begin{tabular}{|c|c|c|}
\hline Working Group & \multicolumn{2}{|l|}{ Indicator } \\
\hline \multirow{12}{*}{$\begin{array}{l}\text { Climate Change } \\
\text { Impacts, } \\
\text { Exposure, and } \\
\text { Vulnerability }\end{array}$} & \multirow[t]{4}{*}{ 1.1: Health and Heat } & 1.1.1: Vulnerability to Extremes of Heat \\
\hline & & 1.1.2: Exposure of Vulnerable Populations to Heatwaves \\
\hline & & 1.1.3: Heat-Related Mortality \\
\hline & & 1.1.4: Change in Labour Capacity \\
\hline & \multirow{3}{*}{$\begin{array}{l}\text { 1.2: Health and Extreme Weather } \\
\text { Events }\end{array}$} & 1.2.1: Wildfires \\
\hline & & 1.2.2: Flood and Drought \\
\hline & & 1.2.3: Lethality of Weather-Related Disasters \\
\hline & \multirow{2}{*}{$\begin{array}{l}\text { 1.3: Climate-Sensitive Infectious } \\
\text { Diseases }\end{array}$} & 1.3.1: Climate Suitability for Infectious Disease Transmission \\
\hline & & 1.3.2: Vulnerability to Mosquito-Borne Diseases \\
\hline & \multirow[t]{2}{*}{ 1.4: Food Security and Undernutrition } & 1.4.1: Terrestrial Food Security and Undernutrition \\
\hline & & 1.4.2: Marine Food Security and Undernutrition \\
\hline & \multicolumn{2}{|c|}{ 1.5: Migration, Displacement and Sea-Level Rise } \\
\hline \multirow{8}{*}{$\begin{array}{l}\text { Adaptation, } \\
\text { Planning, and } \\
\text { Resilience for } \\
\text { Health }\end{array}$} & \multirow{3}{*}{$\begin{array}{l}\text { 2.1: Adaptation Planning and } \\
\text { Assessment }\end{array}$} & 2.1.1: National Adaptation Plans for Health \\
\hline & & $\begin{array}{l}\text { 2.1.2: National Assessments of Climate Change Impacts, } \\
\text { Vulnerability, and Adaptation for Health }\end{array}$ \\
\hline & & 2.1.3: City-Level Climate Change Risk Assessments \\
\hline & \multicolumn{2}{|l|}{ 2.2: Climate Information Services for Health } \\
\hline & \multirow[t]{3}{*}{$\begin{array}{l}\text { 2.3: Adaptation Delivery and } \\
\text { Implementation }\end{array}$} & $\begin{array}{l}\text { 2.3.1: Detection, Preparedness and Response to Health } \\
\text { Emergencies }\end{array}$ \\
\hline & & 2.3.2: Air Conditioning Benefits and Harms \\
\hline & & 2.3.3: Urban Green Space \\
\hline & \multicolumn{2}{|c|}{ 2.4: Spending on Adaptation for Health and Health-Related Activities } \\
\hline \multirow{9}{*}{$\begin{array}{l}\text { Mitigation } \\
\text { Actions and } \\
\text { Health Co- } \\
\text { Benefits }\end{array}$} & \multirow[t]{3}{*}{ 3.1: Energy System and Health } & 3.1.1: Carbon Intensity of the Energy System \\
\hline & & 3.1.2: Coal Phase-Out \\
\hline & & 3.1.3: Zero-Carbon Emission Electricity \\
\hline & \multicolumn{2}{|l|}{ 3.2: Clean Household Energy } \\
\hline & \multicolumn{2}{|c|}{ 3.3: Premature Mortality from Ambient Air Pollution by Sector } \\
\hline & \multicolumn{2}{|l|}{ 3.4: Sustainable and Healthy Transport } \\
\hline & \multirow[t]{2}{*}{ 3.5: Food, Agriculture, and Health } & $\begin{array}{l}\text { 3.5.1: Emissions from Agricultural Production and } \\
\text { Consumption }\end{array}$ \\
\hline & & 3.5.2: Diet and Health Co-Benefits \\
\hline & \multicolumn{2}{|l|}{ 3.6: Mitigation in the Healthcare Sector } \\
\hline \multirow{9}{*}{$\begin{array}{l}\text { Economics and } \\
\text { Finance }\end{array}$} & \multirow{4}{*}{$\begin{array}{l}\text { 4.1: The Health and Economic Costs of } \\
\text { Climate Change and Benefits from } \\
\text { Mitigation }\end{array}$} & 4.1.1: Economic Losses due to Climate-Related Extreme Events \\
\hline & & 4.1.2: Costs of Heat-Related Mortality \\
\hline & & 4.1.3: Loss of Earnings from Heat-Related Labour Capacity Loss \\
\hline & & 4.1.4: Costs of the Health Impacts of Air Pollution \\
\hline & \multirow{5}{*}{$\begin{array}{l}\text { 4.2: The Economics of the Transition to } \\
\text { Zero-Carbon Economies }\end{array}$} & 4.2.1: Investment in New Coal Capacity \\
\hline & & $\begin{array}{l}\text { 4.2.2: Investments in Zero-Carbon Energy and Energy } \\
\text { Efficiency }\end{array}$ \\
\hline & & 4.2.3: Employment in Low-Carbon and High-Carbon Industries \\
\hline & & 4.2.4: Funds Divested from Fossil Fuels \\
\hline & & 4.2.5: Net Value of Fossil Fuel Subsidies and Carbon Prices \\
\hline \multirow{5}{*}{$\begin{array}{l}\text { Public and } \\
\text { Political } \\
\text { Engagement }\end{array}$} & \multicolumn{2}{|c|}{ 5.1: Media Coverage of Health and Climate Change } \\
\hline & \multicolumn{2}{|c|}{ 5.2: Individual Engagement in Health and Climate Change } \\
\hline & \multicolumn{2}{|c|}{ 5.3: Coverage of Health and Climate Change in Scientific Journals } \\
\hline & 5.4: Government Engagement in Health & d Climate Change \\
\hline & 5.5: Corporate Sector Engagement in $\mathrm{He}$ & th and Climate Change \\
\hline
\end{tabular}


514 A changing climate threatens to undermine the last 50 years of gains in public health,

515 disrupting the wellbeing of communities, and the foundations on which health systems are

516 built. ${ }^{30}$ Its effects are pervasive, and impact the food, air, water, and shelter that society

517 depends on, extending across every region of the world and every income group. These

518 effects act to exacerbate existing inequities, with vulnerable populations within and

519 between countries affected more frequently, and with more lasting impact. ${ }^{3}$

520 Section 1 of the 2020 report tracks the links between climate change and human health

521 along several exposure pathways, from the climate signal through to the resulting health

522 outcome. This section begins by examining a number of dimensions of the effects of heat

523 and heatwave, ranging from exposure and vulnerability, through to the effects on labour

524 capacity, and on mortality (Indicators 1.1.1-1.1.4). The indicator on heat mortality has been

525 developed for 2020, and while ongoing work will strengthen these findings in subsequent

526 years, it complements existing indicators on exposure and vulnerability, and represents an

527 important step forward.

528 The second cluster of indicators navigate the effects of extreme weather events, tracking

529 wildfire risk and exposure, flood and drought, and the lethality of extreme weather events

530 (Indicators 1.2.1-1.2.3). The wildfire indicator now tracks wildfire risk as well as exposure,

531 the classification of drought has been updated to better align with climate change trends,

532 and an overview of the attribution of climate change to the health impacts of certain

533 extreme weather events is presented for the first time presented. The climate suitability

534 and associated population-vulnerability of several infectious diseases are monitored, and so

535 too are the evolving impacts of climate change on terrestrial and marine food security

536 (Indicators 1.3.1-1.4.2), with the consideration of regional variation providing more robust

537 estimates of the effects of temperature rise on crop yield potential. Another new indicator

538 closes this section, tracking population exposure to sea level rise in the context of migration

539 and displacement, alongside the resulting health impacts and the policy responses

540 (Indicator 1.5).

\subsection{Health and Heat}

544 Exposure to high temperature and heatwave results in in a range of negative health

545 impacts, from morbidity and mortality due to heat stress and heat stroke, to exacerbations

546 of cardiovascular and respiratory disease. ${ }^{31,32}$ The worst affected are the elderly, those with

547 disability or pre-existing medical conditions, those working outdoors or in non-cooled

548 environments and those living in regions already at the limits for human habitation. ${ }^{33}$ The 
following indicators track the vulnerability, exposure, and impacts of heat and heatwave in

550 every region of the world.

553 Headline finding: Vulnerability to extremes of heat continue to rise in every region of the 554 world, led by populations in Europe, and with those in the Western Pacific, South East Asia 555 and Africa all seeing an increase of more than 10\% since 1990.

556 This indicator re-examines the index results presented in the 2019 report, and introduces a more comprehensive index of heat vulnerability, which combines heatwave exposure data with data on the population susceptibility and the health system's ability to cope. ${ }^{30}$

As a result of aging populations, high prevalence of chronic disease and rising levels of urbanisation, since 1990, European and the Eastern Mediterranean populations have been the most vulnerable to extremes of heat, with vulnerabilities of $40.6 \%$ and $38.7 \%$ respectively in 2017. However, no region of the world is immune, with vulnerability worsening everywhere, and has risen since 1990 in Africa (28.4\% to 31.3\%), South-East Asia (28.3\% to $31.3 \%$ ) and the Western Pacific (33.2\% to $36.6 \%$ ). By taking into account health system strengthening and heat wave exposure across these regions, this vulnerability indicator can be more usefully built in to one which captures population risk. This has been done for the 2020 report (see Appendix), demonstrating trends similar to those seen above, with risk rising in every region. This index will be further developed over the course of 2020, and presented in-full alongside a broader suite of risk indicators, in future reports.

572 Headline finding: A record 475 million additional heatwave exposures affecting vulnerable

573 populations were observed in 2019, representing some 2.9 billion additional days of

574 heatwave experienced.

575 Figure 1 presents the change in days of heatwave exposure since 1980, relative to a historic 576 1986-2005 baseline. It highlights a dramatic rise since 2010, driven by the combination of 577 increasing heatwave occurrences and aging populations. In 2019 there were 475 million 578 additional exposure events. Expressed as the number of days a heatwave was experienced, 579 this breaks the previous 2016 record by an additional 160 million person-days.

580 Indicator 1.1.2 tracks heatwave exposure of vulnerable populations, now updated to make 581 use of the latest climate data and a hybrid population dataset. ${ }^{34-36}$ This indicator has 
undergone several additional improvements (detailed in full, in the Appendix) in order to best capture heatwave exposure in every region of the world, including an improved definition of heatwave; the quantification of exposure-days to capture changing frequency and duration; and improved estimates of demographic breakdown.

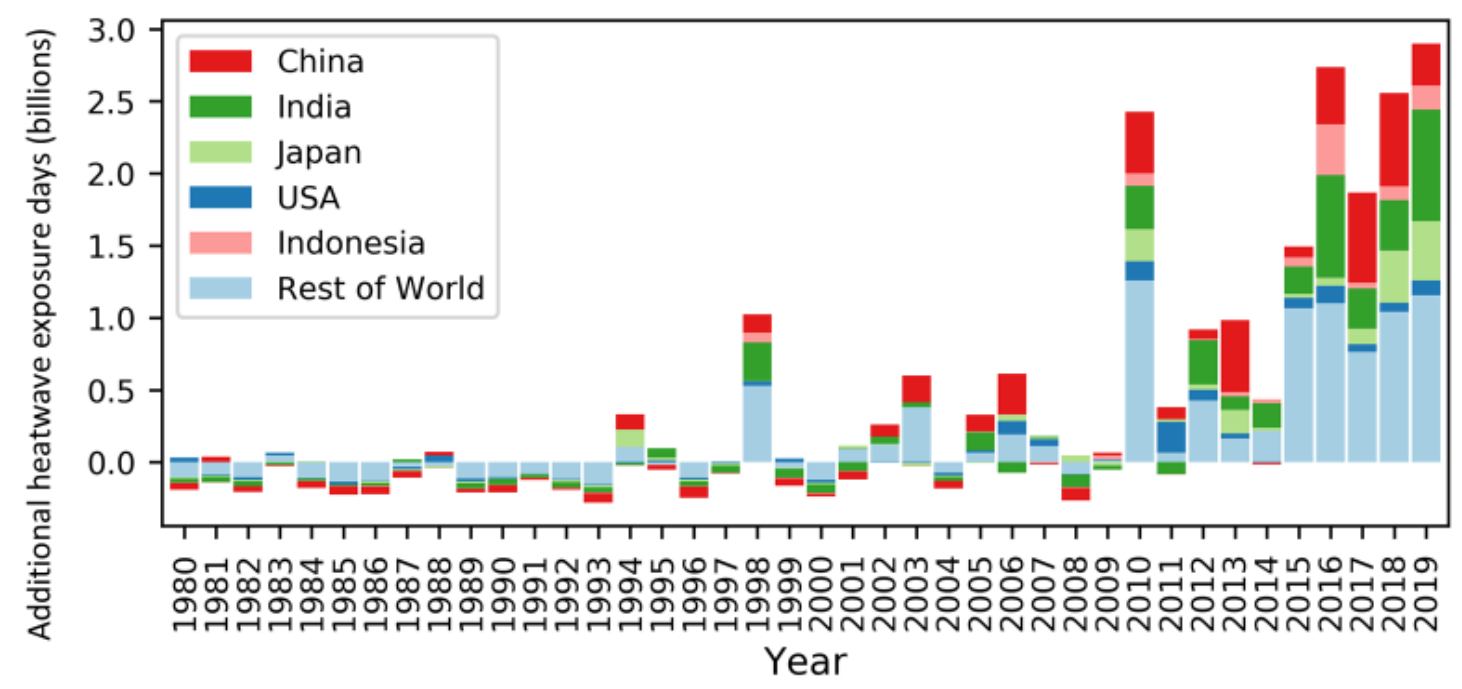

587

588

589

590

591

Indicator 1.1.3: Heat-Related Mortality

592

593

594

595

596

597

598

599

600

601

602 population. described in the Appendix. ${ }^{34-36}$

Figure 1: Change in days of heatwave exposure relative to the 1986-2005 baseline in the over 65

Headline finding: In the past two decades, heat-related mortality in the over-65 population has increased by 53.7\%, reaching 296,000 deaths in 2018, with the majority occurring in Japan, eastern China, northern India, and central Europe.

This metric, newly created for the 2020 report, tracks global heat-related mortality in populations over 65. Using methods originally described by the World Health Organization (WHO), it applies the exposure-response function and optimum temperature described by Honda et al (2014) to the daily maximum temperature exposure of the over 65 population to estimate the attributable fraction and thus the heat-related excess mortality. ${ }^{37,38}$ Daily maximum temperature data is taken from ERA5 and gridded population data was taken from a hybrid of NASA GPWv4 and ISIMIP population data, with a full methodology 
603

604

605

606

607

608

609

610

611

612

613

614

615
This indicator estimates that global average annual heat-related mortality in the over 65 population has increased by $53.7 \%$ from $2000-2004$ to $2014-2018$, with a total of 296,000 deaths in 2018 (Figure 2 and Figure 3). With the largest populations, China and India were greatest affected, with over 62,000 and 31,000 heat-related deaths respectively, followed by Germany (over 20,000), the USA (almost 19,000), Russia $(18,600)$, and Japan (over $14,000)$. At over 104,000 deaths, Europe was the most affected of the WHO regions. Importantly, the effects of temperature on mortality vary by region, and are modified by local factors including population urban green space, and inequality both within and between countries. ${ }^{39,40}$ Work has begun to develop a future form of this indicator, which builds in more localised exposure-response functions, as they become available.

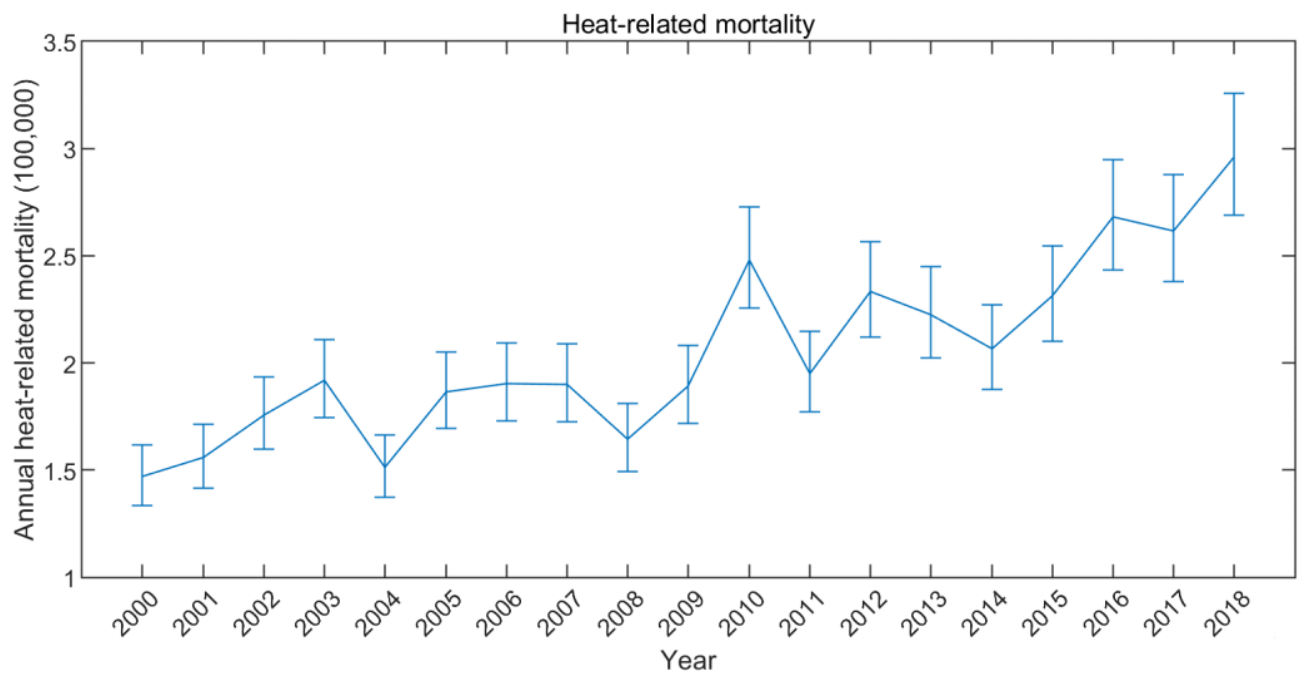

Figure 2: Global heat-related mortality for populations over the age of 65, from 2000-2018. 


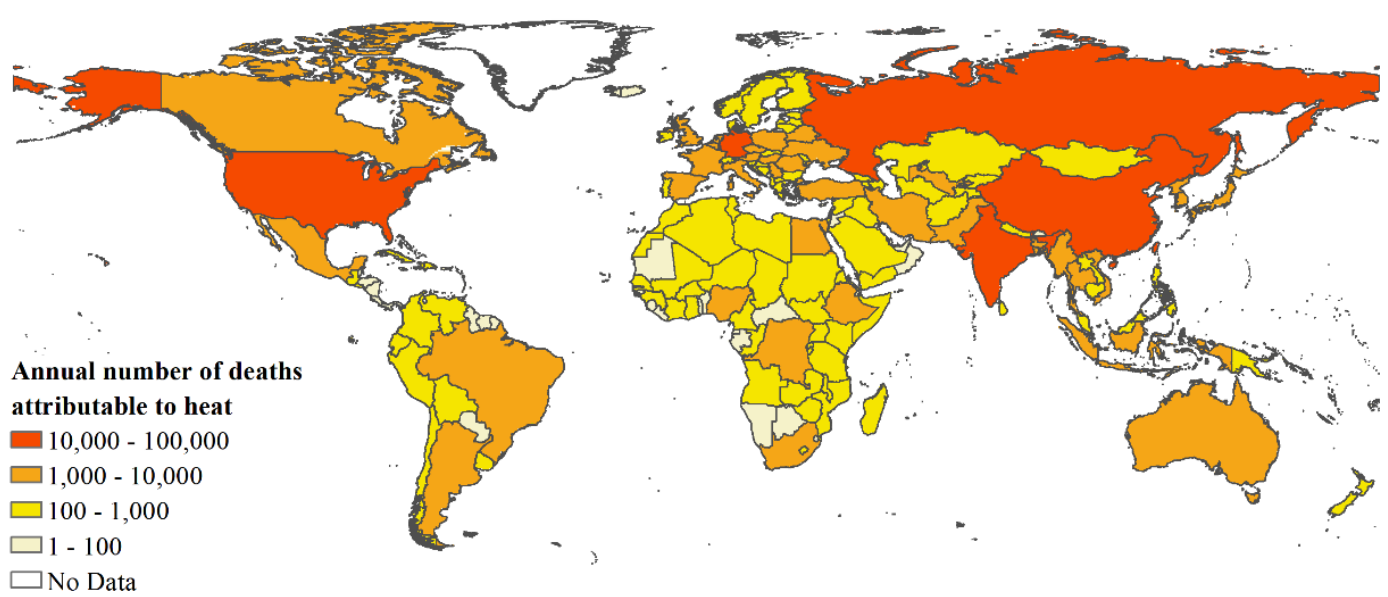

$\square$ No Data

Figure 3: Annual heat-related mortality in the over 65 population, averaged from 2014 to 2018.

620 Headline finding: Rising temperatures were responsible for an excess of 100 billion potential 621 work-hours hours lost globally in 2019 compared to 2000, with India's agricultural sector 622 among the worst affected.

623 This indicator tracks the effects of heat exposure on working people, with impact expressed 624 as potential work hours lost. ${ }^{41}$ It has been updated to capture construction, alongside 625 service, manufacturing, and agriculture sectors, drawing climate data from the ERA5 626 models, with methods and data described in full in the Appendix and previously. . $^{35,42-45}$

627 Across the globe a potential 302 billion work hours were lost in 2019 - 103 billion hours 628 greater than in 2000 . Thirteen countries represent approximately $80 \%$ of the global hours 629 lost in 2019 (Table 1), with India experiencing by far the greatest loss (39\% of total global 630 work hours lost in 2019) and Cambodia the highest impact per capita loss. Agricultural 631 workers experience the worst of these effects in many countries in the world, whereas the 632 burden is often on those in construction in high-income countries such as the USA. 
Table 1: Work hours lost (WHL) due to heat. These estimates are assuming all agricultural and

634 construction work was in the shade or indoors - the lower bounds of potential work hours lost. Work

635 hours lost per person are estimated for the population over 15.

636

\begin{tabular}{|c|c|c|c|c|}
\hline Country & $\begin{array}{l}\text { WHL } 2000 \\
\text { (billions) }\end{array}$ & $\begin{array}{l}\text { WHL } 2019 \\
\text { (billions) }\end{array}$ & $\begin{array}{l}\text { \% of Global } \\
\text { WHL, } 2019\end{array}$ & $\begin{array}{l}\text { WHL per } \\
\text { person, } 2019\end{array}$ \\
\hline Global & 199.0 & 302.4 & $100 \%$ & 52.7 \\
\hline India & 75.0 & 118.3 & $39.1 \%$ & 111.2 \\
\hline China & 33.4 & 28.3 & $9.4 \%$ & 24.5 \\
\hline Bangladesh & 13.3 & 18.2 & $6.0 \%$ & 148.0 \\
\hline Pakistan & 9.5 & 17.0 & $5.6 \%$ & 116.2 \\
\hline Indonesia & 10.7 & 15.0 & $5.0 \%$ & 71.8 \\
\hline Vietnam & 7.7 & 12.5 & $4.1 \%$ & 160.3 \\
\hline Thailand & 6.3 & 9.7 & $3.2 \%$ & 164.4 \\
\hline Nigeria & 4.3 & 9.4 & $3.1 \%$ & 66.7 \\
\hline Philippines & 3.5 & 5.8 & $1.9 \%$ & 71.4 \\
\hline Brazil & 2.8 & 4.0 & $1.3 \%$ & 23.3 \\
\hline Cambodia & 1.7 & 2.2 & $0.7 \%$ & 202.2 \\
\hline USA & 1.2 & 2.0 & $0.7 \%$ & 7.1 \\
\hline Mexico & 0.9 & 1.7 & $0.6 \%$ & 17.4 \\
\hline Rest of world & 28.7 & 58.3 & $19.3 \%$ & 27.5 \\
\hline
\end{tabular}


639 Extreme weather events, including wildfires, floods, storms, and droughts, affect human

640 health in a variety of ways, with the frequency and intensity of such events shifting as a

641 result of climate change. Death and injury as a direct result of an extreme event is often

642 compounded by effects that are mediated through the environment - for example, the

643 exacerbation of respiratory symptoms from wildfire smoke, or the spread of vector- and

644 water-borne diseases following a flood or drought. Finally, impacts are mediated through

645 social systems - for example, the disruption to health services, and the mental ill-health that

646 can result from storms and fires. ${ }^{3,46}$ The following indicators track population risk and

647 exposure to wildfires, changes in meteorological flood and drought, and the lethality of

648 extreme weather events.

Headline finding: 114 countries experienced an increase in the number of days people were

652 exposed to 'very high' or 'extremely high' fire danger risk for the four-year period ending

653 2019. At the same time, 128 countries experienced an increase in population exposure to

654 wildfires.

655 For the 2020 report, analysis on the effects of wildfires has been developed to track the 656 average number of days people are exposed to very high and extremely high wildfire risk 657 annually, as well as the change in actual population wildfire exposure across the globe, 658 using both model-based risk to wildfires and satellite-observed exposure. Climatological 659 wildfire risk is estimated by combining fire danger indices (FDI $\geq 5$ ) with climate and 660 population data for every $0.25^{\circ} \times 0.25^{\circ}$ grid cell. ${ }^{34,47}$ For wildfire exposure, satellite-observed 661 active fire spots were detected using the Moderate Resolution Imaging Spectroradiometer 662 (MODIS), and then aggregated and spatially joined with gridded global population data on a 663 global $10 \mathrm{~km}$ resolution grid, with urban areas excluded. ${ }^{34,48} \mathrm{~A}$ full description of the 664 methodology can be found in the Appendix.

665 Increased wildfire risk was observed in 114 out of 196 countries for the period 2016-2019 666 compared to 2001-2004, with the most prominent increases occurring in Lebanon, Kenya 667 and South Africa (Figure 4). Considering area-weighted rather than population-weighted 668 change, Australia, devastated by the 2019-2020 fire season, had one of the largest increases 669 in wildfire risk. Over the same time period, this risk translated into an additional 194,000 670 daily exposures to wildfires happening annually, around the world, and 128 countries 671 experiencing an increase in this metric. Driven by the record-breaking 2017 and 2018 fires, 
675

676

677

678

679

680

681

682

683

684

685

686

687

688

689

690

691
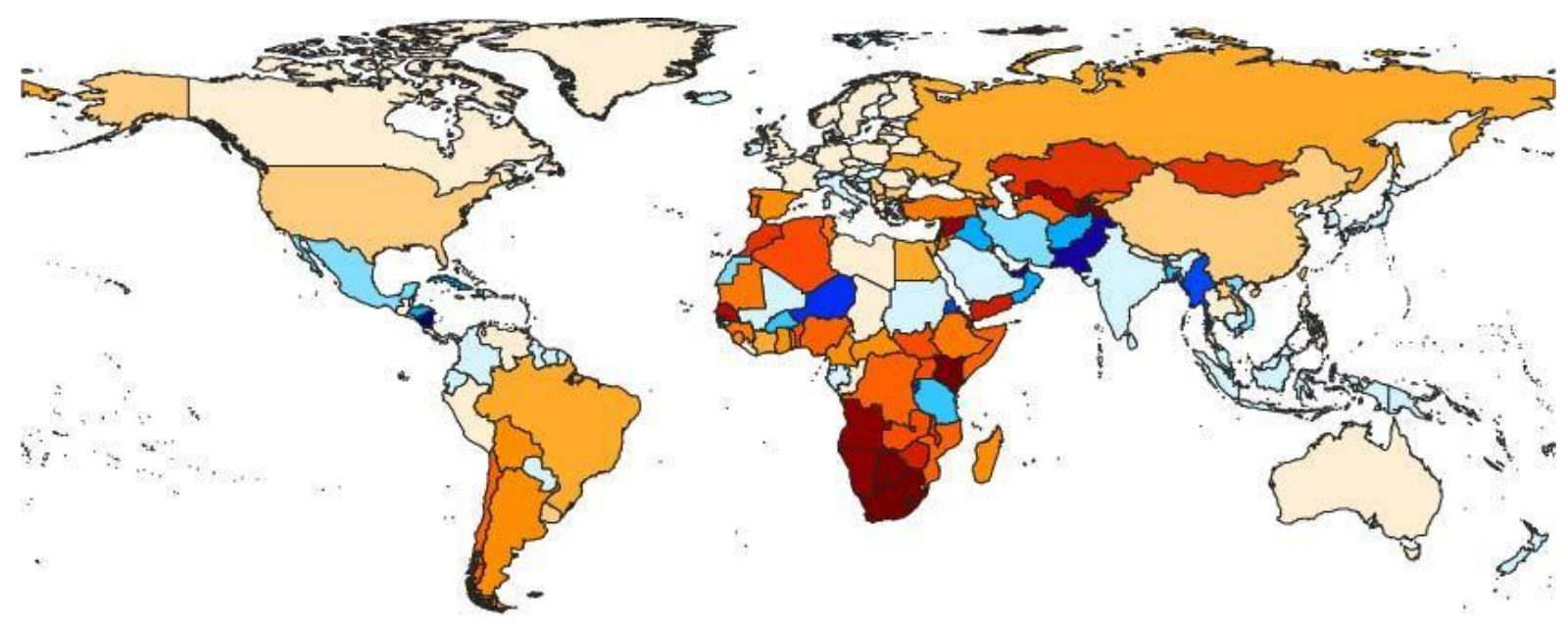

$\begin{array}{lllllllllll}-50 & -40 & -30 & -20 & -10 & 0 & 10 & 20 & 30 & 40 & 50\end{array}$

Change in number of days of exposure to high or very high wildfire risk

Figure 4: Population-weighted mean changes in extremely high and very high fire danger days in 2016-2019 compared with 2001-2004. Large urban areas with population density $\geq 400$ persons $/ \mathrm{km}^{2}$ are excluded.

Indicator 1.2.2: Flood and Drought

Headline finding: 2019 saw over twice the global land surface area affected by excess drought compared with the historical baseline.

Climate change alters hydrological cycles, tending to make dry areas drier and wet areas wetter. ${ }^{27}$ By altering rainfall patterns and increasing temperatures, climate change affects the intensity, duration and frequency of drought events. ${ }^{3,49}$ Drought poses multiple risks for health, threatening drinking water supplies and sanitation, crop and livestock productivity, enhancing the risk of wildfires and potentially leading to forced migration. ${ }^{50}$ At the same time, altered precipitation patterns increase the risk of localised flood events, resulting in direct injury, the spread of infectious diseases and impacts on mental health. ${ }^{51}$

In the 2020 report, meteorological drought is tracked through using the Standardised Precipitation-Evapotranspiration Index (SPEI), which takes into account both precipitation 
692

693

694

695

696

697

698

699

700

701

702

703

704

705

706

707

708

709

710

711

712

713

714

715

716

717

718

719

720

721

722

723

724

725

and temperature, as well as its impact on the loss of soil moisture. This measures significant increases in the number of months of drought compared with an extended historical baseline, from 1950-2005, in order to account for periodic variations such as those generated by the El Niño Southern Oscillation. ${ }^{52} \mathrm{~A}$ full explanation of the methodology and additional analysis are in the Appendix.

Since the turn of the century, the area affected by excess number of months in drought has increased globally, with more exceptional drought events affecting all populated continents in 2018. Areas that experienced unusually high number of months under excess drought in 2018 include Europe, the Eastern Mediterranean region, and specifically, Mongolia.

\section{Indicator 1.2.3: Lethality of Extreme Weather Events}

Headline finding: Long term increasing trends in the number of weather-related disasters from 1990 to 2019 were accompanied by increasing trends in the number of people affected by these disasters, in the countries where health expenditure has reduced or minimally increased over the last two decades.

The links between climate change and the health impacts of extreme weather events are presented in two ways for this indicator. The first studies long-term trends in the occurrence of such events along with the change in the number of people affected, and the resultant mortality. The methods and data for this are similar to that used in previous reports, and described in full in the Appendix. ${ }^{53,54}$ Recognising that an increase in the variability and intensity of these events is also expected, the second part considers the attribution of climate change to individual extreme events in recent years, and the effects that a selection of events have had on the health of populations (Table 2 and Panel 3 ).

There are clear, statistically significant trends in the number of occurrences of weatherrelated disasters, however insufficient evidence in either direction with respect to the number of deaths or number of people affected per event. Within the sub-set of countries demonstrating a reduction, or minimal increase in healthcare expenditure from 2000-2017, a significant increase in the number of people affected is identified. By contrast, in countries with the greatest increase in healthcare expenditure, the number of people affected by extreme weather events has declined despite an increasing frequency of events. One possible explanation for this could be the adaptive effects of health system strengthening. This relationship will be further explored, considering variables such as expenditure for specific healthcare functions and excess deaths in addition to the immediate event-related deaths. 
Event type

Anthropogenic influence increased event likelihood or strength

Heat

36 studies

32 events

Cold and frost

9 studies

8 events

Drought and

reduced

precipitation

26 studies

24 events

\section{Wildfire}

5 studies

6 events

Heavy
precipitation and
flood
23 studies
19 events

\section{Storms}

8 events

8 studies

Marine heat and melting sea ice

10 events

13 studies

Total events and studies 2015: India; Pakistan; China; Indonesia; Lanka; Australia; Global.8,56 Europe; ${ }^{58}$ China; Euro-Mediterranean. 2018: Northeast Asia; Iberia;

Europe.

2019: France; ${ }^{59}$ Western Europe. ${ }^{60}$ 2020: Australia. ${ }^{61}$ 2016: Australia.

2015: USA; Canada; Ethiopia; Indonesia; Australia. 2016: Southern Africa; Thailand. 2017: East Africa; USA; China. 2018: South Africa; ${ }^{64}$ China; USA

2015: USA

2016: Australia; Western North America. 2018: Australia. 2020: Australia. ${ }^{61}$

2015: China; USA. 2017: Bangladesh; Peru; Uruguay; China. 2018: USA; Japan. 6,71

2015: UK; $;^{74}$ Western North Pacific ${ }^{75}$

2017: USA. ${ }^{76}$

2018: USA. ${ }^{77}$

2019: USA. ${ }^{78}$

2015: Northern Hemisphere.

2016: USA; Australia; Coral Sea; 7,80 North

Equatorial Pacific.

2018: Tasman Sea; Bering Sea.

76 events, 81 studies
Anthropogenic influence decreased event likelihood or strength

Anthropogenic influence not identified or uncertain, or had varied effects $(*)$ Europe; ${ }^{8,55}$ Egypt; Japan; Southern India and Sri 2016: Southern Africa; Thailand; Asia; Global. 2017: Australia; ${ }^{57}$ USA; South Korea; Western

2015: USA.

2016: China.

2018: North America;63 UK.

2018: China. Zimbabwe and Zambia;

Pole; 7,81 Gulf of Alaska and Bering Sea; Central

5 events, 6 studies
2015: India.

2016: Germany; 69 Australia;

2017: Bangladesh. ${ }^{72}$ 2018: Mozambique, Australia; India; ${ }^{73}$ China.*

2015: Brazil; 65 Nigeria; Ethiopia. ${ }^{66}$ 016: Brazil; USA; Europe. 2017: Kenya. ${ }^{68}$ USA. 2019: Australia. ${ }^{61}$ 2017: Australia.

2016: USA.

2018: Western Europe. ${ }^{79}$

2015: Central Equatorial Pacific. 2016: Eastern Equatorial Pacific.

28 events, 27 studies studied. References are in Herring et al, 2016, ${ }^{8}$ Herring et al, 2018, ${ }^{7}$ Herring et al, 2019, ${ }^{5}$ Herring et al 2020, ${ }^{6}$ or listed separately. Adapted from the Bulletin of the American Meteorological Society. 
Panel 3: Quantifying the Links between Climate Change, Human Health, and Extreme Events

Formal statistical methods, grouped as detection and attribution studies (D\&A) are already used widely in other sectors, and are increasingly deployed to quantify the extent to which climate change has had observed impacts on population health and health systems. ${ }^{82-84}$ However, recent D\&A studies focusing on the changing likelihood and intensity of extreme events are generally limited to meteorological events in high- and upper-middle income countries. Further development of this body of literature offers an essential and unique way of improving understanding of current impacts and future risks of climate change on lives and livelihoods, guiding evidence-based management and adaptation.

The following three case studies illustrate the linkage of D\&A studies of meteorological events to the resulting health impacts.

\section{Reduced sea ice in the Arctic Region}

The Arctic Region is warming two to three times faster than the global annual average, with observable impacts for Arctic communities, but limited data on the health consequences. ${ }^{85}$ Extreme weather events, shifting migration patterns, and warmer and shorter winters now threaten food security and vital infrastructure.

The winter of 2017-18 heralded warm temperatures and an extreme 'low ice year' in the Bering Sea. ${ }^{86}$ Sea ice extent was the lowest in recorded and reconstructed history: an estimated two in 1800-year event compared with pre-industrial levels. One study suggested that climate change was responsible for $90 \%$ of the attributable risk, and that this level may become the mean within 20 years. ${ }^{87}$

This had multiple detrimental effects on communities in Western Alaska, although the health impacts have rarely been measured. These communities generally depend on sea ice for transportation, hunting and fishing, coastal buffering from storms, and a host of other ecosystem services. During this period of record-low sea ice, a range of events occurred, from the loss of power, and damage to the water treatment plant in Little Diomede to a fatal accident that resulted from open water-holes along a previously frozen travel corridor on the Kuskokwim River. ${ }^{88-90}$

\section{Northern European Heatwaves in 2018 and 2019}

During the summer of 2018, parts of northern Scandinavia experienced record-breaking daily temperatures more than $5^{\circ} \mathrm{C}$ warmer than in 1981-2010, an occurrence that evidence suggests was made five times more likely as a result of climate change. ${ }^{91}$ In Sweden, the Public Health Agency estimated an excess mortality of 750 deaths between July and August, with more than 600 of these attributed to higher temperatures when compared with the same weeks in $2017 .^{92}$

Countries across Western Europe and Scandinavia again experienced record-breaking temperatures in 2019, with several countries exceeding $40^{\circ} \mathrm{C}$ for 3-4 days during June and July. Attribution studies suggest climate change was responsible for a 10 -fold increase in the likelihood of the event occurring, and a $1.2-3^{\circ} \mathrm{C}$ increase in temperature of these events, with almost 1,500 deaths in France and 400 deaths in the Netherlands. ${ }^{60,93,94}$

\section{Japan Heatwave 2018}

The summer of 2018 in Japan saw a combination of a national emergency resulting from extreme precipitation, followed closely by record-breaking temperatures. The event had roughly a $20 \%$ probability of occurring in today's world compared with a zero probability in a world without climate change. ${ }^{95,96}$ Another attribution study compared modest and extreme heatwave days with a 1941-79 baseline, concluding that the probability of the defined heatwave event was 1.5 times higher for 1980-2018 and 7-8 times higher for 2019-2050. This hot summer had large health implications. In 2018, there were an estimated 14,200 heat-related deaths in Japan's over 65 population - over 3,000 more deaths than the previous record set in 2010, and 8,100 greater than the 2000-2004 average (Indicator 1.1.3). 
736

737

738

739

740

741

742

743

744

745

746

747

748

749

750

751

752

753

754

755

756

757

758

759

760

761

762

763

764

765

766

767

768

769

770

771

Headline finding: Changing climatic conditions are increasingly suitable for the transmission of numerous infectious diseases. From 1950 to 2018, the global climate suitability for the transmission of dengue fever increased by $8.9 \%$ for $A$. aegypti, and $15.0 \%$ for $A$. albopictus. In the last 5 years, suitability for malaria transmission in highland areas was $38.7 \%$ higher in the WHO African region and $149.7 \%$ higher in the WHO Western Pacific Region compared to a 1950s baseline.

Climate change is affecting the distribution and risk of many infectious diseases to humans, including vector-, food- and water-borne diseases. ${ }^{3}$ Using three different models, this indicator tracks the change in climate suitability for the transmission of infectious diseases of particular global significance: dengue; malaria; and pathogenic Vibrio bacteria ( $V$. parahaemolyticus, V. vulnificus, and non-toxigenic $V$. cholerae). In the case of Aedes aegypti and $A$. albopictus, temperature-driven process-based mathematical models were used to capture the vectorial capacity (VC) for the transmission of dengue. ${ }^{97}$ Change in the climate suitability for Plasmodium falciparum malaria is modelled based on empirically derived thresholds of precipitation, temperature and relative humidity. ${ }^{97,98}$ Highland areas $(\geq 1500 \mathrm{~m}$ above sea-level) are highlighted in the model, as increasing temperatures are eroding the effect altitude once had as a barrier to malaria transmission, resulting in more favourable conditions in densely populated highland areas, as seen in Ethiopia. ${ }^{99}$ In the case of pathogenic Vibrio species, which cause a range of human infections including gastroenteritis, wound infections, septicaemia, and cholera, recent changes in climate suitability were compared with a 1980s baseline globally, as well as for one region each in Europe (Baltic), the Northeast Atlantic coast of the USA and the Pacific North West coast of North America. ${ }^{100-102}$ Full descriptions of the context of these diseases, the methodology of the models, and additional analysis can be found in the Appendix.

Climate suitability for disease transmission is rising globally, for all diseases being tracked. 2018 was particularly favourable for the transmission of dengue, with a global rise of $8.7 \%$ and $14.5 \%$ above the 1950 s baseline for $A$. aegypti and $A$. albopictus, respectively (Figure 5). Although average suitability for dengue remains low in Europe, 2018 was the most suitable year yet recorded for both vector species in this region $(25.8 \%$ and $40.7 \%$ for $A$. aegypti and A. albopictus, respectively). There have been significant increases in the environmental suitability for the transmission of falciparum malaria in highland areas of four of the five malaria-endemic regions, with an increase of $38.7 \%$ in the African Region and $149.7 \%$ in the Western Pacific Region in 2015-2019 compared to a 1950s baseline (Error! Reference source not found.). The coastal area suitable for Vibrio infections in the past five years has increased at northern latitudes $\left(40-70^{\circ} \mathrm{N}\right)$ by $50.6 \%$ compared to a 1980 s baseline.

Regionally, the area of coastline suitable for Vibrio has increased by $61.2 \%$ and $98.9 \%$ for the 
Baltic and USA Northeast respectively. In 2019, for the second consecutive year, the entirety
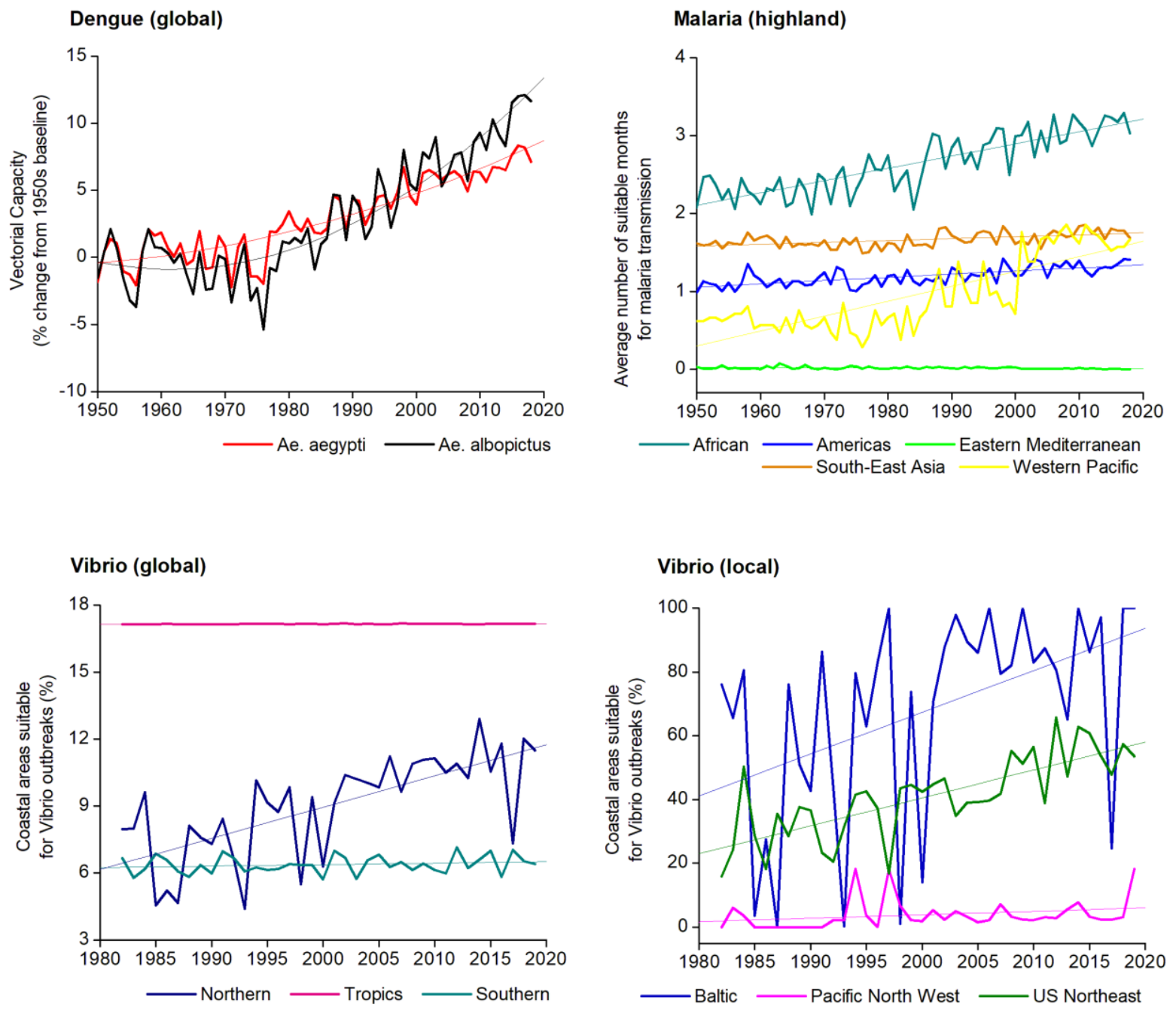

775

776

777

778

779

Indicator 1.3.2: Vulnerability to Mosquito-Borne Diseases

780

781

782 regions $\geq 1500 \mathrm{~m}$ ); and Vibrio species. further data required to establish a trend.
Figure 5: Change in climate suitability for infectious diseases: dengue (A. aegypti); malaria (highland

Headline finding: Following a sharp decline over the last decade, 2016 to 2018 saw small upticks in national vulnerability to dengue outbreaks in four out of six WHO regions, with 
As discussed above, climate change is expected to facilitate the expansion of Aedes mosquito vectors that transmit dengue. Improvements in public health services may counteract these threats in the short- to medium-term, however climate change will continue to make such efforts increasingly difficult and costly. ${ }^{103}$ This indicator tracks vulnerability to mosquito-borne disease by combining the above indicator on climate suitability for the transmission of dengue, with countries' health system core capacities as outlined by the International Health Regulations (IHR), which have been shown to be an effective predictor of protection against disease outbreak. ${ }^{104}$ The methods used here remain unchanged from previous reports, and are described in the Appendix in full. ${ }^{97,105}$

From 2010, a substantial decline in vulnerability for the four most vulnerable WHO regions, is seen around the world, reflecting significant improvements in their core health capacities. However, from 2016 to 2018, this trend begins to halt, and then reverse, with further data required to confirm any long-term shift.

\subsection{Food Security and Undernutrition}

Whilst the global food system still produces enough to feed a growing world population, poor management and distribution has resulted in a lack of progress on the second Sustainable Development Goal (SDG) on hunger, as the global number of under-nourished people projected to rise to over 840 million in $2030 .{ }^{106}$

Climate change threatens to exacerbate this further, with increasing temperatures, climatic shocks and ground-level ozone impacting crop yields, and with sea surface temperature (SST) and coral bleaching impacting marine food security. ${ }^{107}$ These effects will be experienced unequally, disproportionately affecting countries and populations already facing poverty and malnutrition, and exacerbating existing inequalities. The following two indicators monitor these changes, tracking the change in crop yield potential and SST.

\section{Indicator 1.4.1: Terrestrial Food Security and Undernutrition}

Headline finding: Crop yield potential for maize, winter wheat, soybean, and rice has followed a consistently downward trend from 1980 to 2019, with reductions of 5.6\%, 2.1\%, $4.8 \%$ and $1.8 \%$ seen respectively.

Here, crop yield potential is characterised by "crop growth duration" (the time taken to reach a target sum of accumulated temperatures), over its growing season. If this sum is reached early then the crop matures too quickly and yields are lower than average, with a reduction in crop growth duration therefore representing a reduction in yield potential. ${ }^{108}$ 
817 This indicator tracks the change in the crop growth duration for four key staple crops:

818 maize, wheat, soybean, and rice at the individual country level and globally, using a similar

819 approach to previous reports, which has been improved to provide more accurate local

820 estimates, and now uses ERA5 data. ${ }^{36}$

821 The yield potential of maize, winter wheat, soybean, and rice continue to decline globally

822 and for most individual countries, with this indicator demonstrating that it is increasingly

823 difficult to continue to increase or even maintain global production due to the changing

824 climate. In 2019, the reduction in crop growth duration relative to baseline, was 7.9 days

825 (5.6\%), 4.9 days (2.1\%), 6.1 days (4.8\%), and 2 days (1.8\%) for maize, winter wheat, soybean,

826 and rice respectively (Figure 6). For maize, most countries in the world experienced a

827 decline, with large areas of South Africa, the USA, and Europe experiencing reductions in

828 their crop growing seasons of over 20 days - a reduction of over $14 \%$ of the global average

829 crop duration. This compounds the current negative impacts of weather and climate shocks,

830 made more frequent and more extreme by climate change, that are hampering localised

831 efforts to reduce undernutrition. 

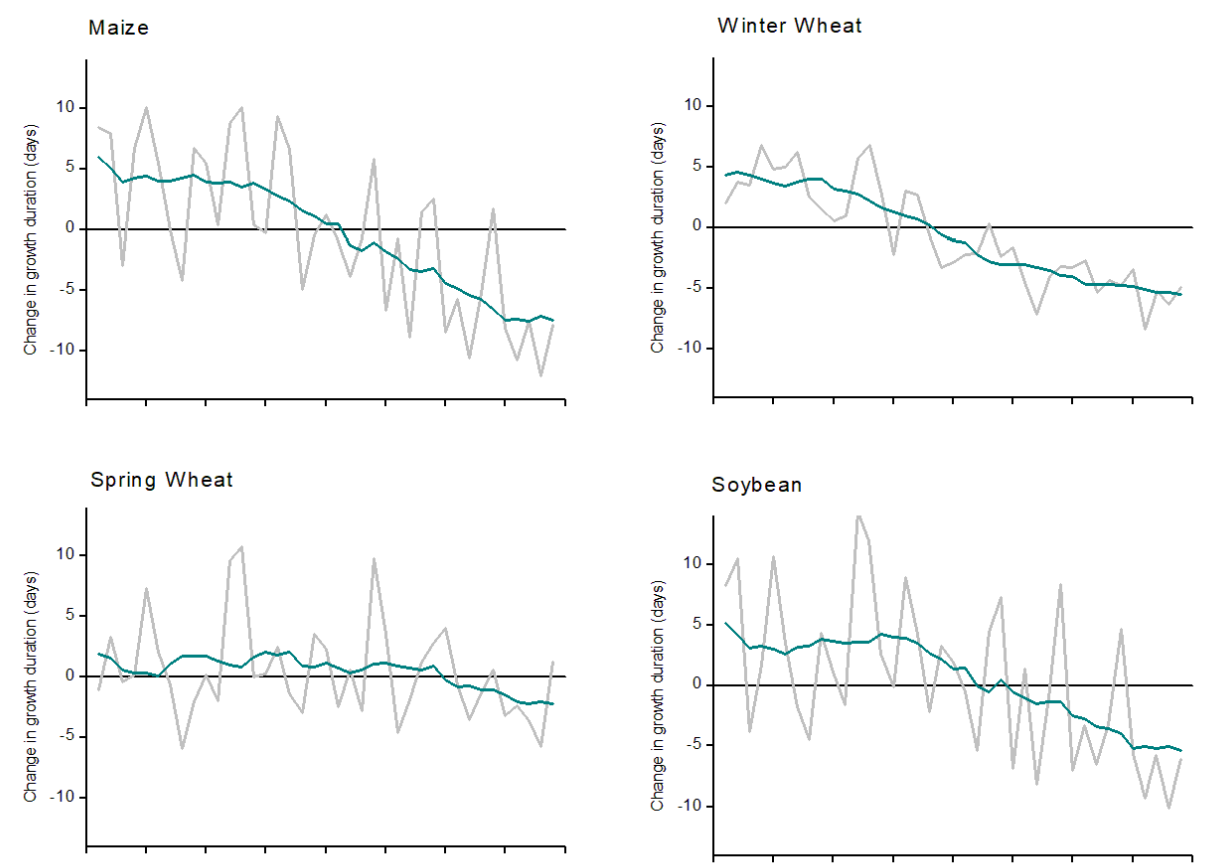

833

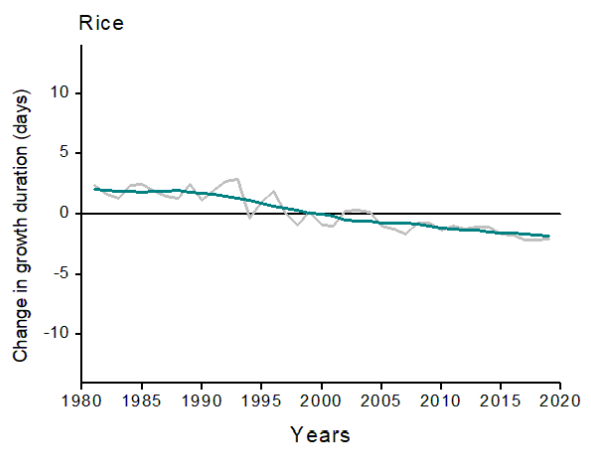
relative to the 1981-2010 global average.

Figure 6: Change in crop growth duration for maize, soybean, spring wheat, winter wheat, and rice,

838 Headline finding: Average sea surface temperature rose in 46 of 64 investigated territorial 839 waters between 2003-2007 and 2015-2019, presenting a risk to marine food security.

840 A large proportion of the global population, especially in low- and middle-income countries 841 is highly dependent on fish sources of protein. ${ }^{109}$ Additionally, omega-3 is important in the 842 prevention of ischaemic heart disease and diets low in seafood omega-3 fatty acids, a risk 843 factor to which over 1.4 million deaths globally were attributed in $2017 .{ }^{110}$ Sea surface 844 temperatures, rising as a consequence of climate change, impair marine fish capacity and 845 capture through a number of mechanisms, including the bleaching of coral reefs and 
reduced oxygen content, putting populations at risk. ${ }^{111}$ This indicator tracks SST in territorial waters of 64 countries located in 16 Food and Agriculture Organization (FAO) fishing areas. ${ }^{112-114}$

849 Comparing 2003-07 and 2015-19 time periods, average SST rose in 46 of the 64 investigated areas, with a maximum increase of $0.87^{\circ} \mathrm{C}$ observed in the territorial waters of Ecuador. Farm-based fish consumption has increased consistently over the last four decades, with a corresponding decline in capture-based fish consumption, exacerbated in part by these evolving temperature trends. ${ }^{111}$ Between 1990 and 2017, diets low in seafood $\omega 3$ increased by $4.7 \%$ at global level with more than $70 \%$ of the countries experiencing an increase in exposure to this risk factor, increasing the mortality risk from ischemic heart disease.

Headline finding: Without intervention, between 145 million and 565 million people living in coastal areas today will be exposed to and affected by future sea level rise.

Through its impacts on extreme weather events, land degradation, food and water security, and sea level rise (SLR), climate change is influencing human migration, displacement, and relocation with human health consequences. ${ }^{115,116}$ Left unabated, average estimates for global mean sea level rise (GMSLR) range from 1-2.5 metres $(\mathrm{m})$ by the end of the century, with projections rising as high as $5 \mathrm{~m}$ when taking into account regional and local coastal variation. ${ }^{117,118}$ This indicator, newly introduced for the 2020 report, tracks current population exposure to future SLR and provides a measure of the extent to which health or

873 Population exposure to GMSLR of $1 \mathrm{~m}$ and $5 \mathrm{~m}$ was determined using a Coastal Digital

874 Elevation Model (CoastalDEM) and current population distribution data, with a full 875 description of this new indicator outlined in the Appendix. ${ }^{119,120}$ Based on today's 876 population distributions, $1 \mathrm{~m}$ of GMSLR could expose 145.5 million of the world's current population to potential inundation, rising to 565 million people with $5 \mathrm{~m}$ of SLR (Figure 7). A range of SLR-related health impacts are likely to be experienced, with changes in water and soil quality and supply, livelihood security, disease vector ecology, flooding, and saltwater intrusion. ${ }^{121,122}$ The health consequences of these effects will depend on a variety of factors, including both in situ and migration adaptation options. ${ }^{123-125}$ These effects could be moderated if countries begin to prepare. A review in 2019 identified 43 national policies, across 37 countries, connecting climate change and migration, and 40 of these policies across 35 countries explicitly referencing health or wellbeing. The policies commonly accept 


\section{Exposure to 1m Global Mean Sea Level Rise}

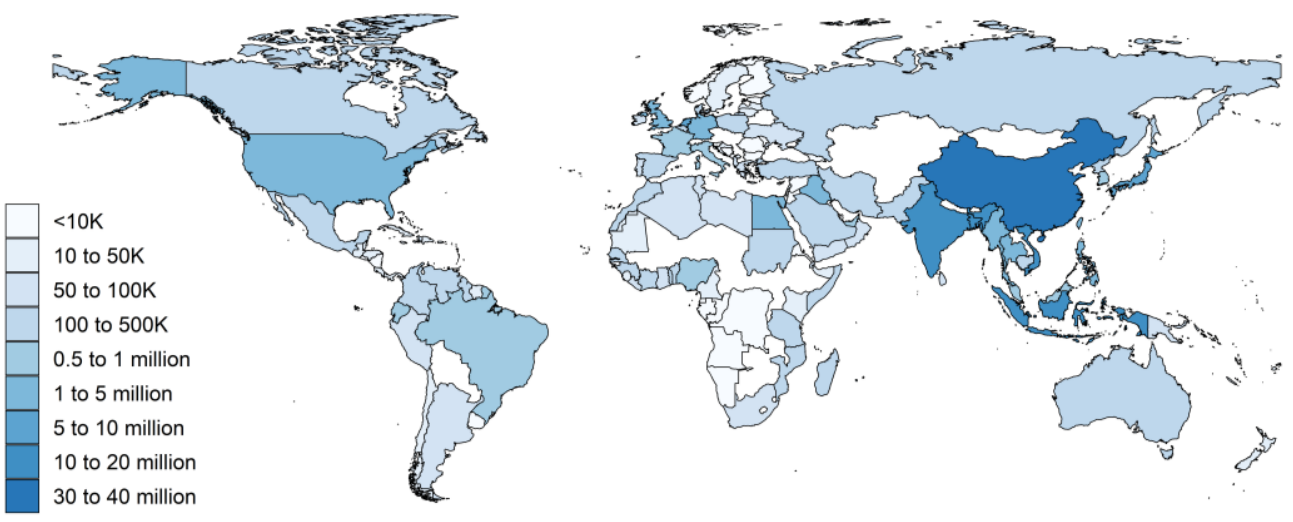

\section{Exposure to 5m Global Mean Sea Level Rise}

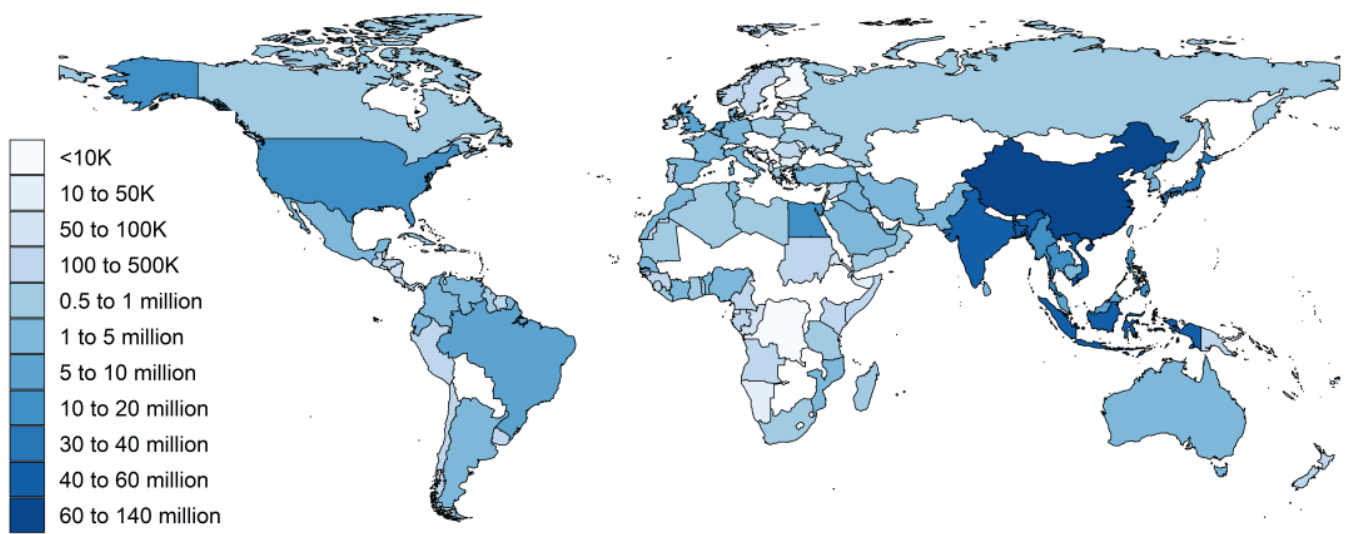

Figure 7: Number of people exposed to $1 \mathrm{~m}$ and $5 \mathrm{~m}$ of global mean sea level rise by country. 
890 The indicators that comprise Section 1 of the 2020 report describe a warming world that is

891 affecting human health both directly and indirectly, and putting already vulnerable

892 populations at higher risk. Metrics of exposure and vulnerability to extreme weather are

893 complemented by trends of worsening global yield potential and climatic suitability for the

894 transmission of infectious disease. Subsequent reports will continue to develop the

895 methods and data underlying these indicators, with a particular focus on the creation of a

896 new indicator on mental health, and the exploration of the gender dimensions of existing

897 indicators.

898 Correlating climate change and mental health is challenging for a number of reasons, 899 including local and global stigma and underreporting, differences in health systems, and 900 variation in cultural understandings of wellbeing. In part because of this, the literature has 901 focused on extremes of heat, with investigations reporting correlations between higher 902 temperatures and heatwaves, and the risk of violence or suicide. Proposed reasons for this 903 association vary from the effects of disrupted sleep through to short-term agitation. ${ }^{126,127}$ 904 Stronger evidence exists outlining the links between extreme weather events and mental ill905 health, with emerging research describing the impact of a loss of access to the environment 906 and ecosystem services. ${ }^{128}$

907 Taken as a whole, the data described in Section 1 provides a compelling justification for an 908 accelerated response. There are clear limits to adaptation, necessitating increasingly urgent 909 interventions to reduce GHG emissions. How communities, governments, and health 910 systems will be able to moderate the impacts of a changing climate is discussed in Section 2 911 and Section 3. 
915 With a growing understanding of the human costs of a warming climate, the need for 916 adaptation measures to protect health is now more important than ever. The current 917 COVID-19 pandemic makes clear the challenges experienced by health systems around the 918 world, when faced with large unexpected shifts in demand, without sufficient adaptation or 919 integration of health services across other sectors. ${ }^{129}$ As this public health crisis continues, 920 and is compounded by climate-attributable risks, rapid and proactive interventions are 921 crucial in order to prepare for and build resilience to both the health threats of climate 922 change and of pandemics. ${ }^{130}$

923 Heavily determined by regional hazards and underlying population health needs, the 924 implementation of adaptation and resiliency measures require localised planning and 925 intervention. National adaptation priorities must take into account subnational capacities, 926 as well as the distribution of vulnerable populations and inequality, locally. As health 927 adaptation interventions are being increasingly introduced, evidence of their success often 928 remains mixed. ${ }^{131}$ Measuring the impact of these long-term interventions at the global scale 929 presents particular challenges, and the indicators in this section aim to monitor adaptation 930 progress through the lens of the WHO Operational Framework for Building Climate Resilient 931 Health Systems. ${ }^{24}$ The adaptation indicators expand beyond the health system to focus on

932 the following domains: planning and assessment (Indicators 2.1.1-2.1.3), information 933 934 systems (Indicator 2.2), delivery and implementation (Indicators 2.3.1-2.3.3), and spend (Indicator 2.4). As is often the case in adaptation, several of these indicators rely on selfreported data on adaptation plans, assessments, and services, which also presents challenges. Where possible, efforts have been made to validate this data.

937 Numerous indicators in this section have been further developed for the 2020 report and 938 one new indicator is presented. The data on national health adaptation planning and 939 assessments (Indicators 2.1.1 and 2.1.2) has been presented in greater detail, whilst 940 calculations of the effectiveness of air conditioning as an intervention (Indicator 2.3.2) have 941 been improved using more recent evidence. The definition of health-related adaptation 942 spending (Indicator 2.4) has been expanded to capture activities that are closely health943 related, in a variety of non-health sectors. Importantly, a new indicator, focusing on the use 944 of urban green spaces as an adaptive measure with numerous health benefits, has been 945 introduced in this year's report (Indicator 2.3.3). 
949 Adaptation planning and risk management is essential across all levels of government, with 950 national strategy and coordination linked to sub-national and local implementation and 951 delivery. ${ }^{132}$ In every case, risk assessments are an important first step of this process.

952 The following three indicators track national- and city-level adaptation plans and 953 assessments, using data from the WHO Health and Climate Change Survey and the CDP 954 Annual Cities Survey. ${ }^{133,134}$ Information on the data and methods for each are presented in the Appendix. Data from the WHO survey has not been updated for this year, and hence further qualitative analysis has been conducted to investigate the barriers to adaptation.

Headline finding: 51 out of 101 of countries surveyed have developed national health and climate change strategies or plans. However, funding remains a key barrier to implementation, with less than $10 \%$ of countries reporting to have the funds to fully implement their plans.

963 National governments identified financing as one of the main barriers to the implementation of national health and climate change plans..$^{30,134}$ Of the countries with these plans, only four report having adequate national funding available to fully implement them. This highlights the importance of access to international climate finance for governments from low-resource settings. Despite this, less than half of national health authorities from low and lower-middle income countries (17 out of 35 LLMICs) report having current access to climate funds from mechanisms such as the Global Environment Facility, the Adaptation Fund, the Green Climate Fund (GCF) or other donors. The GCF, which so far has not funded a single health sector project for the 10th year running, is now looking to align its programming to incorporate health and wellbeing co-benefits in light of, and in response to COVID-19. While not yet accredited to submit and implement projects, WHO became a GCF Readiness Partner in 2020, giving WHO the ability to support countries in their efforts to develop health components of National Adaptation Plans and to strengthen health considerations related to climate change.

977 A second key barrier to the implementation of national health and climate strategies is a 978 lack of multisectoral collaboration within government. Progress on cooperation across 979 sectors remains uneven, with 45 out of 101 countries reporting the existence of a memorandum of understanding between the health sector and the water and sanitation sector, on climate change policy. However, less than a third of countries have a similar agreement with the agricultural, or social service sectors. Furthermore, only about a quarter of countries reported agreements in places between health and the transport, household 
energy or electricity generation sectors. This represents a significant missed opportunity to recognise the health implications of national climate policies and to promote activities that maximise health benefits, avoid negative health effects and evaluate the associated health savings that may result.

Indicator 2.1.2: National Assessments of Climate Change Impacts, Vulnerabilities, and Adaptation for Health

Headline finding: Just under half of 101 countries surveyed have conducted a national vulnerability and adaptation assessment for health, with further investment required to adequately fund these vital components of health system resilience.

Strengthening all aspects of a health system allows it to protect and promote the health of a population in the face of known and unexpected stressors and pressures. In the case of climate change, this requires a comprehensive assessment of current and projected risks, and population vulnerability. This indicator focuses on national-level vulnerability assessments and the barriers faced by national health systems. ${ }^{134}$

Similar to the lack of funding highlighted above, it is clear that vulnerability assessments for health are also under-resourced. Indeed, conducting vulnerability assessments were among the top three adaptation priorities identified as being underfunded by national health authorities, alongside the strengthening of surveillance and early warning systems, and broader research on health and climate change. This was thought to be particularly true for sub-national assessments and for those designed to be particularly sensitive to the needs of vulnerable population groups.

\section{Indicator 2.1.3: City Level Climate Change Risk Assessments}

Headline finding: Of the 789 global cities surveyed, $76 \%$ have either already completed or are currently undertaking climate-change risk assessments, with $67 \%$ expecting climate change to seriously compromise their public health assets and services, a substantial increase from 2018.

Cities are home to more than half of the world's population, produce $80 \%$ of global gross domestic product (GDP), consume two thirds of the world's energy, and represent a crucial component of the local adaptation response to climate change. ${ }^{135}$ As such, this indicator captures cities that have undertaken a climate change risk or vulnerability assessment, as well as their expectations on the vulnerability of their public health assets. First presented in 
1028

1029

1030

1031

1032

1033

1034

1035

1036

1037

1038

1039

1040

1041

1042

1043

1044

1045

1046

1047 the 2017 report of the Lancet Countdown and since improved to include further public health-specific questions, data for this indicator is sourced from the CDP's 2019 survey of 789 global cities: a 33\% increase in survey respondents from $2018 .{ }^{133,136}$

In $2019,62 \%$ of cities had completed a climate-change risk or vulnerability assessment, and a further $28 \%$ of city assessments were either in the process of doing so, or will have completed one within the next two years. While some selection bias likely exists, it is important to note that a growing number of risk assessments are being completed by cities in low-income countries (63\% of cities in LICs in 2019), highlighting the beginning of adaptation where it is arguably most needed. The survey also reveals a core driving factor in these assessments - some $67 \%$ of cities report that their vital public health infrastructure would be seriously compromised by climate change.

\section{Indicator 2.2: Climate Information Services for Health}

Headline finding: The number of countries with meteorological services providing climate information to the health sector has continued to grow, increasing from 70 to 86 counties over the past 12 months.

The use of meteorological services in the health sector is an essential component of adaptation. This indicator tracks the collaboration between these two parts of government, using data reported by national meteorological and hydrological services to the World Meteorological Organization (WMO). ${ }^{137}$ Further detail is provided in the Appendix.

A total of 86 national meteorological and hydrological services of WMO member states reported providing climate services to the health sector, an increase of 16 from the 2019 report of the Lancet Countdown. ${ }^{30}$ By WHO region, 19 of the countries reporting were from Africa, 16 from the Americas, seven from the Eastern Mediterranean Region, 23 from Europe, eight from South East Asia, and 13 from the Western Pacific Region. Of the 86 positive respondents, 66 reported being 'highly engaged' with their corresponding health service, alongside other sectors such as agriculture, water, and electricity generation. As detailed in Indicator 2.1.1, multi-sector collaborations present governments with the opportunity to support a fully integrated adaptation approach to the risks of climate change. 
1051

1052

1053

1054

1055

1056

1057

1058

1059

1060

1061

1062

1063

1064

1065

1066

1067

1068

1069

1070

1071

1072

1073

1074

1075

1076

1077

1078

1079

1080

1081

1082

Headline finding: In preparation for a multi-hazard public health emergency, 109 countries have reported medium to high implementation of a national health emergency framework.

The International Health Regulations (IHR) are an instrument of international law designed to aid the global community in preventing and responding to potential public health emergencies. ${ }^{105}$ This indicator focuses on core capacity eight (C8), which evaluates the degree to which countries have implemented a national health emergency framework by assessing levels of planning, management and resource allocation. ${ }^{105}$ The national health emergency framework applies to all public health events and emergencies, air pollution, extreme temperatures, droughts, floods, and storms. The IHR core capacities are also important components of the response to infectious disease threats, with similar capacities and functions considered when assessing preparedness to a pandemic such as COVID-19. ${ }^{138}$ The results of this survey are provided in full, in the Appendix.

In 2019, 166 out of 194 WHO member states completed the assessment portion related to C8, 16 fewer than in 2018. Of these, 109 countries have reported having medium to high degrees of implementation of multi-hazard preparedness and capacity, a $10 \%$ increase compared to 2018 data. The level of implementation varies by region, with medium-to-high levels reported in over $85 \%$ of countries in the Americas, Western Pacific, and Europe, $60 \%$ of Eastern Mediterranean and South East Asian countries, but only $26 \%$ of African countries. Despite disparities here, capacities have increased across all regions, and the global average increased from $59 \%$ in 2018 to $62 \%$ in 2019.

\section{Indicator 2.3.2: Air Conditioning Benefits and Harms}

Headline finding: Between 2016 and 2018, the world's air conditioning stock continued to rise, further contributing to climate change, air pollution, peak electricity demand and urban heat islands, whilst also conferring protection against heat-related illness.

Air conditioning represents one of a number of effective indoor cooling mechanisms for preventing heat-related illness and mortality. ${ }^{139}$ However, in 2018, air conditioning accounted for an enormous $8.5 \%$ of total global electricity consumption, contributing to, if sourced from fossil fuels, $\mathrm{CO}_{2}$ emissions, fine particulate matter $\left(\mathrm{PM}_{2.5}\right)$ emissions, and ground-level ozone formation, with the potential to leak hydrofluorocarbons which act as powerful GHGs. On hot days, air conditioning can be responsible for more than half of peak electricity demand locally, and emits waste heat that contributes to the urban heat island 
effect. ${ }^{140,141}$ Further research is needed to determine if the overall harms of air conditioning outweigh its benefits. However, increased air conditioning use in response to the warming climate could result in around 1,000 additional air-pollution-related deaths every summer in the eastern USA by $2050 .{ }^{142}$

1087 International programs and organisations, including Sustainable Energy for All, the Kigali 1088 Cooling Efficiency Program, and the International Energy Agency (IEA), are working to develop solutions to provide efficient indoor cooling that protects vulnerable populations against heat-related illness whilst minimising the health-associated harms. Such measures include building designs with improved insulation, energy efficiency measures, and improved ventilation, as well as increasing urban green space, detailed in Indicator 2.3.3. 1093 Recent evidence suggests that simple electric fans could also be an effective stay-at-home measure against most heatwaves during the COVID-19 pandemic. ${ }^{143}$

1095 This indicator draws on data provided by the IEA, and includes an improved calculation of the prevented fraction of deaths from air conditioning, making use of an updated metaanalysis which builds on the previously available 2007 assessment, with full detail described in the Appendix. ${ }^{139,144}$

1099 Between 2016 and 2018, the world's air conditioning stock (residential and commercial) 1100 increased from 1.74 to 1.90 billion units and the proportion of households with air 1101 conditioning increased from $31.1 \%$ to $33.0 \%$ : a $56.7 \%$ rise since 2000 (Figure 8). 1102 Correspondingly, the global prevented fraction of heatwave related mortality increased 1103 from $23.6 \%$ in 2016 to $25.0 \%$ in 2018, but global emissions from air conditioning electricity 1104 consumption increased from 1.04 to $1.07 \mathrm{GtCO}_{2}$ (2\% of total global emissions), highlighting the need for sustainable cooling methods in the face of a warming climate. 


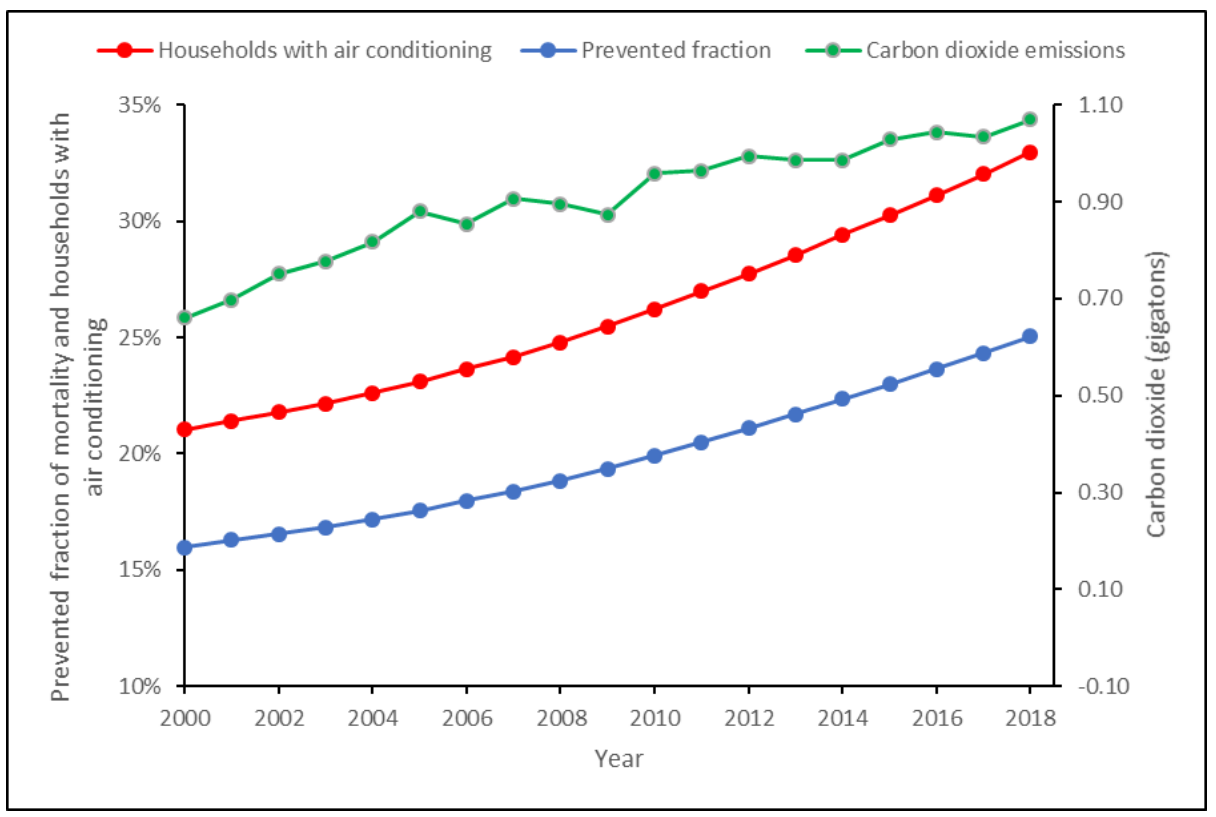

1107 Figure 8: Global proportion of households with air conditioning (red line), prevented fraction of 1108 heatwave-related mortality due to air conditioning (blue line), and carbon dioxide emissions from air 1109 conditioning (green line), 2000-2018.

1112 Headline finding: Urban green space is an important measure to reduce population heat exposure, with $8.5 \%$ of global urban centres having a very high or exceptionally high degree of greenness in 2019, and over 156 million people living in urban centres with concerningly low levels.

1116 Access to urban green space provides benefits to human health by reducing exposure to air 1117 and noise pollution, relieving stress, providing a setting for social interaction and physical 1118 activity, and reducing all-cause mortality. ${ }^{145,146}$ In addition, green space sequesters carbon and provides local cooling benefits which disrupt urban heat islands, providing both climate change mitigation and heat adaptation benefits. As access can often disproportionately benefit the most privileged in society, it is important that careful consideration is given to how green spaces are designed and distributed, ensuring safety and equitable access. ${ }^{147,148}$

1123 This indicator, new in the 2020 report, quantifies urban green space exposure for 2019 in 1124 the 467 urban centres of over one million inhabitants, as defined by the Global Human 1125 Settlement (GHS). ${ }^{149,150}$ It is based on remote sensing of green vegetation through the satellite-based normalised difference vegetation index (NDVI), which measures the reflectance signature of visible red and near-infrared parts of spectrum of green plants, providing an indication of the level of green coverage of the earth surface. The maximum 
NDVI for all seasons was used to define the average level of greenness of each urban area. A

1131 In 2019, only $8.5 \%$ of global urban centres had very high to exceptionally high levels of greenness, with five capital cities - Colombo, Washington DC, Dhaka, San Salvador, and Havana - highlighted (Figure 9). Concerningly, 9.9\% of urban centers, home to over 156 million people and including 21 capital cities, lie at the opposite end of the spectrum, with very low levels of urban green space. ${ }^{40}$

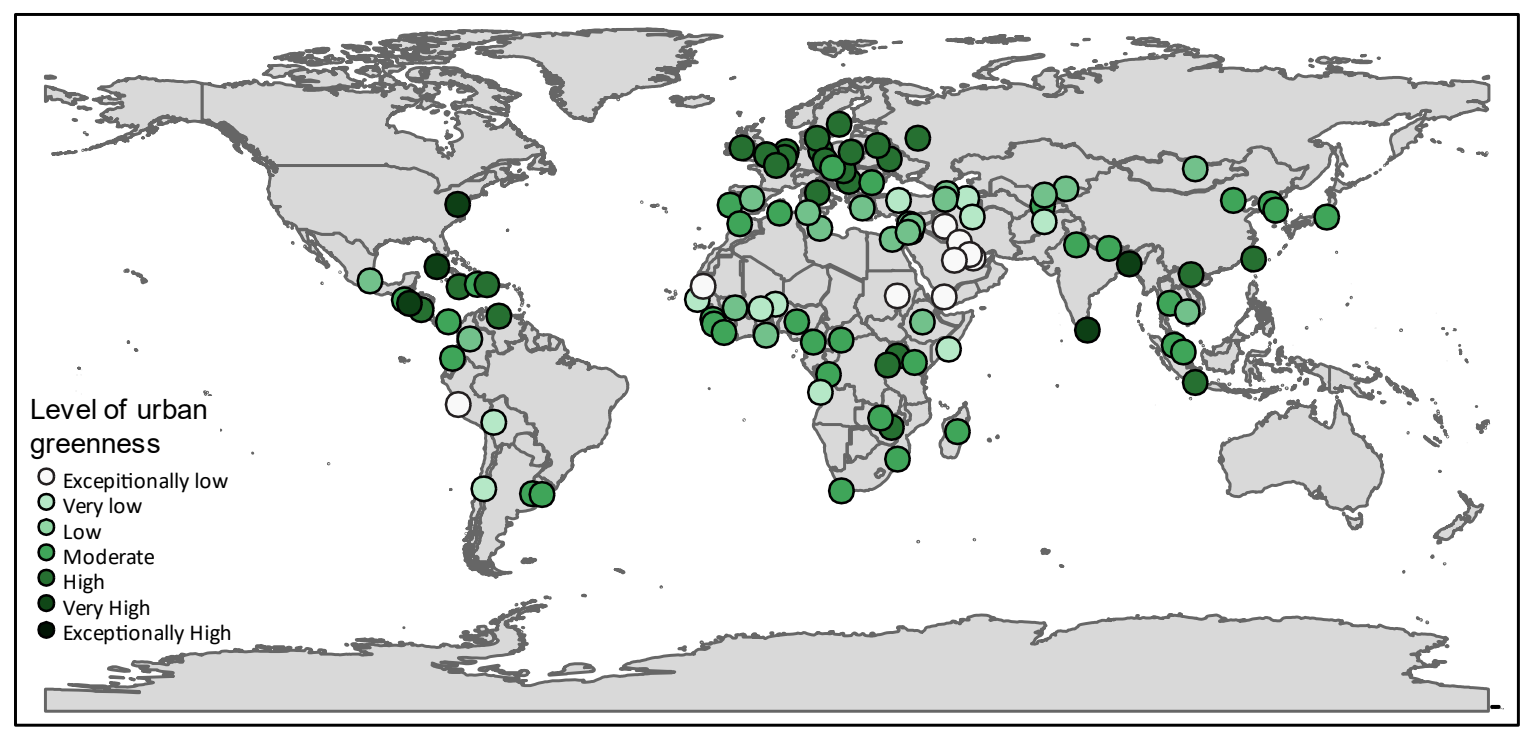

1136

1137

1138

1139

1140

1141

1142

1143

Figure 9: Urban greenness in capital cities >1 million inhabitants in 2019.

\section{Indicator 2.4: Spending on Adaptation for Health and Health-Related Activities}

Headline finding: At US\$18.43 billion in 2019, global spending on health adaptation rose to $5.3 \%$ of total adaptation spending, while health-related spending remained flat at approximately $28.4 \%$ from 2015 to 2019.

As noted in the evaluation of national adaptation plans (Indicator 2.1.1), inadequate financial resource poses the largest barrier to the implementation of adaptation measures. This indicator tracks health and health-related adaptation spending within the Adaptation and Resilience to Climate Change dataset from the data research firm, kMatrix, which includes spend data from 191 countries. ${ }^{151}$ Health-specific spend is that which occurs within the formal healthcare sector. For the 2020 report, an enhanced definition of health-related spending was developed through an expert review workshop to more accurately categorise spend. It captures adaptation spending within other sectors (agriculture $\&$ forestry, the built environment, disaster preparedness, energy, transportation, waste, or water) that have a direct impact on one or more of the basic determinants of health (food, water, air, or 
1153 shelter), with a demonstrated link to health outcomes in the literature. A full description of 1154 the methodology can be found in the Appendix.

1155 Climate change adaptation spending within the healthcare sector increased by $12.7 \%$ to 1156 US\$18.43 billion in 2018/19, compared to 2017/18 data (Figure 10). As a share of all 1157 adaptation spending globally, health adaptation spending is now at 5.3\% in 2018/19, above $11585 \%$ for the first time. The wider measure of health-related adaptation spending increased by $11597.2 \%$ to US\$99.9 billion in $2018 / 19$, although as a share of global adaptation spending, it has 1160 remained more or less constant: $28.4 \%$ in 2015/16 and 28.5\% in 2018/19.

1161 Grouped by WHO region, spending for health adaptation varies from US\$0.48 per capita in 1162 Africa to US\$5.92 in the Americas, remaining below US\$1 per capita in South East Asia. 1163 Again, taking the broader health-related adaptation spend, a wider variation, ranging from 1164 US\$2.63 (Africa) to US\$30.82 (Americas), is evident.
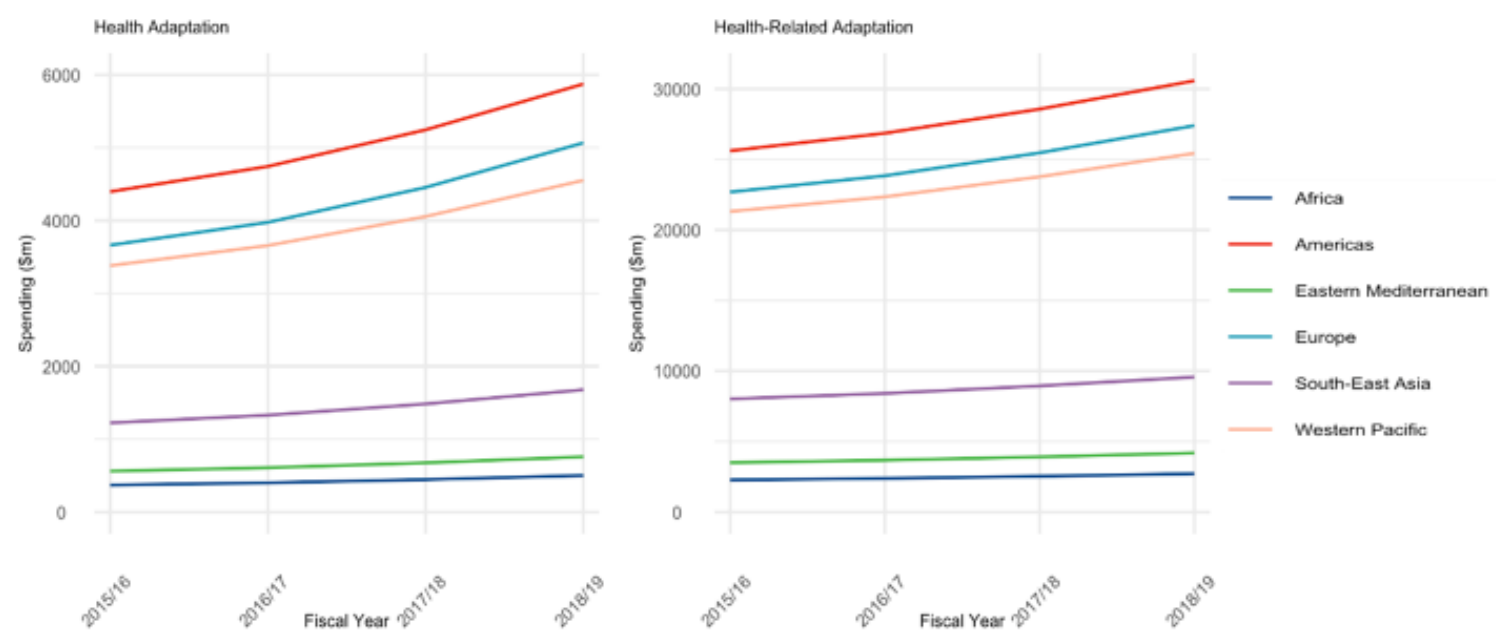

Figure 10: Adaptation and Resilience to Climate Change (A\&RCC) spending for financial years 2015/16 to 2018/19 by WHO Region. A) Health A\&RCC spending (\$m), B) Health-related A\&RCC adaptation spending (\$m). 
1173 The indicators presented in this section continue to move in a positive direction, with

1174 growing recognition of the impacts of climate change within the health community.

1175 However, there is much more work to do, with a need to move from planning to

1176 implementation, and to better engage with other sectors of society in adaptation

1177 interventions (Indicators 2.1.2, 2.1.2, and 2.2). The IHR core capacity scores show a need for

1178 support across many African and Eastern Mediterranean countries (Indicator 2.3.1),

1179 requiring additional engagement and resource.

1180 Global spending trends have shown promise over recent years for health and health-related 1181 adaptation (Indicator 2.4), however governments remain unable to fully implement their 1182 national health adaptation plans (Indicator 2.1.1). The findings here reiterate the need to 1183 strengthen underlying health systems and create multi-sectoral alignment to protect human 1184 health, particularly for the most vulnerable populations. COVID-19 has dramatically altered 1185 the pattern of healthcare demand, with health systems restructuring services overnight. ${ }^{152}$

1186 While the full impact of these changes are unclear, the rapid introduction of new online and 1187 telemedicine services brings many synergies with efforts to reduce the emissions of the 1188 healthcare sector, and with those to increase service delivery resilience. As governments 1189 continue to respond to the public health and economic effects of COVID-19, it will be 1190 important to align these priorities and ensure that enhanced preparedness for future 1191 pandemics also confers increased capacity to respond to climate change. 
1194 In 2018, GHG emissions rose to an unprecedented $51.8 \mathrm{GtCO}_{2} \mathrm{e}\left(55.3 \mathrm{GtCO}_{2} \mathrm{e}\right.$ including land 1195 use change), with fossil fuel emissions from transport, power generation, and industry accounting for $72 \% .{ }^{153}$ The vast majority of the growth in emissions, the economy, and the demand for energy occurred in low- and middle-income countries, despite global economic headwinds. ${ }^{154}$

1199 COVID-19 has had a profound effect on the global economy and on emissions. Ongoing volatility makes the projections of any long-term effects challenging, although daily $\mathrm{CO}_{2}$ emissions were 17\% lower in April 2020 compared with April 2019, with some countries experiencing emissions reductions of up to $26 \%{ }^{155}$ Current estimates suggest that global emissions will fall by $8 \%$ in 2020 as a result of both the economic downturn, and restrictions to local and international travel. ${ }^{22,155}$ As efforts to revitalise the economy take effect, aligning such interventions with those necessary to mitigate climate change will allow governments to generate a synergistic response, improving public health in the short-term and in the long-term.

1208 If carefully planned and implemented, these interventions will yield major health benefits, 1209 underlining the importance of a "health in all policies" approach. ${ }^{156,157}$ Highlighting this 1210 practice, the following section tracks climate change mitigation efforts in the sectors most 1211 relevant to public health: power generation and air pollution (Indicators 3.1.1-3.1.3 and 1212 3.3); household energy and buildings (Indicator 3.2); transport (Indicator 3.4); diets and 1213 agriculture (Indicators 3.5.1 and 3.5.2); as well as mitigation within the healthcare sector 1214 (Indicator 3.6). New in the 2020 report are indicators of the national emissions from 1215 agricultural consumption (Indicator 3.5.1) as well as the associated premature mortality 1216 from unhealthy and emissions-intensive diets (Indicator 3.5.2). The methodologies of each 1217 of the existing indicators have also improved, particularly Indicator 3.6, which, based on 1218 feedback, has been revised to better estimate emissions from the healthcare sector.

1219 Importantly, this section must be interpreted with the understanding that enhanced 1220 ambition is urgently required, and that countries will need to increase the strength of their 1221 mitigation commitments within the Paris Agreement's NDCs by a factor of three to achieve 1222 a $2^{\circ} \mathrm{C}$ target, and by a factor of five for $1.5^{\circ} \mathrm{C} .{ }^{153}$ 
1226 Headline finding: The carbon intensity of the global primary energy supply has remained flat 1227 for the last three decades. Whilst in 2017 it was at its lowest since 2006, it still remained $12280.4 \%$ higher than 1990 levels.

1229 As fossil fuel combustion in the energy system continues to be the biggest source of GHG 1230 emissions, mitigation in this area is key to meeting the commitments of the Paris

1231 Agreement. This indicator tracks the carbon intensity of the global energy system, expressed 1232 as the $\mathrm{CO}_{2}$ emitted per terajoule of total primary energy supply (TPES), with methods and 1233 data described in the Appendix. ${ }^{158,159}$

1234 The carbon intensity of the global energy system has barely altered in almost 30 years: in 12352017 it was 0.4\% higher than in 1990 (Figure 11). Regional values have changed 1236 substantially, however, with reductions in the carbon intensity of the USA and north and 1237 western Europe now $12 \%$ and $20 \%$ lower than 1990 levels. China's carbon intensity of TPES 1238 remains high at $72 \mathrm{tCO}_{2} / \mathrm{TJ}$, however it is decreasing, and in 2017 was $4 \%$ lower than its 1239 peak in 2013. Early statistics for 2020 suggest that global demand for all fossil fuels has 1240 reduced in the first quarter due to COVID-19, and will continue to decline across the year, 1241 with resulting reductions in emissions. ${ }^{22}$ However, without targeted intervention, emissions could rebound, as they did following the 2008-2009 global financial crisis, where a $1.4 \%$ decrease in $\mathrm{CO}_{2}$ emissions in 2009 was offset by a 5.9\% rise in 2010. ${ }^{160}$ 


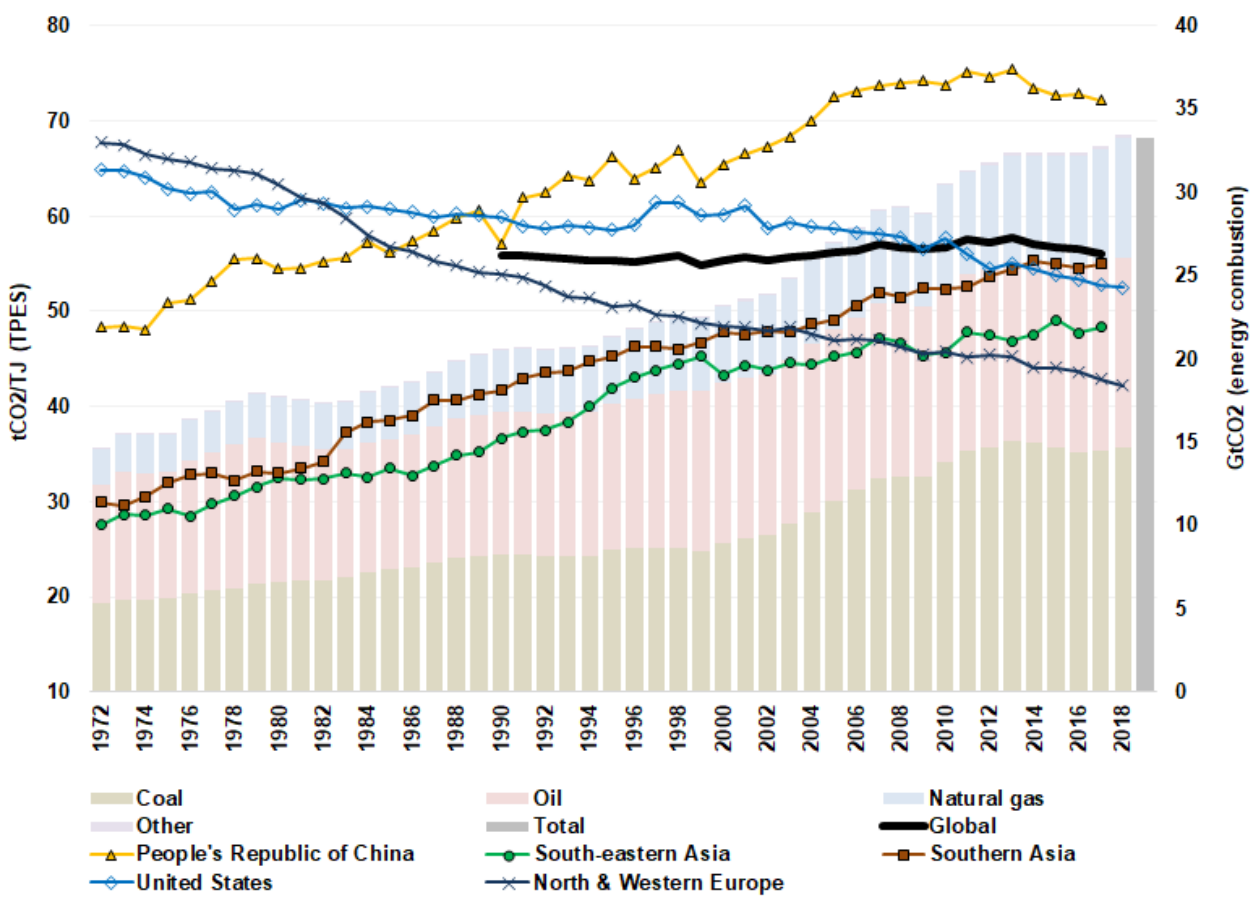

1246

1247

1248

1249

1250

1251

1252

1253

1254

1255

1256

1257

1258

1259

1260

1261

1262

1263

1264

Figure 11: Carbon intensity of Total Primary Energy Supply (TPES) for selected regions and countries, and global $\mathrm{CO}_{2}$ emissions by fuel type, 1971-2019. Carbon intensity trends are shown by trend line (primary axis) and global emissions by stacked bars (secondary axis). This carbon intensity metric estimates the tonnes of $\mathrm{CO}_{2}$ for each unit of total primary energy supplied (tCO $\left.\mathrm{CO}_{2} / \mathrm{TJ}\right)$. For reference, carbon intensity of fuels (tCO $2 / T J)$ are as follows: coal 95-100, oil 70-75, and natural gas 56.

\section{Indicator 3.1.2: Coal Phase-Out}

Headline finding: Global energy supply from coal in 2018 increased by 1.2\% from 2017 and was $74 \%$ higher than in 1990.

Coal combustion continues to be the largest contributor to emissions from the energy sector, and is a major contributor to premature mortality due to air pollution (Indicator 3.3). The phase-out of coal-fired power is therefore an important first step in the mitigation of climate change. This indicator reports on progress towards a global phase-out, tracking the TPES from coal, as well as coal's share of total electricity generation, with methods provided in full in the Appendix. ${ }^{161}$

Global coal use for energy increased by 1.2\% from 2017 to 2018, and while it remains below its 2014 peak, it has increased by $74 \%$ overall since 1990 . China, responsible for $52 \%$ of global coal consumption, has driven the rise in recent years, counteracting a 2017-2018 
1276 reduction in coal use from other major economies such as Germany (-6\%), the USA $(-4.2 \%)$, Australia (-3.3\%), and Japan (-1.2\%). Importantly, Figure 12 makes clear that this is not the full picture: China's share of coal in its power generation is falling rapidly, from $80 \%$ in 2007 , to $66 \%$ in 2018, as it moves to other sources to meet rising demand for electricity. Likewise, northern and western Europe have seen falls in their share of coal power, from 21\% in 2013 to $13 \%$ in 2018.

As a result of the COVID-19 pandemic, as well as cheap oil and continued growth in renewables, global demand for coal fell by almost $8 \%$ in the first quarter of 2020 , where it is expected to remain throughout the year. ${ }^{22}$ Additionally, Austria and Sweden closed their last coal-fired power plants in April 2020, with other countries soon to follow. ${ }^{162}$

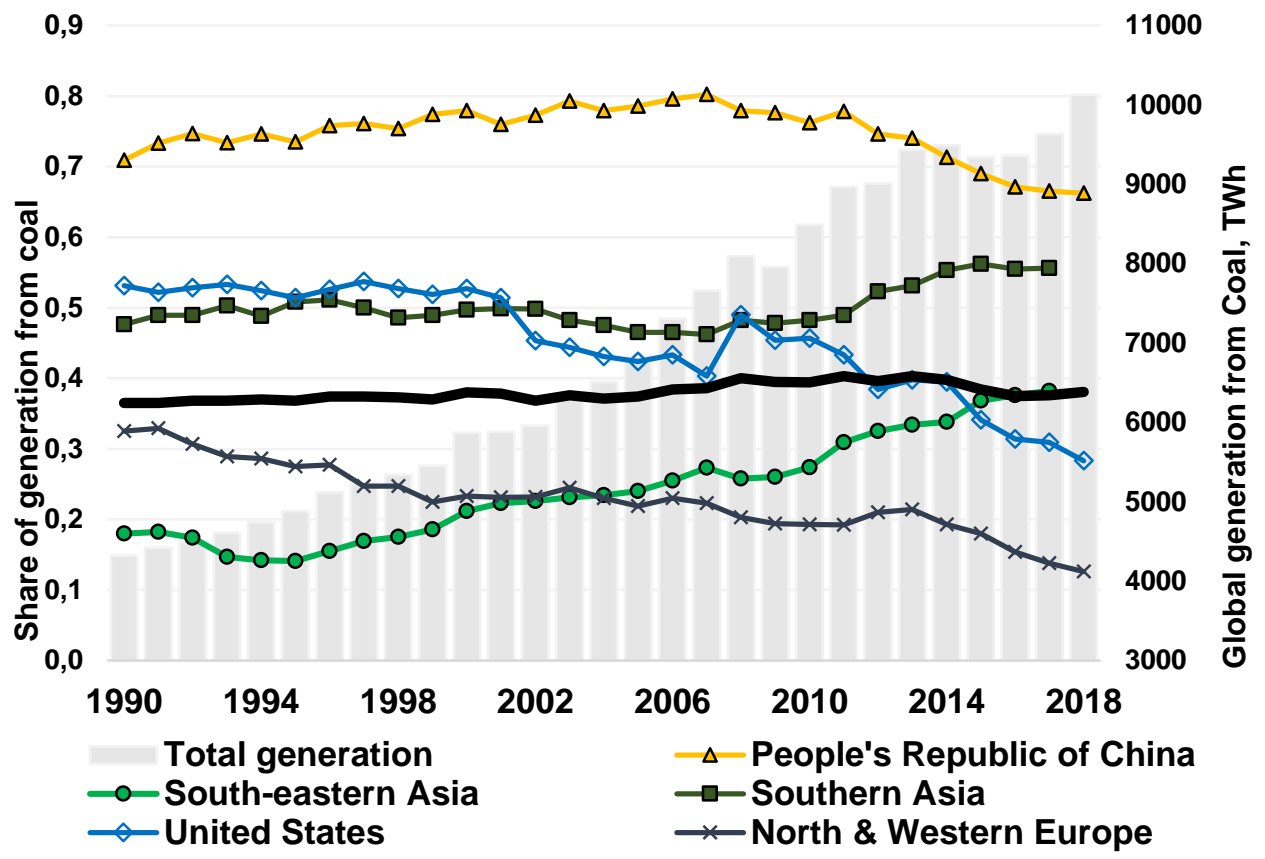

Figure 12: Share of electricity generation coal in selected countries and regions, and global coal generation. Regional shares of coal generation are shown by the trend lines (primary axis) and total coal generation by the bars (secondary axis). Global share of generation from coal is shown with the thick black line. Data series are shown to at least 2017 and extended to 2018 where data allows. 
1284

1285

1286

1287

1288

1289

1290

1291

1292

1293

1294

1295

1296

1297

1298

1299

1300

1301

1302

1303

1304

1305

1306

1307

1308

1309

1310

1311

1312

1313

1314

1315

1316

Headline finding: The average annual growth rate in power generation from wind and solar was 21\% globally and 38\% in China, from 2010 to 2017, with all forms of low-carbon energy responsible for $33 \%$ of total generation, globally.

Continued growth in renewable energy, particularly wind and solar, is key to displacing fossil fuels. This indicator tracks electricity generation (in TWh) and the share of total electricity generation from all low-carbon sources (nuclear and all renewables, including hydro) as well as renewables (wind and solar, excluding hydro and biomass). A full description of the methods and data can be found in the Appendix. ${ }^{161}$

Low-carbon electricity generation continues to rise, growing by 10\% from 2015 to 2017 , to then account for $33 \%$ of total generation. China experienced a $21 \%$ increase over the same period, reaching 1800 TWh and $28 \%$ of all electricity produced.

Focussing on wind and solar energy reveals a similar picture, with a global annual rate of $21 \%$ between 2010 and 2017. China saw an even higher growth rate of approximately $38 \%$ per year, due to a rapid increase in solar, reaching 425 TWh in 2017. Despite this, its share of renewable energy generation remains relatively small at 6.5\%; comparable to India's at $5 \%$. Contrary to the decline in demand for fossil fuels, the IEA expect renewable energy demand to increase in 2020, due to low operational costs compared to fossil fuel sources, but further policy support is necessary in order to continue this growth. ${ }^{22,163}$

\section{Indicator 3.2: Clean Household Energy}

Headline finding: Primary reliance on healthy fuels and technology for household cooking continued to rise, reaching $63 \%$ in 2018 . However total consumption of zero emission energy for all household needs remains low, at $26 \%$.

The use of unhealthy and unsustainable fuels and technologies for cooking, heating and lighting in the home contributes both to GHG emissions and to dangerous concentrations of household air pollution. ${ }^{164}$ Primary reliance on such fuels and technologies for cooking is particularly problematic, resulting in recurrent direct exposure to high concentrations of poor quality air, causing over 3.8 million premature deaths every year. ${ }^{165}$ This disproportionately affects women and children, who in many cultural contexts spend more time in the home, may be in charge of food preparation, and face threats to their safety associated with the gathering of cooking fuels. ${ }^{164}$

This indicator draws on national surveys collected by the WHO across 194 countries, to track the proportion of the population using clean fuels and technologies for cooking, defined 
1317 those whose emission rate targets meeting WHO air quality guidelines. It also tracks zero1318 emission energy usage in the residential sector, measured as fuels with both zero GHG and 1319 zero particulate emissions at the point of use (mainly electricity and renewable heating) 1320 using data from the IEA. ${ }^{161}$

1321 In 2018, 63\% of the global population relied primarily on clean fuels and technologies for 1322 cooking, an increase of $26 \%$ since 2000 . In China, this proportion increased from $43 \%$ in 13232000 to $64 \%$ in 2018, while in Viet Nam it increased from 13\% to 64\% over the same period 1324 (Figure 19). However, little progress has been made in Sub-Saharan Africa, where only 15\% 1325 of households rely on clean fuels and technology for cooking. Importantly, overall use of 1326 zero emission energy in the home (for all sources, including heating and lighting) remains 1327 low, at 26\% globally, increasing by only 2\% per year since 2010 (Figure 13).

1328 This section of the report is continuously evolving to understand the health co-benefits of 1329 mitigation efforts, and is now able to present findings from a new indicator under development, that tracks mortality from household air pollution. Taking data on fuel and stove types used for cooking as well as typical housing ventilation characteristics, this indicator calculates household fine particulate matter $\left(\mathrm{PM}_{2.5}\right)$ exposure, both from cooking and from air pollution infiltrating from outside. A full explanation of the methods is described in the Appendix. Here, the estimated effect of household factors on deaths attributable to $\mathrm{PM}_{2.5}$ pollution in 2018 are presented for selected countries (Figure 14). In the middle-income countries assessed, the use of solid fuels for cooking is combined with poor housing ventilation to increase mortality from $\mathrm{PM}_{2.5}$ exposure. For other mostly highincome countries, housing design and extract ventilation are preventing ambient air pollution from entering the home. Combined with the use healthy cooking fuels, this results in a net negative effect on total (both household and ambient) $\mathrm{PM}_{2.5}$ attributable mortality, demonstrating a clear co-benefit of mitigation. 
Clean Cooking

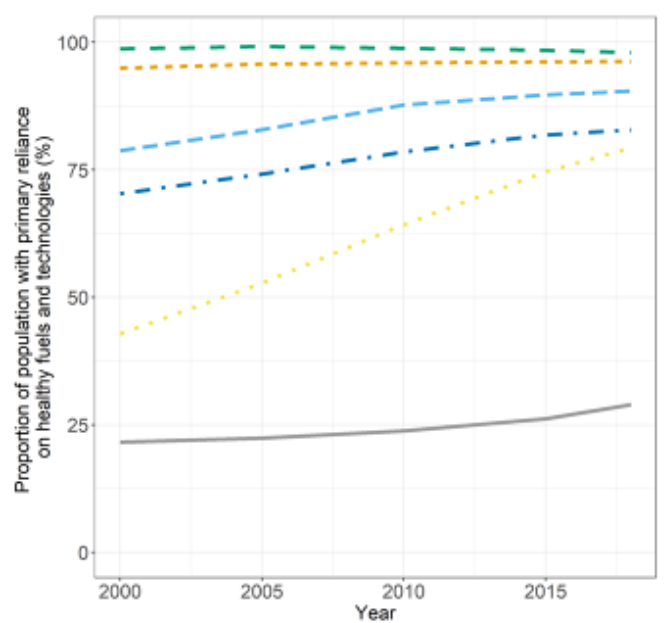

Zero-Emission Household Energy

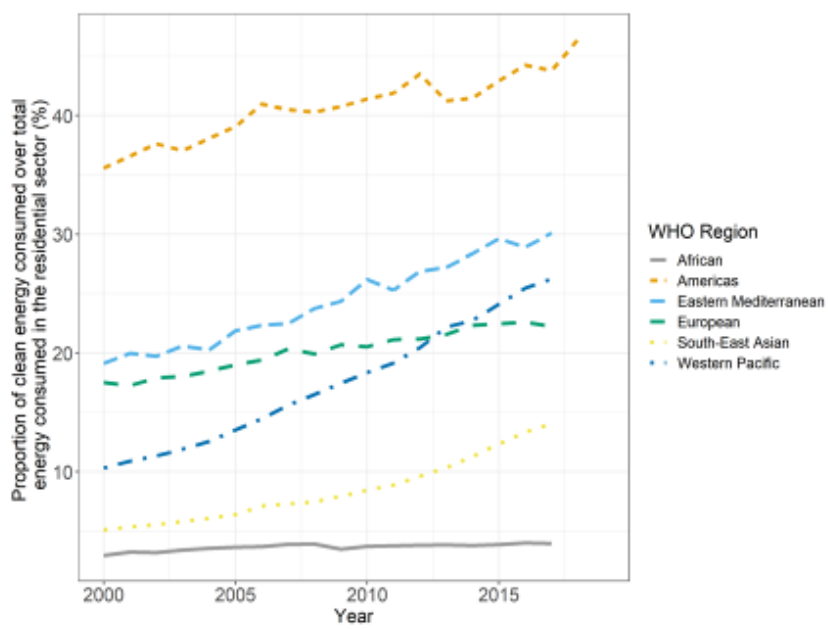

1345 Figure 13: Household energy usage: proportion of population with primary reliance on healthy fuels and technology for cooking by WHO region 2000-2018 (left); and proportion of clean energy consumption in the global residential sector, 2000-2016 (right). Proportion is measured as fuels with no emissions at point of use (not generation) over total residential sector consumption. Electricity comprises 75\% of total clean energy use in 2016.

\section{0}

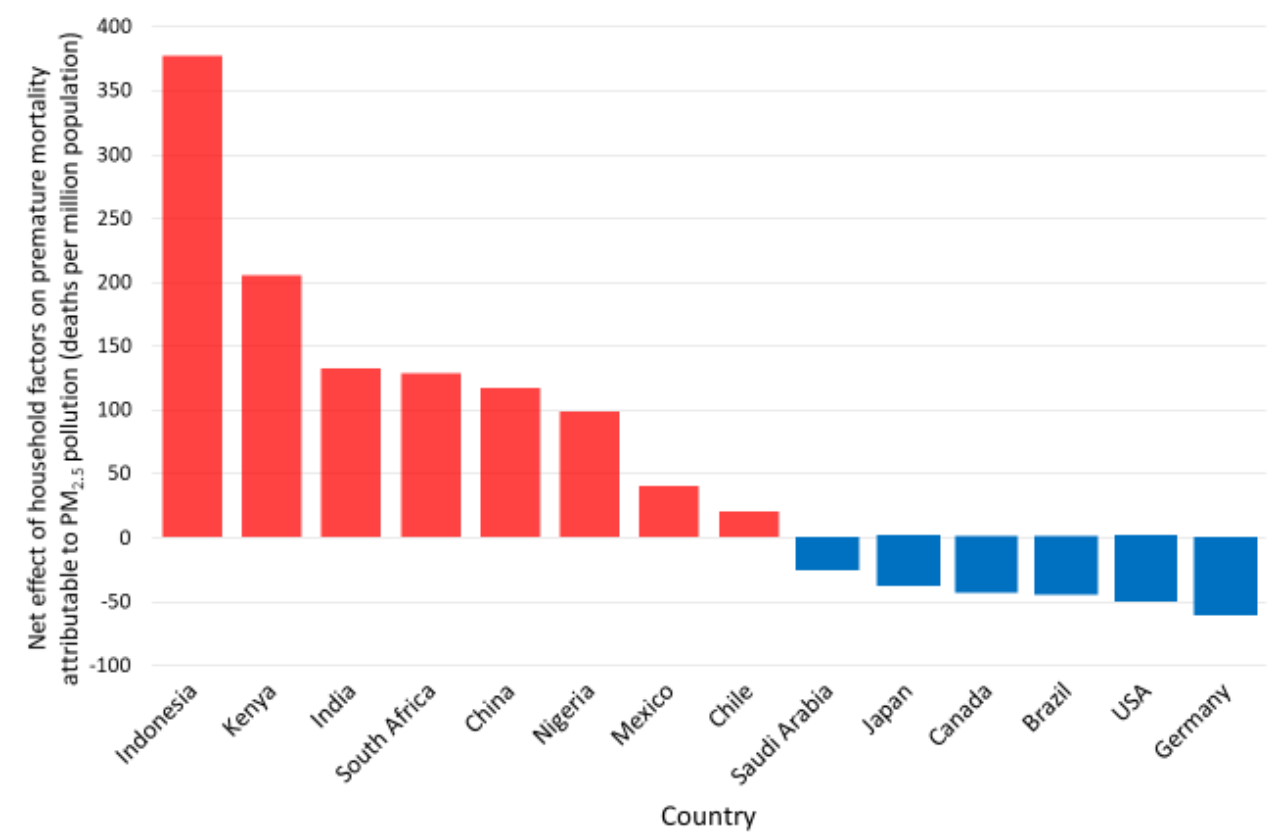

Figure 14: Estimated net effect of housing design and indoor fuel burning on premature mortality due 
1355

1356

1357

1358

1359

1360

1361

1362

1363

1364

1365

1366

1367

1368

1369

1370

1371

1372

1373

1374 If measures to respond to the economic fall-out from COVID-19 are aligned with the 1375 priorities of the Paris Agreement, transient reductions in air pollution following the sudden 1376

1377

Headline finding: Premature deaths from ambient particulate pollution attributed to coal use are rapidly declining, from 440,000 in 2015 to 390,000 in 2018. However, total deaths from ambient particulate pollution have increased slightly over this time period, from 2.95 million to 3.01 million, highlighting the need for accelerated intervention.

Many of the leading contributors to global GHG emissions also contribute to ambient air pollution, disproportionately impacting on the health of low-socioeconomic communities. ${ }^{166}$ Indeed, some $91 \%$ of deaths from ambient air pollution come from LMICs. ${ }^{167}$ This indicator tracks the source-attributable premature mortality from outdoor ambient air pollution. The methods remain unchanged and are described in the Appendix. ${ }^{168,169}$

Trends in air pollution mortality vary by world region, with decreases in Europe and China as a result of the implementation of emission control technologies and reductions in the use of raw coal in the power and residential sectors. ${ }^{170}$ The overall number of deaths attributable to ambient $\mathrm{PM}_{2.5}$ in 2018 is estimated at 3.01 million, a slight increase from 2.95 million deaths in 2015. Nonetheless, the total and per-capita deaths attributable to coal combustion have decreased from roughly 440,000 in 2015 to fewer than 390,000 in 2018 (Figure 15). Decreases are also seen in the contribution from biomass burning to ambient $\mathrm{PM}_{2.5}$ deaths (about 410,000 deaths in 2015 decreasing to 360,000 in 2018), mostly due to increasing access to cleaner household fuels, although 2.6 billion people still rely on fuelwood combustion in the home. ${ }^{171}$

halt in economic activities and road transport, could become more permanent, resulting in further improvements in health and air quality in 2020 and into the future. 


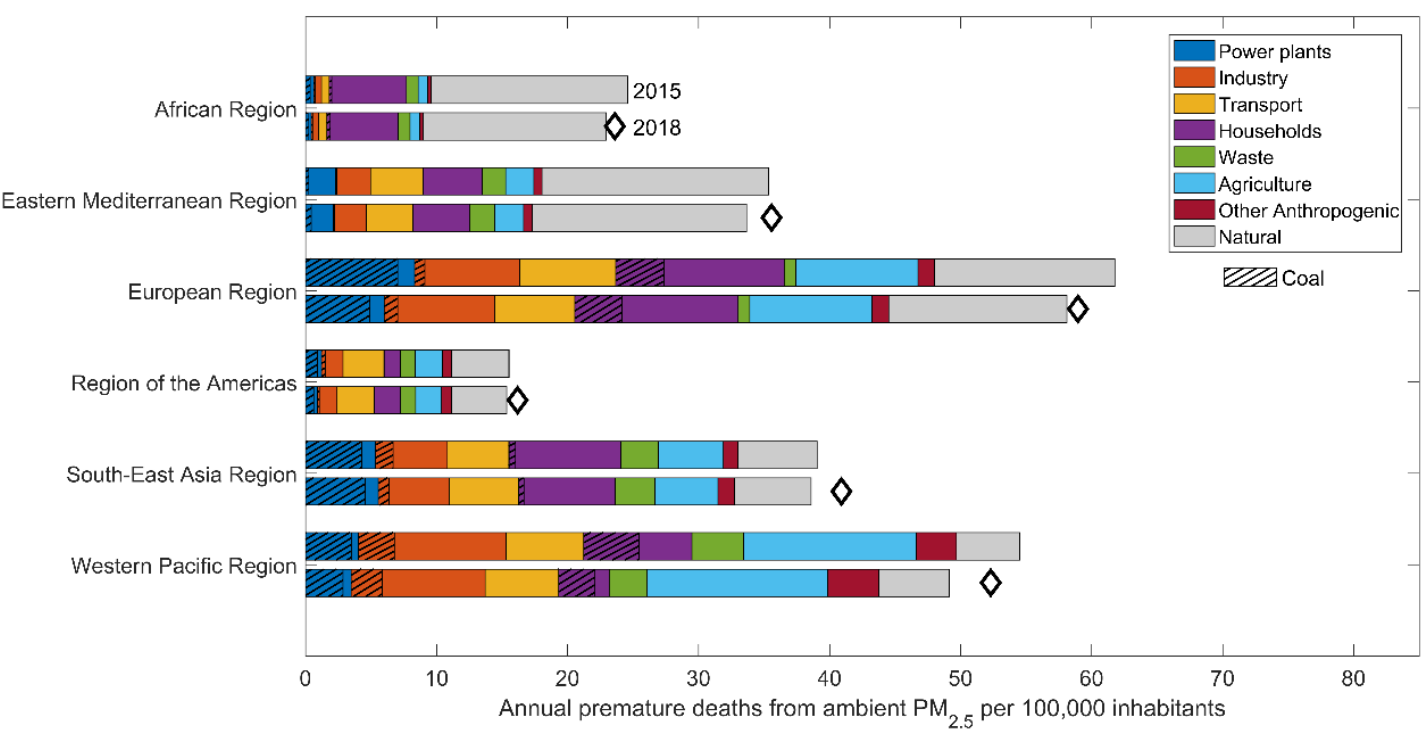

1379

1380

1381

1382

1383

1384

1385

1386

1387

1388

1389

1390

1391

1392

1393

1394

1395

1396

1397

1398

1399

1400

1401

1402

Figure 15: Premature deaths attributable to exposure to ambient fine particulate matter (PM 2.5) in 2015 and 2018, by key sources of pollution in WHO-specified regions. Coloured bars: attributable deaths with constant 2015 population structure, diamonds: totals for 2018 when considering demographic changes.

\section{Indicator 3.4: Sustainable and Healthy Transport}

Headline finding: While fossil fuels continue to dominate the transport sector, the use of electricity rose by 18.1\% from 2016 to 2017, and the global electric vehicle fleet increased to more than 5.1 million in 2018 (rising by 2 million in only 12 months).

The transition to ultra-low emissions vehicles is another essential component of climate change mitigation. In addition, policies that reduce overall vehicle use and increase walking and cycling will yield the greatest benefits in terms of reductions in GHG emissions and air pollution, as well as the health benefits of increased physical activity. ${ }^{172}$ Well-designed public transport and active travel infrastructure can also help reduce inequality and improve mobility for those who otherwise have limited travel options. ${ }^{173}$ For the 2020 report, global trends in fuel use for road transport are monitored, with methods and data available in the Appendix. ${ }^{174}$

Global per-capita road transport fuel use increased by 0.5\% from 2016 to 2017, with the rate of growth slowing slightly from previous years (Figure 16). Although fossil fuels continue to contribute the vast majority of total fuel use, the use of clean fuels is growing at a much faster pace. Total fossil fuel use for transport increased by 1.7\% between 2016 and 2017, compared with 18.1\% growth in electricity. From 2017 to 2018, the global electric vehicle fleet grew by an enormous $64.5 \%$, rising above 5.1 million in 2018. In line with this 
1410

1411

1412

1413

1414

1415

1416

1417

1418

1419

1420

1421

1422

1423

1424

1425

1426

1427
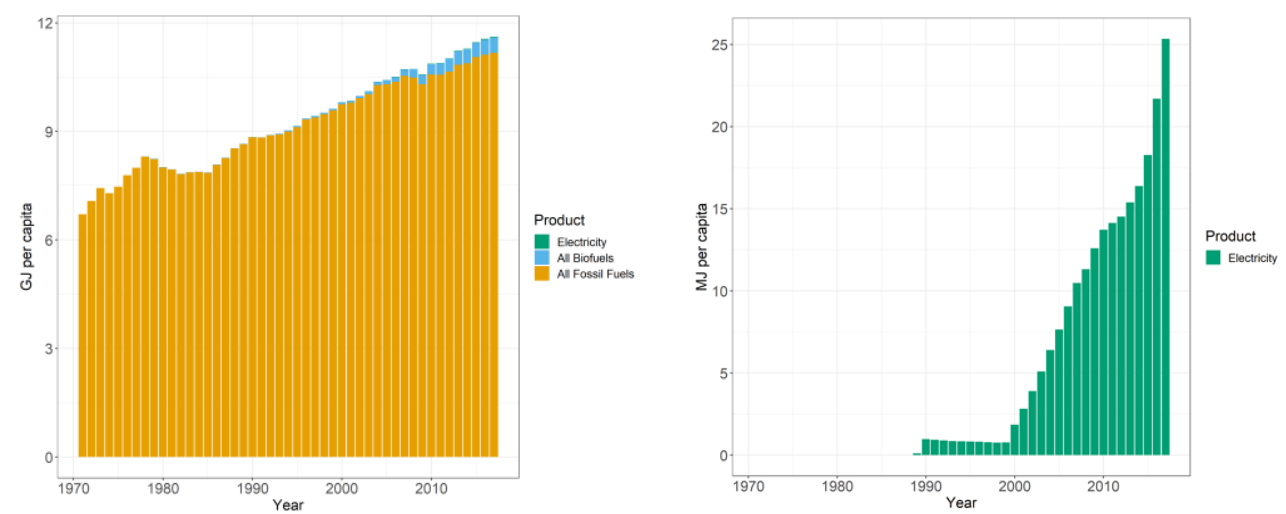

Figure 16: Per capita fuel use for road transport: A) All fossil fuels, biofuels, electricity; B) Electricity only. NB. The varying scales in y-axes.

\subsection{Food, Agriculture, and Health}

\section{Indicator 3.5.1: Emissions from Agricultural Production and Consumption}

Headline finding: Ruminant livestock continue to dominate agriculture's contribution to climate change, responsible for $56 \%$ of its total emissions, and $93 \%$ of all livestock emissions globally. This represents a 5.5\% increase in the per capita emissions from beef consumption since 2000, which is particularly concerning, given the sharp rise in population over this time period, and the health impacts of excess red meat consumption.

The food system is responsible for $20-30 \%$ of global GHG emissions, with the majority originating from meat and dairy livestock. ${ }^{175}$ Improved for the 2020 report, agricultural emissions from countries' production and consumption (adjusting for international trade) are tracked using data from the FAO, with a full description of methods and data provided in the Appendix. ${ }^{176-178}$ While countries' emissions are typically measured on a production basis, it is their consumption that generates the demand, and results in diet-related health outcomes.

Overall emissions from livestock production have increased by $16 \%$ since 2000 to over 3.2 billion tonnes of $\mathrm{CO}_{2} \mathrm{e}$ in 2017. Ruminants contribute $93 \%$ of total livestock emissions, with non-dairy cattle contributing $67 \%$ of this. Moving to consumption emissions, beef industry 
products dominate, both in absolute and per-capita terms (Figure 17). Average beef consumption emissions were $402 \mathrm{~kg} \mathrm{CO}_{2} \mathrm{e}$ per person in 2017, compared to $380 \mathrm{~kg} \mathrm{CO}$ e per person in 2000.

1431 Ultimately, effective mitigation will maximise human health while reducing food and agricultural emissions, however no one diet is applicable everywhere, and there are important nuances and variations to be considered across regions and countries. Excessive consumption of red meat brings significant health consequences, as outlined below, and less emissions-intensive plant-based sources are important alternatives, particularly in Europe and the Americas, where per capita emissions are high. In other parts of the world, sustainable farming and agricultural practices are being implemented to meet the nutritional requirements of rapidly growing populations while also keeping emissions low. ${ }^{179}$

1439
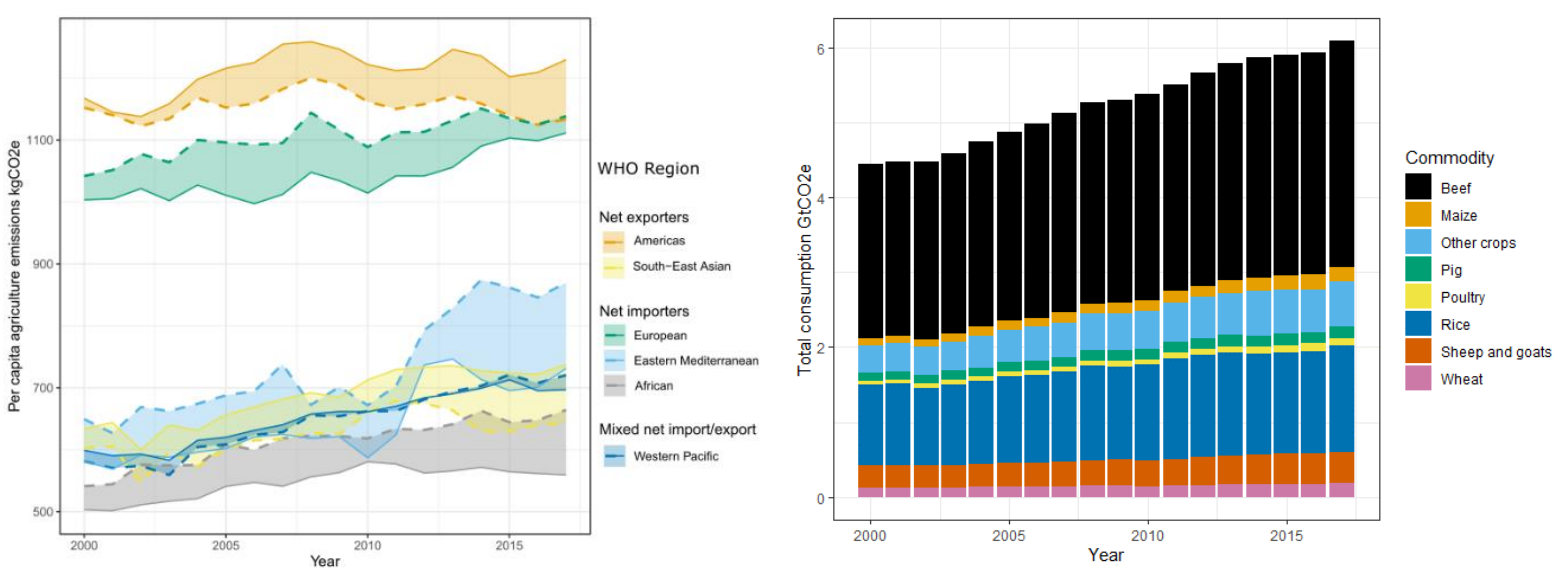

Figure 17: Agricultural production and consumption emissions 2000-2017 calculated using FAO trade data: per capita production (solid line) and consumption (dotted line) emissions by WHO region (left); Global agricultural consumption emissions by commodity (right).

\section{Indicator 3.5.2: Diet and Health Co-Benefits}

Headline finding: The global number of deaths due to excess red meat consumption has risen to 990,000 in 2017 , a 72\% increase since 1990.

Unhealthy diet is one of the leading risk factors for premature death, both globally and in most regions. ${ }^{110}$ Combined with a range of food-system-wide interventions, it is possible to achieve dietary change consistent with the Paris Agreement and the SDGs, by reducing reliance on red meat consumption and prioritising healthier alternatives, with a variety of diets and choices available depending on the region, individual, and cultural context. ${ }^{180,181}$ New to the 2020 report, this indicator presents the change in deaths attributable to dietary risks, by focusing in on one particular area - the consumption of excess red meat. Here, it 
links food consumption from the FAO's food balance sheets with dietary and weight-related

1456 Globally, diet and weight-related risk factors accounted for 8.8 million deaths in 2017, which represented $19 \%$ of total mortality, with little overall change since 1990 . The regions with the largest ratio of diet-related deaths include the Eastern Mediterranean (28\%), Europe (25\%), and the Americas (22\%). High red meat consumption was responsible for 990,000 deaths globally in 2017 (Figure 18). The greatest contribution to this total came from the Western Pacific, where red meat consumption was responsible for an estimated 411,500 deaths (3.3\% of all deaths) and, while there has been an overall improvement in dietary risk factors in Europe, the share of all deaths attributable to red meat consumption still accounts for $3.4 \%$ (306,800 deaths) .

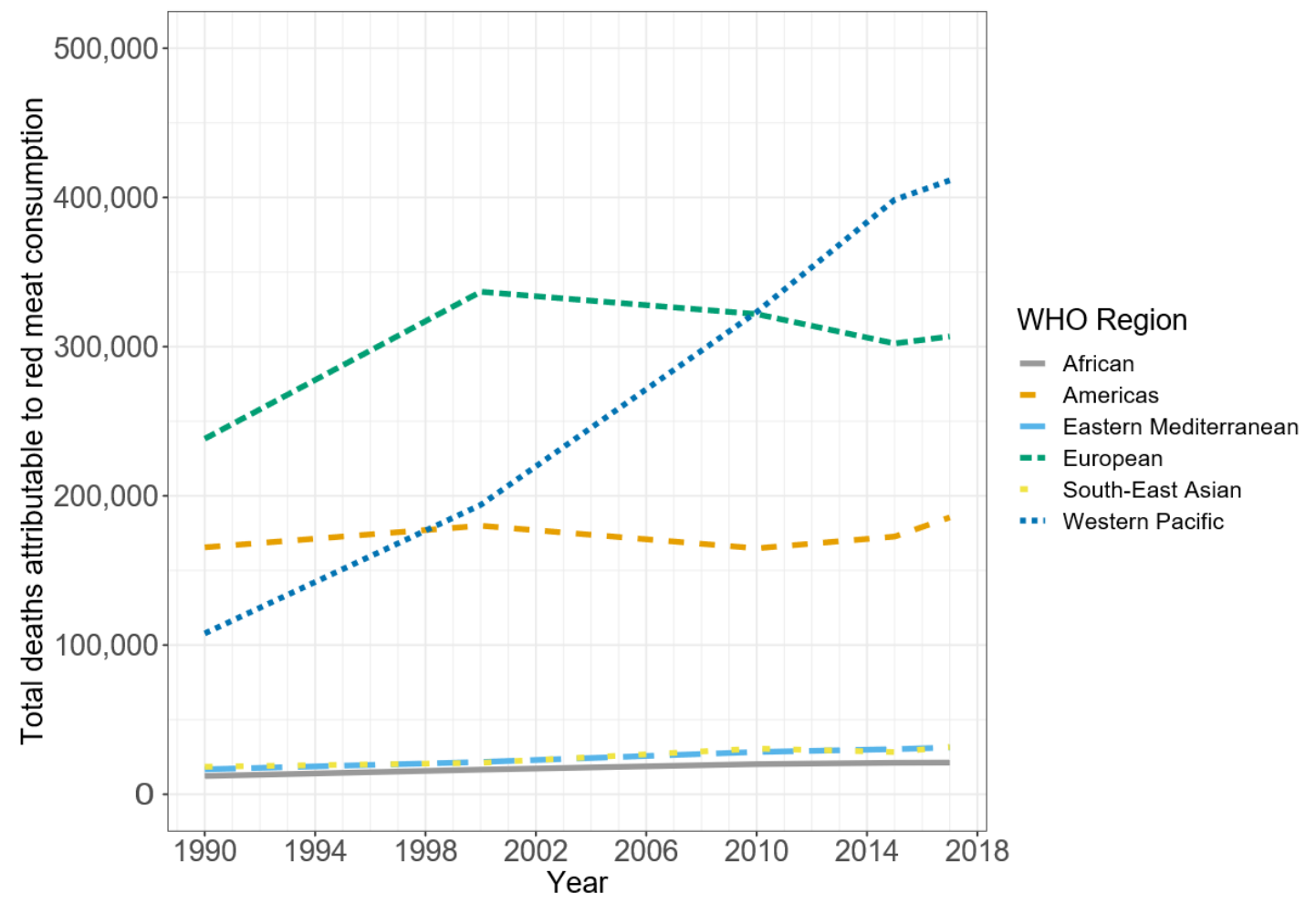


1471 Headline finding: The healthcare sector was responsible for approximately $4.6 \%$ of global 1472 GHG emissions in 2017, with substantial variations in per capita emissions and healthcare 1473 access and quality.

1474 Healthcare is among the most important sectors in managing the effects of climate change 1475 and, simultaneously, it has an important role to play in reducing its own carbon emissions 1476 (Panel 4). Emissions from the global healthcare sector are modelled using environmentally 1477 extended multi-region input-output (EE MRIO) models combined with WHO healthcare 1478 expenditure data. ${ }^{183-187}$ Based on external review and feedback, the methodology 1479 improvements include adjustments in the EE MRIO satellite accounts that reflect recent 1480 shifts in emissions intensities, particularly in the energy sector, with a full description of 1481 methods and additional analysis in the Appendix.

1482 In updated results to 2017, the healthcare sector contributed approximately $4.6 \%$ of global 1483 GHG emissions, a rise of 6.1\% from 2016. On a per capita level, comparing emissions alone 1484 fails to capture vital differences in health outcomes among countries, including access to care. Similarly, increases in emissions in a single country over time may reflect additional healthcare spending that improves population health. Figure 19 plots per capita healthcare GHG emissions against the Healthcare Access and Quality (HAQ) Index. ${ }^{184}$ There is a clear positive relationship between the two, up to $400 \mathrm{kgCO}_{2} \mathrm{e}$ per person. Above this point, countries achieve very similar HAQ levels with vastly different emissions profiles. For example, France, Japan, and the USA have very high $\mathrm{HAQ}$ attainment, with per capita emissions ranging from $350 \mathrm{kgCO}_{2} \mathrm{e}$, through to $1,220 \mathrm{kgCO}_{2} \mathrm{e}$, and $1,720 \mathrm{kgCO}_{2} \mathrm{e}$ respectively, suggesting that much of healthcare can achieve high-quality patient outcomes, with significantly reduced emissions. 


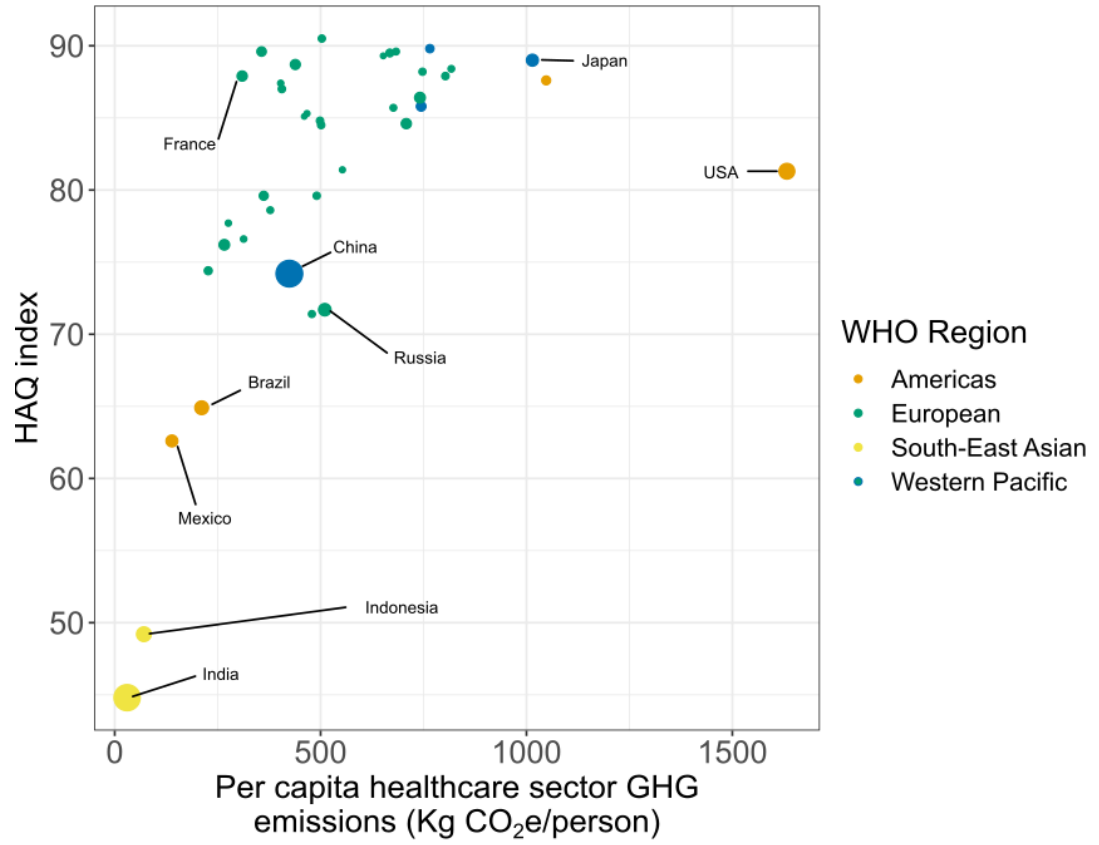

1496 Figure 19: National per capita healthcare GHG emissions against the Healthcare Access and Quality

Panel 4: For a Greener NHS

With over 1.5 million employees, England's National Health Service (NHS England) is the largest single employer in Europe and is the largest single-payer healthcare system in the world, with an annual budget of $f 134$ billion. While providing high-quality healthcare to a population of almost 56 million, NHS England contributes 4-5\% of the country's total GHG emissions. Accountable to both NHS England and Public Health England, the Sustainable Development Unit was founded in 2008 to ensure the health service met its commitments under the UK Climate Change Act. Since then, the NHS has achieved impressive reductions in GHG emissions whilst maintaining high standards of care and reducing costs. ${ }^{188}$ In January 2020, NHS England announced its commitment to become the world's first 'net zero health system', alongside its new campaign "For a greener NHS". ${ }^{189} \mathrm{~A}$ new baseline of NHS England's current carbon footprint was quantified, identifying the different sources of emissions using a hybrid model of bottom-up measurements of direct emissions (on-site fossil fuel use, fleet and transport, and anaesthetic gases) and energy use and top-down MRIO-based measurements to estimate other indirect emissions (including upstream energy system emissions, pharmaceutical procurement, and patient use of metered dose inhalers). NHS England is now working to develop a strategy for how and when Net Zero emissions can be achieved. 
1500 The trends over the past year show a concerning lack of progress in a number of sectors, 1501 including a continued failure to reduce the carbon intensity of the global energy system, a 1502 rise in the use of coal-fired power, and rising agricultural emissions and premature deaths 1503 from excess red meat consumption. This is in-part counteracted by the growth of renewable 1504 energy and improvements in low-carbon transport. While these continue to rise at a pace, it 1505 is important to consider that they are starting from a low baseline.

1506 In many cases, it is likely that 2020 will be an inflection point for a number of indicators 1507 presented over the coming decade, with the direction of future trends yet to be seen..

1508 Ensuring that the recovery from the pandemic is synergistic with the long-term public health 1509 imperative of responding to climate change will be vital in the coming months, years, and 1510 decades. 
1514 Section 1 described the emerging human symptoms of climate change, while Sections 2 and 15153 detailed efforts to adapt and mitigate against the worst of these effects. In turn, Section 4 1516 examines the financial and economic dimensions of both the impacts of climate change, and 1517 efforts to respond.

1518 The Intergovernmental Panel on Climate Change (IPCC) estimate limiting warming to $1.5^{\circ} \mathrm{C}$ 1519 would require annual investment in the energy system equivalent to around $2.5 \%$ of global 1520 GDP, through to $2035 .{ }^{85}$ Such investment would both limit the cost of the damage from 1521 climate change (up to US\$4 trillion per year by 2100 from a $3^{\circ} \mathrm{C}$ world as compared to a $2^{\circ} \mathrm{C}$ world) and generate a range of other economic benefits (including the creation of new technologies and industries) and health benefits from avoiding the effects of climate change current carbon-intensive activities. Once such factors are considered, the overall economic implications of limiting warming to $1.5^{\circ} \mathrm{C}$ are likely to be positive - particularly if policy responses are accelerated as soon as possible to a level commensurate with the scale of the challenge. Recent estimates suggest that investment to "bend the curve" from the world's current path, to a limited temperature rise of $1.5^{\circ} \mathrm{C}$ by 2100 , would generate global net benefit of US\$264-610 trillion (3.1-7.2 times of the size of the global economy in 2018). ${ }^{12}$

1530 The global economy will look substantially different following the recovery from the COVID19 pandemic. As governments around the world grapple with the challenge of restarting their economies, it will be important to ensure these efforts are aligned with the response to climate change. If the enormous fiscal stimulus that will be required is directed away from high-carbon, and towards low-carbon infrastructure and activities, an opportunity to permanently bend the curve presents itself. Metrics examining these core concepts are currently tracked in this report, allowing future data to reveal the long-term effect of COVID-19 on the low-carbon economy.

The nine indicators in this section fall into two broad domains. The first is the health and economic costs of climate change and its mitigation (Indicators 4.1.1 to 4.1.4). This includes two new indicators for the 2020 report, on the economics of heat-related mortality and the potential reduction in earnings from heat-related labour capacity loss (Indicators 4.1.2 and 4.1.3). The second domain examines the economics of the transition to zero-carbon economies (Indicators 4.2.1 to 4.2.5), which is fundamental to the improvement of human health and wellbeing. This theme also includes a new indicator, (Indicator 4.2.5), which merges three indicators presented in previous reports (on fossil fuel subsidies, the strength and coverage of carbon prices, and carbon pricing revenues) to examine the "net" carbon prices in place around the world. 
1551

1552

1553

1554

1555

1556

1557

1558

1559

1560

1561

1562

1563

1564

1565

1566

1567

1568

1569

1570

1571

1572

1573

1574

1575

1576

1577

1578

1579

1580

1581

1582

1583

1584

Headline finding: Economic losses from climate-related extreme events in 2019 were nearly five times greater in low-income economies than high-income economies, and with just 4\% of these losses insured, compared to $60 \%$ in high-income economies.

Section 1 presented the evidence linking the impacts of climate change to human health and wellbeing. The loss of physical infrastructure (agricultural land, homes, health infrastructure) due to such events will further exacerbate these health impacts. This indicator tracks the total annual economic losses (insured and uninsured) that result from climate-related extreme events. The methodology is described in full in the Appendix, which has changed compared to previous years. ${ }^{190,191}$

In 2019 there were 236 recorded climate-related extreme events, with absolute economic losses totalling US\$132 billion. Although most of these losses occurred in high-income economies, when normalised by GDP, the value of total economic losses in low-income countries is nearly five times greater. In addition, while $60 \%$ of losses in high-income economies were insured, this reduces to $3-5 \%$ for other income groups. It is important to note that, when normalised by GDP, relative economic losses have been decreasing, while the number of total extreme events is increasing, suggesting that adaptation and prevention are reducing their impacts. ${ }^{192}$

\section{Indicator 4.1.2: Costs of Heat-Related Mortality}

Headline finding: In 2018, the monetised value of global heat-related mortality reached $0.37 \%$ of Gross World Product, compared to $0.23 \%$ in 2000. Europe suffered the most in 2018 , with costs equal to the average income of 11 million of its citizens, and $1.2 \%$ Gross National Income.

As Indicator 1.1.3 highlights, rising temperatures and extremes of heat are resulting in worsening morbidity and mortality for populations around the world. The 2020 report introduces a new indicator, which considers the economic impact of this, by tracking the monetised value of global heat-related mortality. To do so, it makes use of the value of a statistical life (VSL), drawing on estimates produced for the Organisation for Economic Cooperation and Development (OECD) for those countries, making use of a fixed ratio of VSL to gross national income (GNI) for non-OECD countries, and applying this to the heat-related mortality data from Indicator 1.1.3. ${ }^{193,194}$ To address any distributional effects, and more accurately capture the economic harm that climate change presents to low- and middleincome countries, two indices have been calculated. The value of mortality is presented as a 
proportion of total $\mathrm{GNI}$, and as the average income per person this loss would be equivalent to, in a given country and region. A full description of the methods, data, caveats and further analysis are described in the Appendix.

1588 As global heat-related mortality increased from 2000, so too did the monetised cost of these deaths. At a global level and represented as a proportion of Gross World Product (GWP), the cost increased from $0.23 \%$ in 2000 to $0.37 \%$ in 2018 . Due the high number of heat-related deaths, Europe was the worst affected, reaching a cost equivalent to the income of 11 million of its citizens in 2018 (led by Germany at 1.9 million, Figure 20), and $1.2 \%$ of regional GNI. While the value in terms of proportion of GNI for the Western Pacific and South East Asia were comparatively low at $0.43 \%$ and $0.19 \%$ respectively, these impacts are more substantial when considered against the average income in those regions.

Figure 20: Monetised value of heat-related mortality represented as the number of people to whose

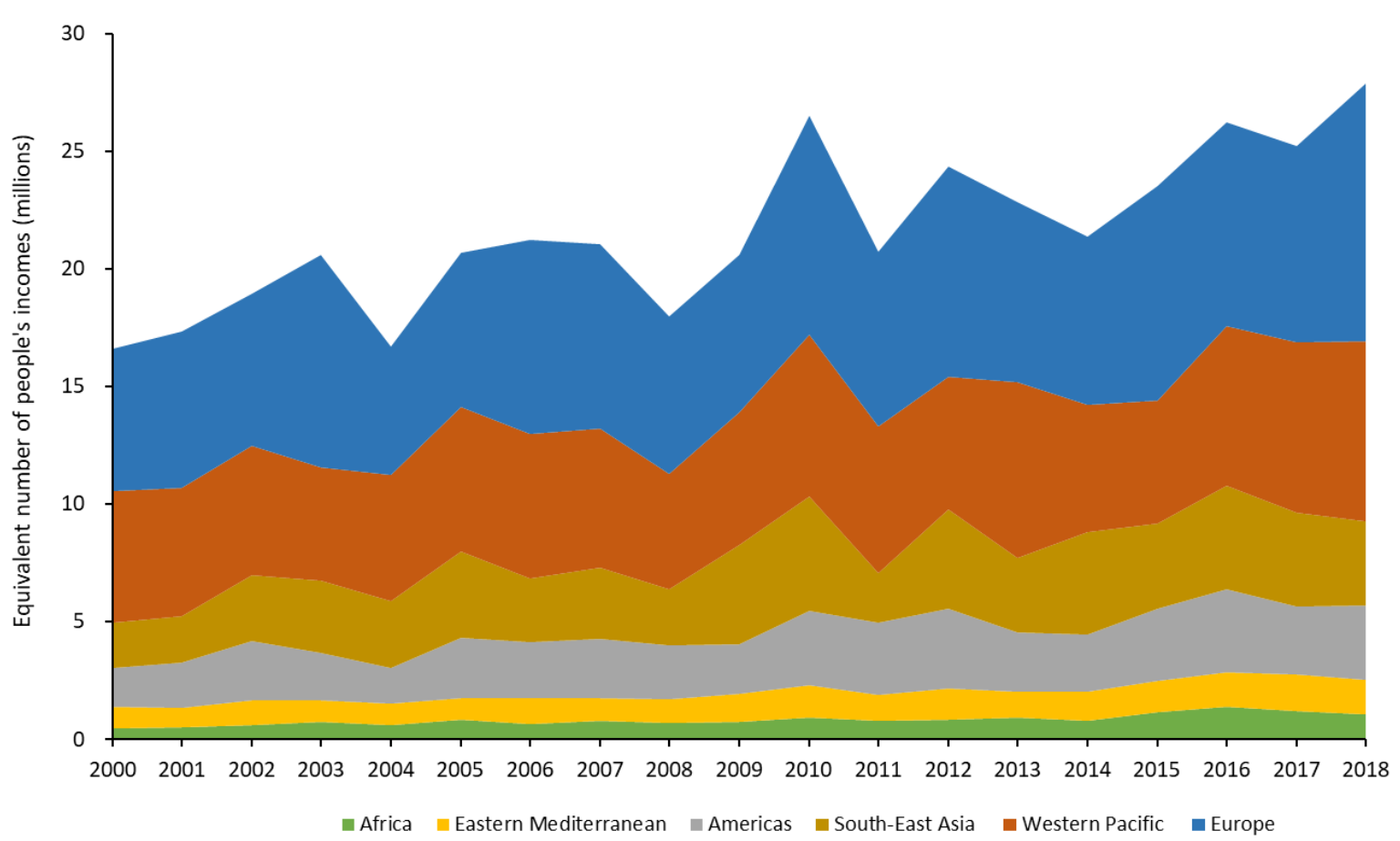

Headline finding: Rising temperatures make outdoor labour increasingly difficult, often 
borne out, the heat related reduction in labour capacity experienced would result in earnings losses equivalent to an estimated 4-6\% of GDP in lower-middle income countries tracked.

Higher temperatures, driven by climate change, are affecting people's ability to work (Indicator 1.1.4). This new indicator considers the loss of earnings that could result from such reduced capacity, compounding the initial cause of ill health and impacting on wellbeing. It adopts the outputs of Indicator 1.1.4 for 25 countries, selected by the impact their workers experience and for geographical coverage, and combines these with data on average earnings by country and sector held in the International Labor Organization (ILO) databases. ${ }^{42}$ These estimates will be modified by a variety of factors, ranging from whether or not sick leave was taken, the presence of workers sick pay rights, and the availability of shade. A full description of the methods and additional analysis is provided in the Appendix.

When taken as a share of GDP, low- and lower middle-income countries are the hardest hit, with losses predominantly seen in agriculture, despite this being on average the lowest paid of the sectors considered. By 2015, averaged estimated earnings losses reached the equivalent of 4-6\% of GDP for lower-middle income countries tracked including Indonesia, India, and Cambodia, and between 0.6-1\% for upper-middle income countries, including China, Brazil, and Mexico.

\section{Indicator 4.1.4: Economics of the Health Impacts of Air Pollution}

Headline finding: Across Europe, ongoing reductions in particulate air pollution from human activity were seen from 2015 to 2018. If held constant, this improvement alone would lead to an annual average reduction in years of life lost to the current population worth $\$ 8.8$ billion.

As described in Indicator 3.3, global mortality due to ambient $\mathrm{PM}_{2.5}$ pollution has risen from around 2.95 million in 2015 to 3.01 million in 2018. However, due to improvements in air quality, including the closure of coal power stations, premature mortality due to air pollution in Europe has decreased over the same period. This indicator captures the cost of that change in the European Union (EU) by placing an economic value on the Years of Life Lost (YLL) that result from exposure to $\mathrm{PM}_{2.5}$ from anthropogenic sources, with the methods and data described in full in the Appendix. ${ }^{195}$

If the population of the EU in 2015 were to experience anthropogenic $\mathrm{PM}_{2.5}$ emissions at 2018 levels instead of levels experienced in 2015, consistently over the course of their lives, the total average economic value of the reduction in YLLs would be around $\$ 8.8$ billion (€9.85 billion), every year. Despite this, $2018 \mathrm{PM}_{2.5}$ levels are still damaging to cardiovascular and respiratory systems, and the total annual average cost to the current population would still be $\$ 116$ billion ( $€ 129$ billion). Based on 2018 levels of air pollution, 
1642 the average life lost per person in the EU is 5.7 months, but this loss of life is estimated at 1643 over 8 months per person for Poland, Romania, Hungary, Italy and Belgium (Figure 21).

1644

1645

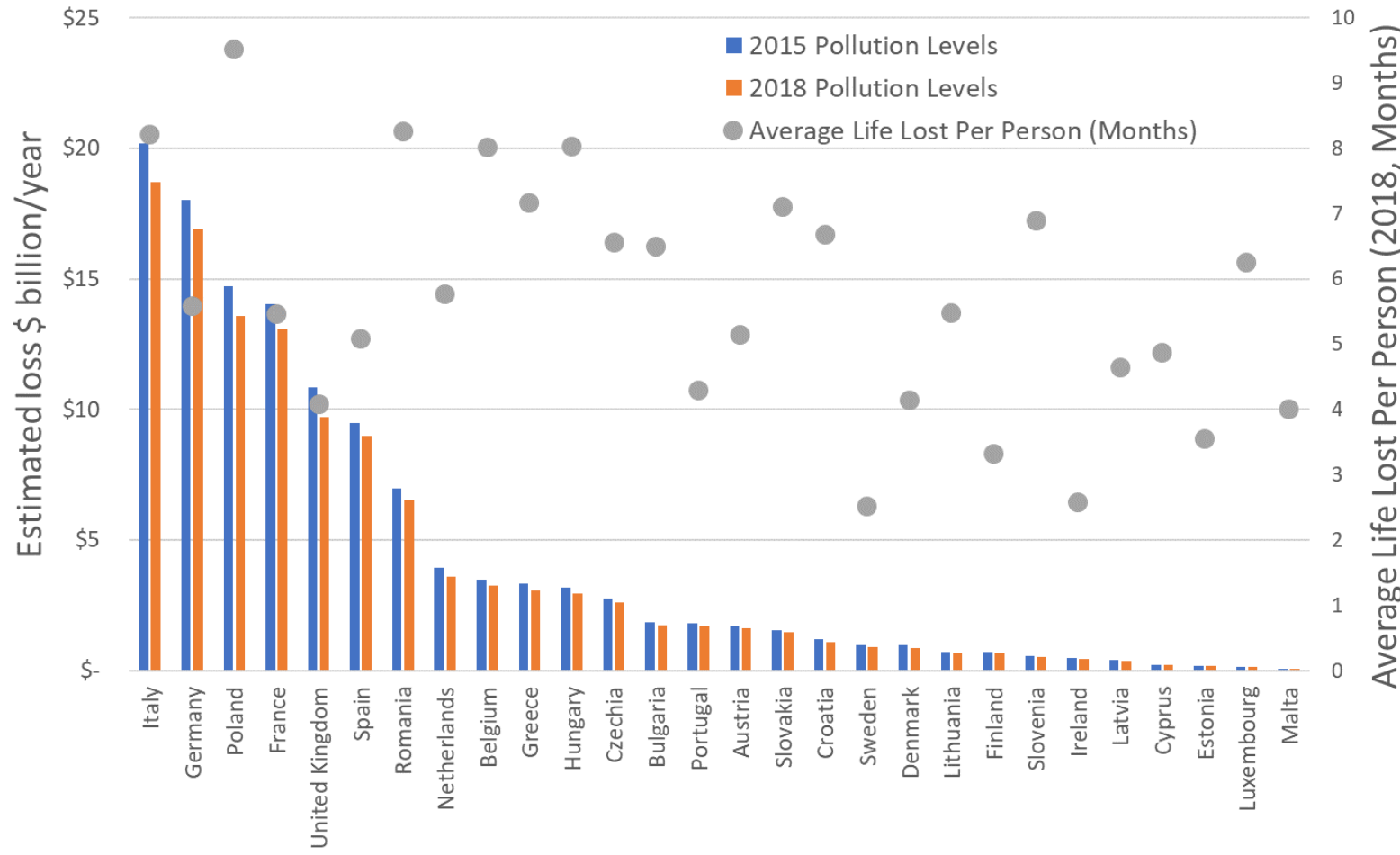

Figure 21: Annual monetised value of YLLs due to anthropogenic PM2.5 exposure, and average 1648 months of life lost per person (2018 pollution levels). 
1652 Headline finding: Largely driven by China, investment in new coal capacity has been 1653 declining since 2011 and reduced by 6\% from 2018 to 2019. Despite this, global coal capacity 1654 continues to increase, with fewer coal plant retirements than additions for every year 1655 tracked.

1656 As identified in Section 3, coal phase-out is essential, not only for the mitigation of climate 1657 change, but also for the reduction of premature mortality due to air pollution. Taking data 1658 from the IEA, this indicator points to future coal use, tracking investment in new coal-fired 1659 power generation. The data represents 'ongoing' capital spending, with investment in a new 1660 plant spread evenly from the year new construction begins, to the year it becomes 1661 operational. ${ }^{196}$ For the 2020 report, data is presented for key countries and regions, 1662 alongside the global trend. Further details on the methods and data are found in the 1663 Appendix.

1664 Following the trend since 2011, global investment reduced a further $6 \%$ between 2018 and 1665 2019. With a 27\% reduction in investments over these two years, China has been driving 1666 this decline. Final Investment Decisions (FIDs, the point at which the project's future 1667 development is approved) have reached their lowest point in 40 years, with a further $11 \%$ 1668 reduction in investment forecast for 2020 - driven by declining investment in Asia, in part as 1669 a result of COVID-19. However, despite a substantial decline in actual investment, FIDs in 1670 China increased in 2019 compared to 2018, and, with the approval of 8 GW of new capacity, 1671 reached 2019 levels by March 2020. Additionally, with fewer coal plant retirements than 1672 additions in 2019 (and in every year presented), there was an overall increase in global 1673 capacity. 


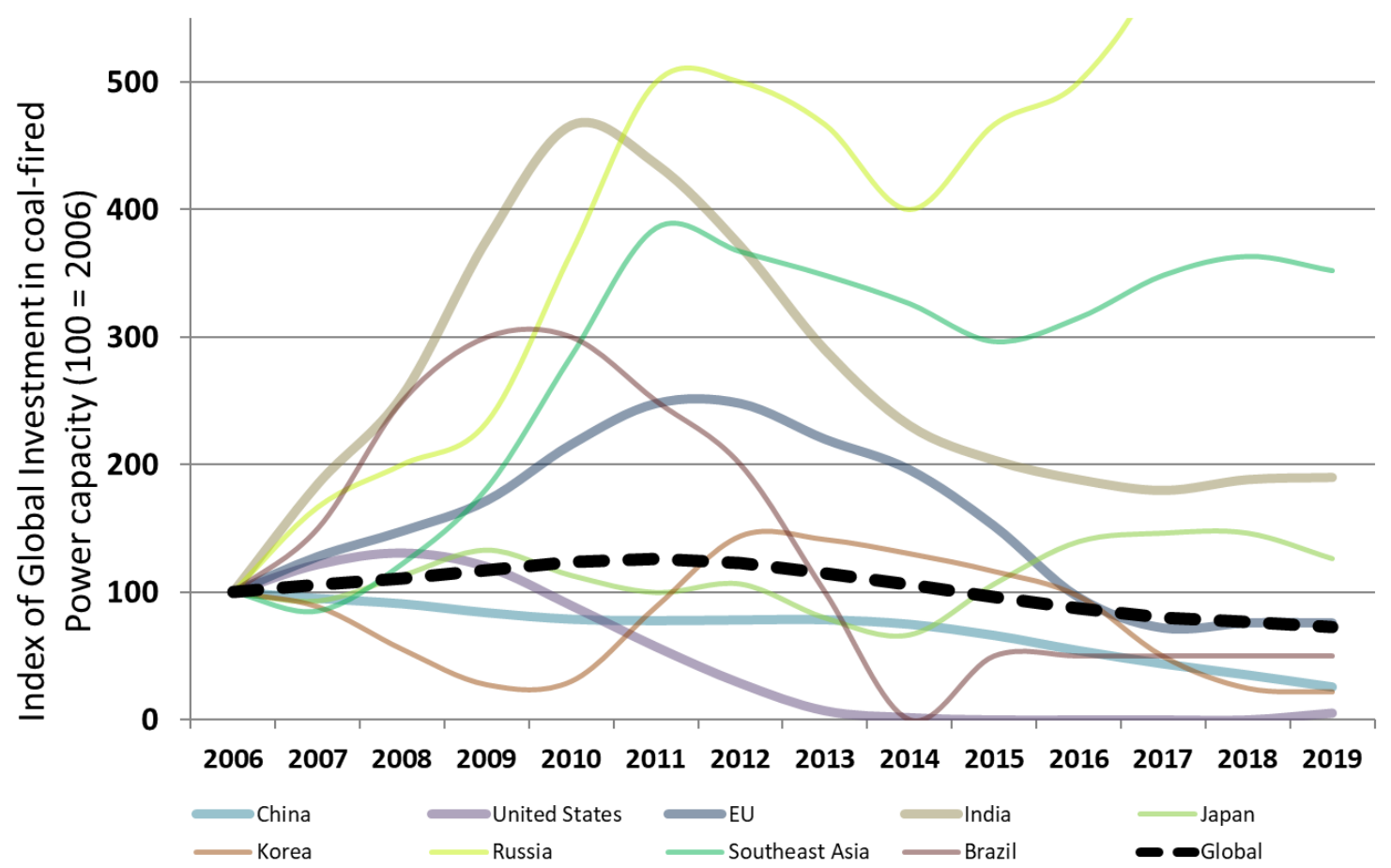

1675

1676

1677

1678

1679

1680

1681

1682

1683

1684

1685

1686

1687

1688

1689

1690

1691

1692

1693

Figure 22: Annual investment in coal-fired capacity 2006-2019 (an index score of 100 corresponds to 2006 levels).

\section{Indicator 4.2.2: Investments in Zero-Carbon Energy and Energy Efficiency}

Headline finding: Progress towards zero-carbon energy has stalled in recent years, and investments in zero-carbon energy and energy efficiency have not risen since 2016, and are a long way from the doubling by 2030 required to be consistent with the Paris Agreement.

This indicator monitors annual global investment in these areas, as well as investment in all fossil fuels, complementing and providing a wider context to Indicator 4.2.1, above. Data is sourced from the IEA, and the methodology remains the same as the 2019 report of Lancet Countdown, with hydropower now considered separately and all values presented in US\$2019. ${ }^{196}$

Since 2016, investment in global energy supply and energy efficiency has remained relatively stable at just under US\$1.9 trillion, with fossil fuel supply consistently accounting for around half this value, and all renewables and energy efficiency combined maintaining a share of $32 \%$. For a pathway consistent with $1.5^{\circ} \mathrm{C}$ of warming this century, annual investments must increase to US\$4.3 trillion by 2030 , with investment in renewable electricity, electricity networks and storage, and energy efficiency accounting for at least 50\%. ${ }^{197}$ 
1694

1695

1696

1697

1698

1699

1700

1701

1702

1703

1704

1705

1706

1707

1708

1709

1710

1711

1712

1713
As a result of the COVID-19 pandemic, short-term disruption and long-term reassessments of likely returns mean that total energy investment is estimated to reduce by $20 \%$ in $2020-$ the largest fall ever recorded - with oil and gas supply investment to be reduced by a third. Renewable investment is likely to fare better than fossil fuel capacity, with investment in zero-carbon energy (nuclear, hydropower and other renewables) and energy efficiency projected to jump from $32 \%$ to $37 \%$ of investment in 2020 , due to falling investments in fossil fuels. ${ }^{196}$ Stimulus plans focussed on boosting energy efficiency and renewable energy will be essential to ensure that the power generation system is on track to meet the SDGs and the goals of the Paris Agreement. ${ }^{163}$

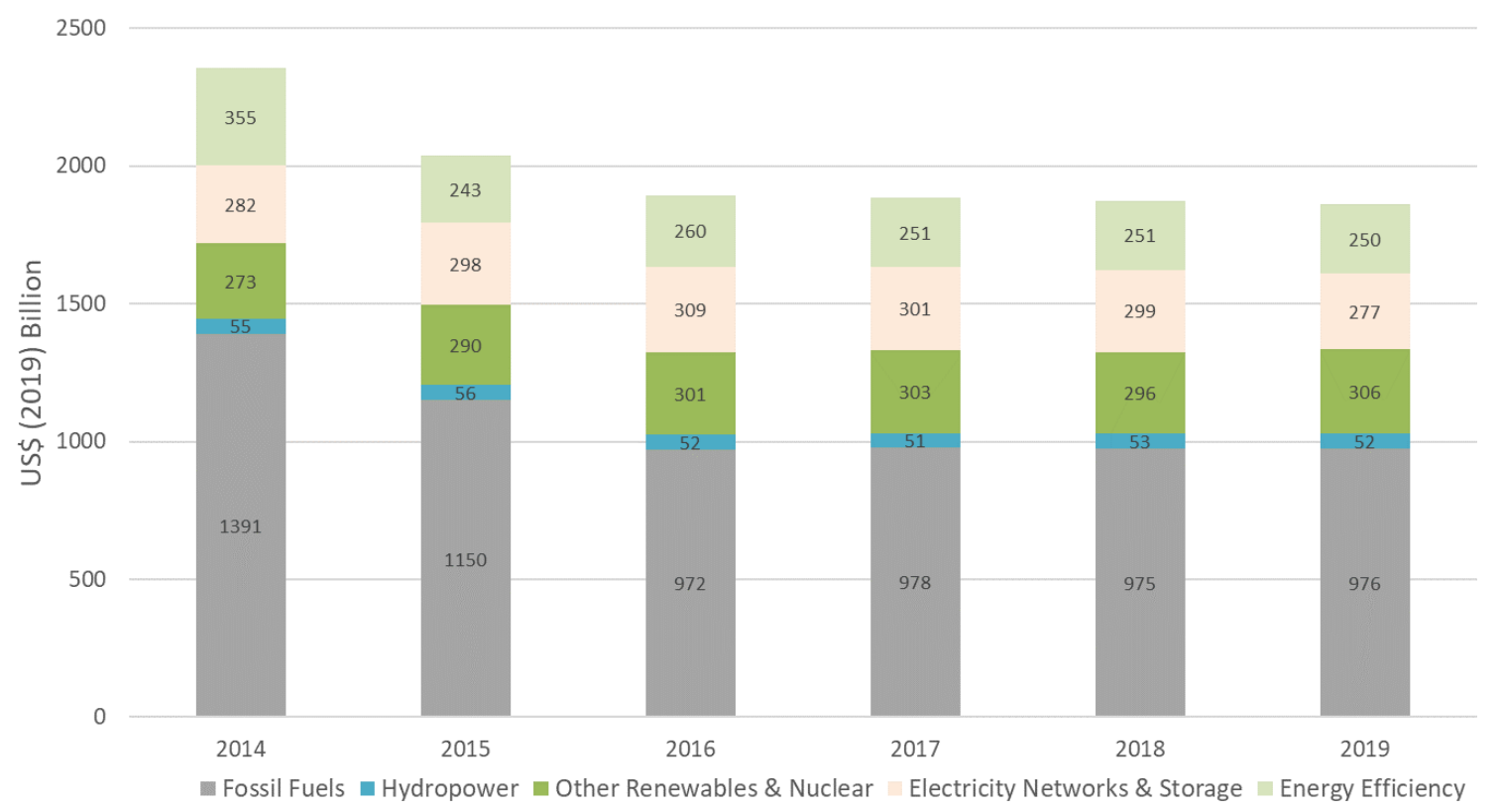

Figure 23: Annual Investment in energy supply and efficiency.

Indicator 4.2.3: Employment in Renewable and Fossil Fuel Energy Industries

Headline finding: Renewable energy provided 11 million jobs in 2018, a 4.2\% rise from 2017. Whilst still employing more people overall, employment in fossil fuel extraction declined by 3\% from 2018 to 2019.

There is mounting evidence that employees in some fossil-fuel extractive industries, particularly coal mining, and populations living in close proximity, suffer a greater incidence of certain illnesses, such as chronic respiratory diseases, cancers and congenital 
anomalies. ${ }^{198,199}$ Combined with increased job certainty, a managed transition of employment opportunities away from fossil fuel-related industries, and towards low-carbon industries will result in improved occupational health of employees within the energy sector. This indicator tracks global direct employment in fossil fuel extraction industries (coal mining and oil and gas exploration and production) and direct and indirect (supply chain) employment in renewable energy for the most recent year available, with a full description of the methods and data available in the Appendix. ${ }^{200-202}$

1721

1722

1723

1724

1725

1726

1727

1728

1729

1730

1731

1732

1733

1734

1735

1736

1737

1738

1739

1740

1741

1742

1743

1744

1745

1746

1747

1748

1749

Around 11 million people globally were employed directly or indirectly by the renewable energy industry in 2018, representing an increase of $4.2 \%$ from 2017 . Solar photovoltaic (PV) continues to provide the largest share of jobs, at over 3.6 million, with employment also rising in wind, bioenergy, and other technologies. Fossil fuel extraction industries continue to employ more people globally than all renewable energy industries, although the number of jobs in 2019 are slightly lower than in 2018, at 12.7 million compared with 13.1 million.

As the demand for fossil fuels declines, planned efforts, including retraining and job placement is important to ensure the ongoing employment of those currently working in fossil fuel extraction industries. The same will be true as part of the response to COVID-19, with structured re-training and deployment programmes for renewable energy potentially forming an important component of a recovery plan. Indeed, the IEA estimates that such a strategy, which accelerates the deployment of low-carbon electricity sources, expands electricity grid access and energy efficiency, and delivers cleaner transport, would create an additional nine million jobs a year, globally over the next three years. ${ }^{163}$

\section{Indicator 4.2.4: Funds Divested from Fossil Fuels}

Headline finding: The global value of new funds committed to fossil fuel divestment in 2019 was US\$4.01 trillion, of which health institutions accounted for around US\$19 million. This represents a cumulative sum of US\$11.51 trillion since 2008, with health institutions accounting for US\$42 billion.

By encouraging investors to reduce their financial interests in the fossil fuel industry, divestment efforts both remove the 'social license to operate' and guard against the risk of losses due to 'stranded assets' in a world in which demand for fossil fuels rapidly reduces. ${ }^{203,204}$ This indicator tracks the total global value of funds divested from fossil fuels, and the value of divested funds coming from health institutions, using data provided by 350.org, with annual data and full methodology described in the Appendix. ${ }^{205}$

From 2008 to the end of 2019, 1,157 organisations, with cumulative assets worth at least US\$11.51 trillion have committed to fossil fuel divestment. Of these, only 23 are health 
1750

1751

1752

1753

1754

1755

1756

1757

1758

1759

institutions, including the World Medical Association, the British Medical Association, the Canadian Medical Association, the UK Faculty of Public Health, the Royal College of General Practitioners, the Royal Australasian College of Physicians, Gundersen Health System, the Berlin Doctors Pension Fund, and the Royal College of Emergency Medicine, with total assets of approximately US\$42 billion. The annual value of new funds committed to divesting increased from US\$2.14 trillion in 2018 to US\$4.01 trillion in 2019. However, divestment from health institutions has slowed, with US\$19 million divested in 2019, compared to US\$867 million in 2018 , owing primarily to divestment from particularly large institutions in previous years.

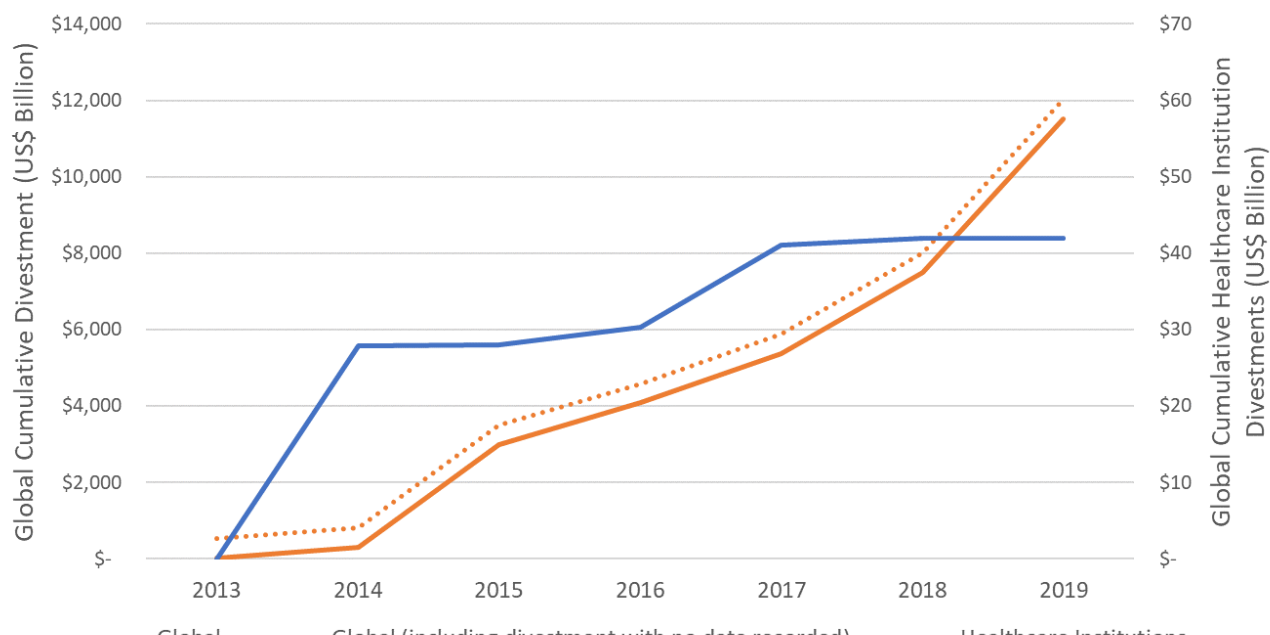

1760

Global $\quad$..... Global (including divestment with no date recorded) _ Healthcare Institutions

Figure 24: Cumulative divestment - Global total and in healthcare institutions.

1762

1763

Indicator 4.2.5: Net Value of Fossil Fuel Subsidies and Carbon Prices

1764 Headline finding: 58 out of 75 countries reviewed were operating with a net-negative carbon 1765 price in 2017. The resulting net loss of revenue was in many cases equivalent to substantial 1766 proportions of the national health budget.

1767 Placing a price on GHG emissions provides an incentive to drive the transition towards a 1768 low-carbon economy. ${ }^{206,207}$ It also allows for a closer reflection of the true cost of emissionsintensive practices, particularly fossil fuel use, capturing some of the negative externalities resulting from their impact on health. However, not all countries explicitly set carbon prices, and in some cases the strength of any carbon price may be undermined by the opposing influence of subsidies on fossil fuel production and consumption. ${ }^{208,209}$ 
Indicator 4.2 .5 has been created for the 2020 report by combining previous indicators on fossil fuel subsidies and carbon pricing. It calculates "net" economy-wide average carbon prices and associated net carbon revenue to government. The calculations are based on the value of overall fossil fuel subsidies, the revenue from carbon pricing mechanisms, and the total $\mathrm{CO}_{2}$ emissions of the economy. Data on fossil fuel subsidies are calculated based on analysis from the IEA and OECD. ${ }^{210,211}$ Together these sources cover 75 countries and account for around $92 \%$ of global $\mathrm{CO}_{2}$ emissions. Carbon prices and revenues are derived from data in the World Bank Carbon Pricing Dashboard and include international, national and subnational mechanisms within countries, 38 of which overlap with those covered by subsidy data and thus form part of this analysis. ${ }^{212} \mathrm{~A}$ full description of the methodology, other data sources, and the methods for integrating them, can be found in the Appendix.

Most of the 75 countries in 2016 and 2017 had net-negative carbon prices (61 and 58 respectively), and only $25 \%$ with a price above zero in both years, resulting from substantial subsidies for fossil fuel production and consumption (Figure 25). The median net carbon revenue was negative - a pay-out of US\$0.7 billion, with some countries providing net fossil fuel subsidies in the tens of billions of dollars each year. In many cases these subsidies are equivalent to substantial proportions of the national health budget - greater than $100 \%$ in eight of the 75 countries in 2017. Of the 38 countries that had formal carbon pricing mechanisms in place in 2017, 21 nonetheless had net-negative carbon prices.

1793
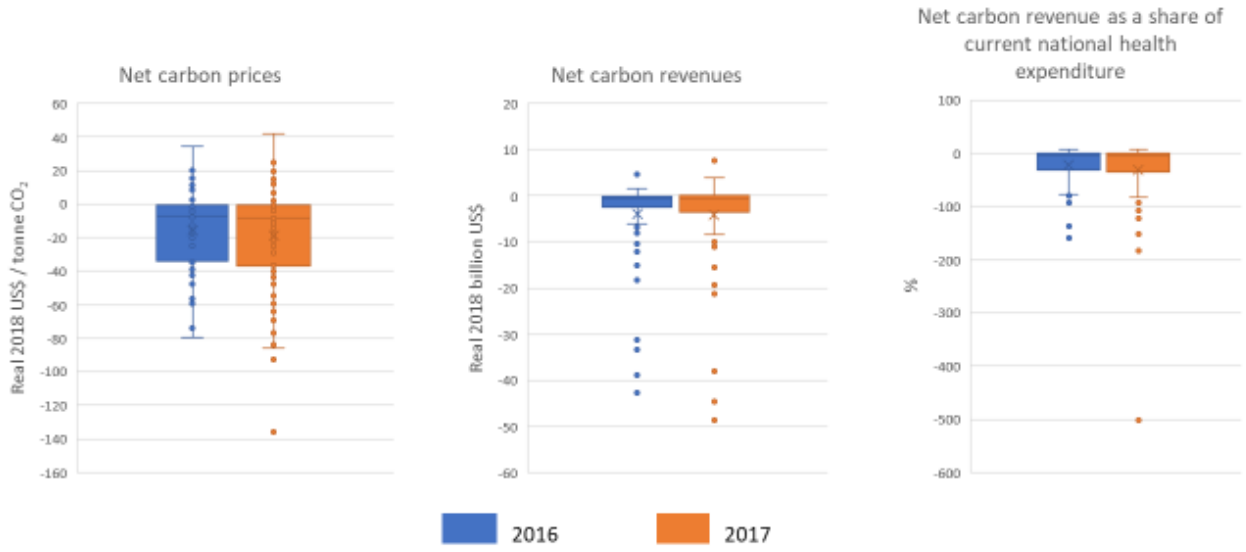

Figure 25: Net carbon prices; net carbon revenues; and net carbon revenue as a share of current national health expenditure, across 75 countries, 2016 and 2017. Boxes show the interquartile range $(I Q R)$, horizontal lines inside the boxes showing the medians. The means are shown by crosses. The brackets represent the range from minimum to maximum, however points are represented as outliers beyond this range if they are 1.5 times the IQR below the 1st quartile, or above the 3rd quartile. 
1802 The economic and financial dimensions of public health and climate change are central to 1803 any comprehensive mitigation and adaptation effort. This section has covered both the 1804 health and economic costs of climate change, as well as indicators of progress underlying a 1805 transition to a low-carbon economy. It has developed a number of new metrics to inform 1806 this and will continue to expand the geographical coverage and reach of these in 1807 subsequent reports.

1808 The outlook presented here is mixed. On the one hand, investment in new coal capacity 1809 continues to decline, and employment in renewable energy continues to rise. On the other 1810 hand, composite indicators of net carbon pricing reveal that government policies are often 1811 mis-coordinated, resulting in inefficiencies and disrupted price signals. The full economic 1812 impacts of COVID-19 will continue to play out over the course of a number of years, leaving 1813 a lasting impact on the world. Indeed, the nature and extent of the economic impact and 1814 response to this pandemic will play a defining role in determining whether or not the world 1815 meets its commitments under the Paris Agreement. It is for this reason that strong 1816 investment in mitigation and adaptation technologies and interventions is more important 1817 now than ever before, leading to healthier and more prepared hospitals, economies, and 1818 populations. 
1820 As previous sections make clear, the health impacts of climate change are multiplying, 1821 hitting hardest those who have contributed least to rising global temperatures. The public 1822 are voicing concern as individuals, and as members of Indigenous communities, and new 1823 social movements, urging greater ambition from those with the power to curb carbon emissions. ${ }^{213-220}$

1825 This section tracks engagement in health and climate change across multiple parts of society, including the media, by individuals, scientists, governments, and the corporate sector. For each of these, methods used in previous Lancet Countdown reports have been enhanced, increasing the sensitivity and specificity of health and climate change engagement in each.

The media, and national newspapers in particular, are central to shaping public perceptions of climate change. ${ }^{221-224}$ The media indicator (Indicator 5.1) tracks newspaper coverage of health and climate change in 36 countries, with additional analysis provided for China's People's Daily, the official voice of the government and China's most influential newspaper, and content analysis of newspaper coverage in India and the USA. ${ }^{225,226}$

Individual engagement (Indicator 5.2) is tracked through the use of Wikipedia, an online information source that has outpaced traditional encyclopaedias in terms of reach, coverage and comprehensiveness. ${ }^{227-231}$

1838 Reintroduced in 2020 with a revised methodology, the scientific indicator (Indicator 5.3) 1839 tracks academic engagement with health and climate change in peer-reviewed journals, the premier source of high-quality research that provides evidence used by the media, government, and the public. ${ }^{228,232,233}$

1842 The fourth indicator (Indicator 5.4) focuses on the governmental domain, a key arena for 1843 driving the global response to climate change. It tracks government engagement in health 1844 and climate change at the UN General Assembly, where the UN General Debate provides a 1845 platform for national leaders to address the global community. ${ }^{234,235} \mathrm{New}$ to the 2020 1846 report, it also examines engagement with health in the NDCs which underpin the UN 1847 Framework Convention on Climate Change (UNFCCC) 2015 Paris Agreement. 4,236,237

1848 The final indicator (Indicator 5.5) focuses on the corporate sector, which, through its behaviour and wider political influence is central to the transition to a low-carbon economy. ${ }^{238-240}$ This indicator tracks engagement with health and climate change in healthcare companies within the UN Global Compact, the world's biggest corporate sustainability framework. ${ }^{241}$ 
1854 Headline finding: While total climate change coverage increased substantially from 2018 to 1855 2019, the rise was even greater for health and climate change coverage, which increased by 1856 96\% over this period, and has increased substantially from 2007 to 2019.

1857 This indicator tracks coverage of health and climate change from 2007 to 2019 in 36 1858 countries, together with separate analyses of China's People's Daily and the content of 1859 coverage in leading newspapers in India and the USA. Full descriptions of the methods, data 1860 sources and further analyses are presented in the Appendix.

1861 Across the 36 countries, an increasing proportion of newspaper articles on climate change 1862 refer to human health. From 2018 to 2019, health and climate change coverage increased 1863 by $96 \%$, outpacing the increase in overall climate change coverage (74\%). From 2007 to 18642019 , the average monthly number of newspaper articles on health and climate change 1865 increased by $57 \%$ compared to a $23 \%$ increase in articles on climate change. Overall, the 1866 coverage for health and climate change only makes up $16 \%$ of all climate change coverage in 1867 the 2007-19 period (Figure 26).

1868 Coverage of health and climate change peaked in months that coincided with COP15 in 2009 1869 (Copenhagen) and COP21 in 2015 (Paris). It rose again in late 2018 and remained high across 18702019 , corresponding with the time of the rise of the School Climate Strikes and a series of 1871 extreme weather events, including the Californian and southern Australian wildfires.

1872 The analysis was based on key word searches for health and climate change in 61 1873 newspapers (English, German, Portuguese, Spanish) selected to provide a global spread of 1874 higher-circulation papers. The search strategy was revised for the 2020 report in order to 1875 exclude false positives whilst retaining true positive articles. 


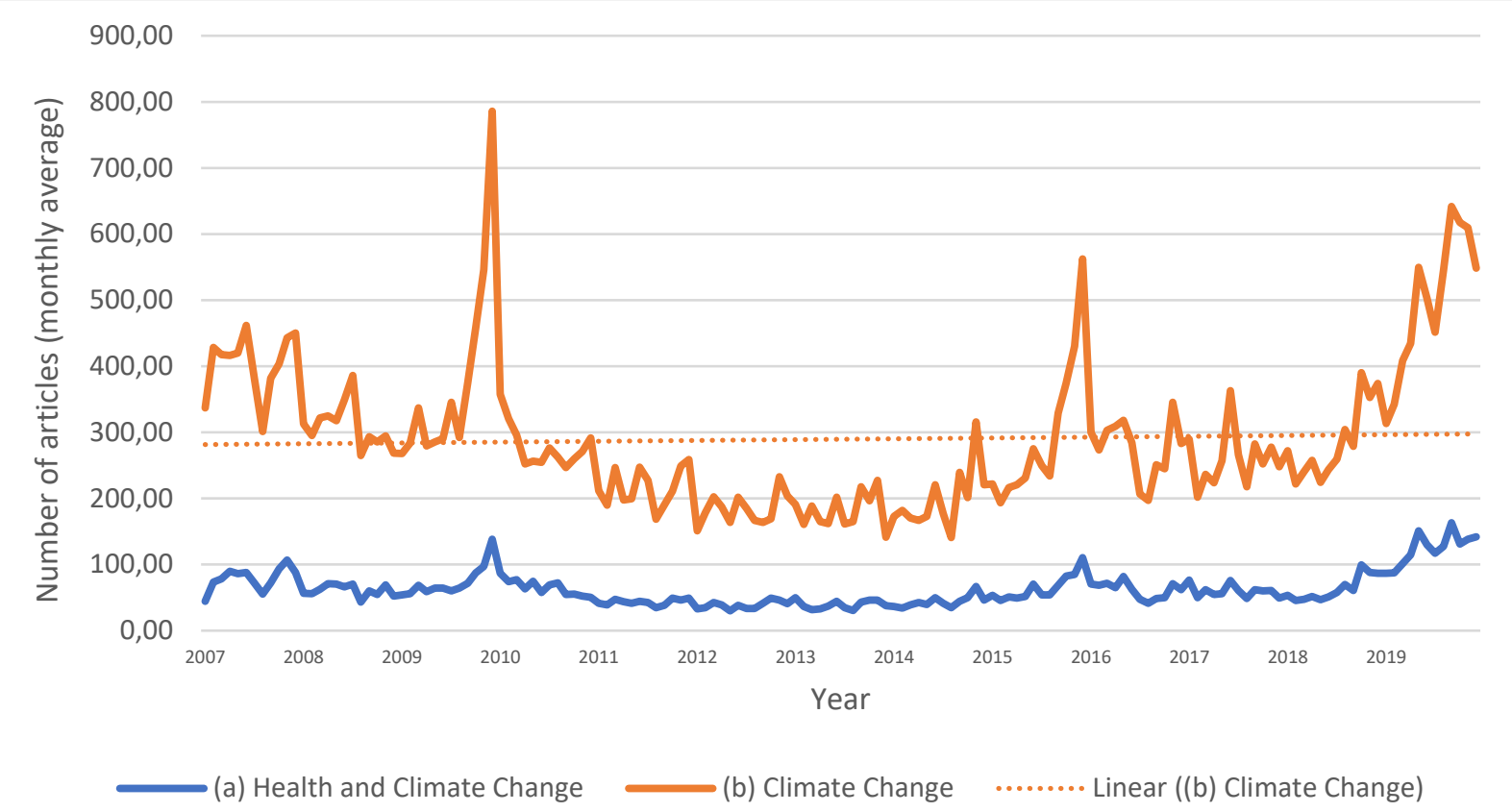

Figure 26: Average monthly coverage of (a) health and climate change and (b) climate change in 61 newspapers (36 countries), 2007-2019.

Additionally, coverage of health and climate change in Renmin Ribao, the Chinese language edition of People's Daily, was tracked using keyword searches, algorithm-based natural language processing and manual screening. Between 2008 and 2019, 2\% of articles on climate change were related to health. Health-related coverage spiked in 2013 with coverage of the health threats of air pollution and heatwaves. ${ }^{242}$

The content of coverage of health and climate change was analysed in India (the Times of India and the Hindustan Times) and the USA (the New York Times and the Washington Post) from July-September and November-December 2019, chosen to include periods of extreme weather (monsoons, drought) and COP25. ${ }^{30}$ The newspapers form part of the 'elite press' which, via their influence on the country's political and economic elites, have an influence on the policy agenda. ${ }^{243-248}$

Three broad themes were identified in articles linking health and climate change. The dominant theme was the health impacts of climate change, discussed in $68 \%$ of articles. References were often to broad health impacts (e.g. "few countries are likely to suffer from the health effects of climate change as much as India", Hindustan Times, 14 November). More specific connections were also made to climate-related stressors (e.g. extreme weather events, wildfires, population displacement) and health sequelae (e.g. vector-borne disease, mental ill-health). 
1900

1901

1902

1903

1904

1905

1906

1907

1908

1909

1910

1911

1912

1913

1914

1915

1916

1917

1918

1919

1920

1921

1922

1923

1924

1925

1926

1927

1928

1929

1930

1931

1932

1933

The second theme relates to the common causes and co-benefits of addressing climate change and health, discussed in $39 \%$ of articles. Air pollution was the most frequently highlighted. Co-benefits of lifestyle changes to protect health and reduce emissions were also noted. The third theme focused on adaptation, discussed in $12 \%$ of articles. For example, the Times of India, 10 December, noted that "all levels of government need to prioritize building health system resilience to climate change". In addition, a small group of articles (six across the corpus) made a link between health and climate change with respect to activism and protest.

The relative prominence of the three main themes in the 2019 analysis matches that for 2018 and the Times of India again gave greater emphasis to common causes and co-benefits than the other newspapers. ${ }^{30}$

For this indicator, articles were searched by health and climate change keywords and manually screened; the final sample of 209 articles was independently coded using the template developed for the 2018 analysis. ${ }^{30,249}$

\section{Indicator 5.2: Individual Engagement in Health and Climate Change}

Headline finding: Individual information-seeking about health and climate change increased by $24 \%$ from 2018 to 2019, driven primarily by initial interest in health.

Wikipedia usage provides a digital footprint of individual information-seeking. ${ }^{250,251}$ This indicator tracks individuals' engagement in health and climate change, by capturing visits to pairs of articles, for example, an individual clicking from a page on human health to one on climate change. Using data from the Wikimedia Foundation on the English version of Wikipedia (representing around 50\% of global traffic to all Wikipedia language editions), this indicator is based on 6,902 articles related to health and 1,837 articles related to climate change. ${ }^{252,253}$ Methods, data sources and further analyses are described in the Appendix.

In both 2018 and 2019, individuals typically visited articles on either health or climate change, with little co-click activity between them, and when they were linked, the majority (75\%) of co-visits started from a health-related page. While the overall number of health and climate change co-views is low, it increased by 24\% across from 2018 to 2019, pointing to a rising individual engagement in the links between these two topics. In both years, coclicks increased in months coinciding with key events in climate politics. As well as the 2019 COP, co-clicks from articles on climate change to health in 2019 spiked in September at the time of Greta Thunberg's speech at the UN's Climate Action Summit. ${ }^{254}$ 
1936 Headline finding: There was a nine-fold increase in original research on health and climate 1937 change between 2007 and 2019, a trend driven by research led by scientists in high-income 1938 countries.

1939 Between 2007 and 2019, 5,579 published academic articles referred to links between 1940 climate change and health. The period saw a nine-fold increase in original research (primary 1941 studies and evidence reviews) and a three-fold increase in research-related articles 1942 (editorials, reviews, comments, letters). Since 2011, original research has now surpassed 1943 research-related articles, with new research representing $61 \%$ of total scientific output in 19442019 (Figure 27).

1945 Consistent with observations in Section 1 (see Panel 3), the overall increase in research on 1946 health and climate change was primarily led by scientists based in high-income countries. 1947 USA-led and UK-led research made up $27 \%$ and $15 \%$ of the total output for 2007 to 2019 , 1948 and respectively, 26\% and 15\% in 2019. Major contributions to 2019 output also come from 1949 the Netherlands (8\%) and Switzerland (7\%). Increases were also evident for China, South 1950 Africa, and India.

1951 Across the period, articles on health and climate change represented only a small 1952 proportion (9\%) of total articles on climate change. However, the increase in articles relating 1953 to health and climate change was greater than for overall climate change output.

1954 This indicator is based on key word searches for health and climate change in OVID Medline 1955 and OVID Embase using the comprehensive indexing systems and thesaurus of Medical 1956 Subject Headings (MeSH) for Medline and Emtree for Embase. Methods, data sources and 1957 further analyses are described in the Appendix. 


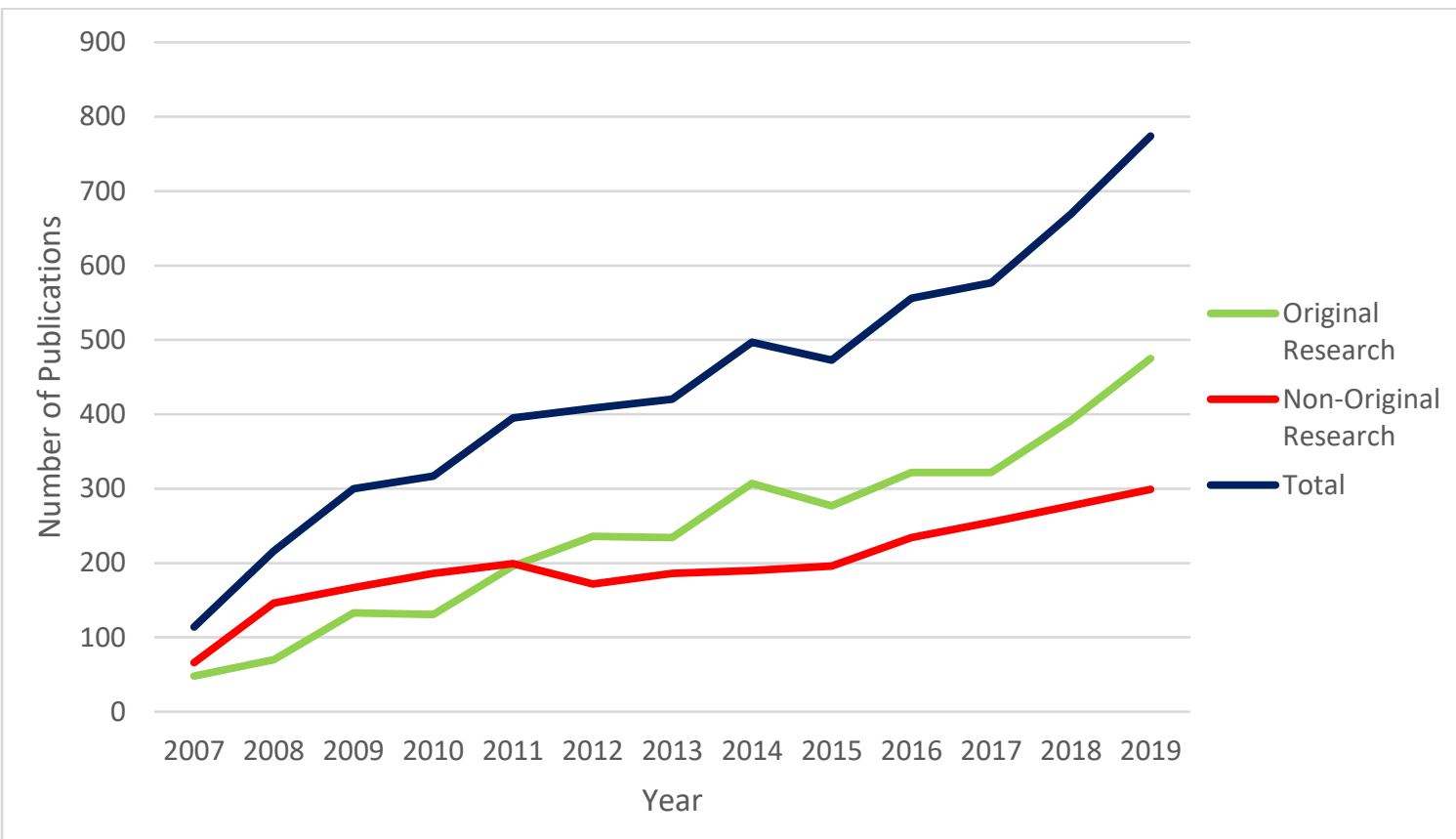

Figure 27: Scientific journal articles relating to health and climate change, 2007-2019.

Headline finding: National governments are increasingly paying attention to health and climate change. Small island developing states are leading this trend at the UN General Debate, and poorer and more climate-vulnerable countries are more likely to reference health in their NDCs, with 95\% of the least developed countries making these references.

1968 This indicator examines engagement with health and climate change in the UN General Debate (UNGD) and with health in the NDCs committed to as part of the 2015 Paris Agreement. ${ }^{4,234}$ The indicator is based on a key word search of the United Nations General Debate corpus, with algorithm-based natural language processing applied to the official English versions of the statements. ${ }^{255,256}$ References to health-related terms (e.g. 'health', 1973 'illness', 'disease' and 'malnutrition') and climate-related health exposures were examined 1974 in the 185 countries registering their NDCs in the UNFCCC repository by March 2020, with a 1975 total of 2,159 pages of text analysed. Building on previous analyses, this indicator analyses 1976 not only references, but the prominence they are given in the text. ${ }^{237,257}$ Methods, data sources and further analyses are described in the Appendix. 
1978

1979

1980

1981

1982

1983

1984

1985

1986

1987

1988

1989

1990

1991

1992

1993

1994

1995

1996

1997

1998

1999

2000

2001

2002

2003

2004

2005

2006

2007

2008

2009

2010

2011

2012
As part of the annual UN General Assembly, the UNGD provides a global forum for national leaders to discuss issues they consider important. Health has been a long-standing issue, whilst engagement with climate change was limited until the late 1980s (Error! Reference source not found.). From the mid-2000s, national leaders began to focus on the connections between health and climate change, with the proportion rising rapidly from 2007 and peaking in 2014 at $24 \%$.

Engagement in health and climate change continues to be led by the small island developing states (SIDS), particularly in the Western Pacific Region. In contrast, engagement remained low among the more powerful global actors, particularly those with the highest $\mathrm{CO}_{2}$ emissions (USA, China, and the EU). For the third consecutive year, President Donald Trump's statement on behalf of the USA failed to make a single reference to climate change, let alone to climate change and health linkages. However, 2019 did see growing engagement with climate change and health by other high-income nations (including Australia, Canada, Germany, and Spain) and by low-income countries, particularly in the African Region (for example Burkina Faso, Botswana, Côte d'Ivoire, Niger, and Togo).

At the 2019 UNGD, the majority of health and climate change references focused on the health impacts of climate change. For example, Dominica highlighted the impacts of climate change on SIDS', including "rising sea levels, violent tropical storms and hurricanes, periods of severe drought alternating with floods and forest fires, new plant diseases, and vectorborne disease such as chikungunya and Zika present an existential threat." Similarly, Tonga's UNGD statement discussed how extreme weather events linked to climate change "are increasingly more intense, inflicting damage and destruction on our communities and ecosystems and putting the health of our peoples at risk."

The 2019 UNGD also saw discussion of adaptation and resilience to "upgrade and climateproof our health-care facilities" (Nauru), improve "the quality of health care and the durability of health-care systems in the face of the climate crisis" (Palau) and build "climate change resilience in our sectoral policies and strategies for health, transport, agriculture and pastoral production" (Niger).

The second part of this indicator focuses on health within the NDCs, assessing both the references and their prominence within the text. Here, some $73 \%$ of NDCs included considerations of public health. At the WHO regional level, all countries in the South East Asian and Eastern Mediterranean Regions discuss these links (Figure 28). At the country level, references to health are particularly common among Least Developed Countries (95\%). In contrast, the European Union (representing the contributions of 28 countries) and the USA NDCs have none. 


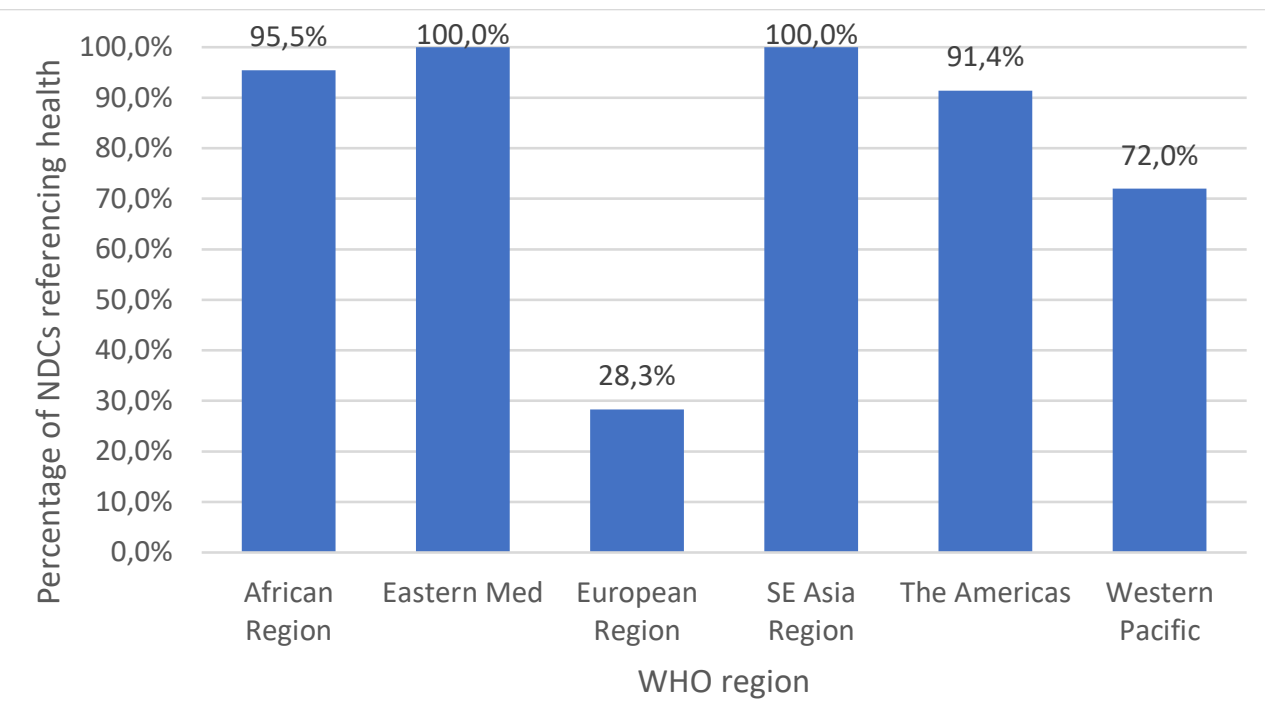

Figure 28: Reference to health in the NDCs by WHO region. The European region (which consists of 53 countries) is adjusted for the single NDC representing 28 EU countries; treating the EU as one country would increase the regional proportion to $60 \%$.

A range of health dimensions were highlighted in the NDCs, including the direct impacts of climate change on health and health-related infrastructure. For example, in their respective NDCs, Morocco notes that climate change would increase deaths "by 250,000 annually between 2030 and 2050 due to malnutrition, malaria, diarrhea and heat-related stress" and Cambodia discusses the effects of climate change on "death, injury, psychological disorders and damage to public health infrastructure". There are also references to the co-benefits of interventions; for example, Saint Lucia refers to "human health benefits" among "cobenefits associated with its mitigation efforts".

Among the NDCs considering health and climate change, extreme weather events (e.g. floods, drought) and food security were most commonly cited, with $52 \%$ discussing these links. The proportion was highest in the NDCs from countries in South East Asia, and lowest in Europe. Examples include Sri Lanka's NDC, which warns of its "water borne diseases" which "can increase due to extreme heat and drought" and Nepal's NDC which describes "an increased frequency of extreme weather events such as landslides, floods and droughts resulting to the loss of human lives". 
2037 Headline finding: engagement in health and climate change increased to 24\% in 2019

2038 among healthcare companies in the UN Global Compact, although this engagement

2039 continues to lag behind other sectors.

2040 The UN Global Compact (UNGC) is a UN-supported platform, created to promote

2041 environmental and social responsibility in the business sector. ${ }^{258}$ It represents over 10,000 companies from more than 160 countries. ${ }^{241}$ Focusing on the healthcare sector, Figure 29 tracks engagement in health and climate change in the UNGC Communication on Progress reports that companies submit each year.

Analysis was based on key word searches of health-related and of climate change-related terms in 20,775 annual reports in the UNGC database, and engagement in health and climate change was identified using natural language processing. ${ }^{241}$ Methods, data sources and further analyses are described in the Appendix.

This indicator points to an increase in healthcare sector engagement in 2019, with $24 \%$ of companies referring to the links between climate change and health (Figure 29). However, other sectors have higher levels of engagement, including the energy sector and real estate investment sector.

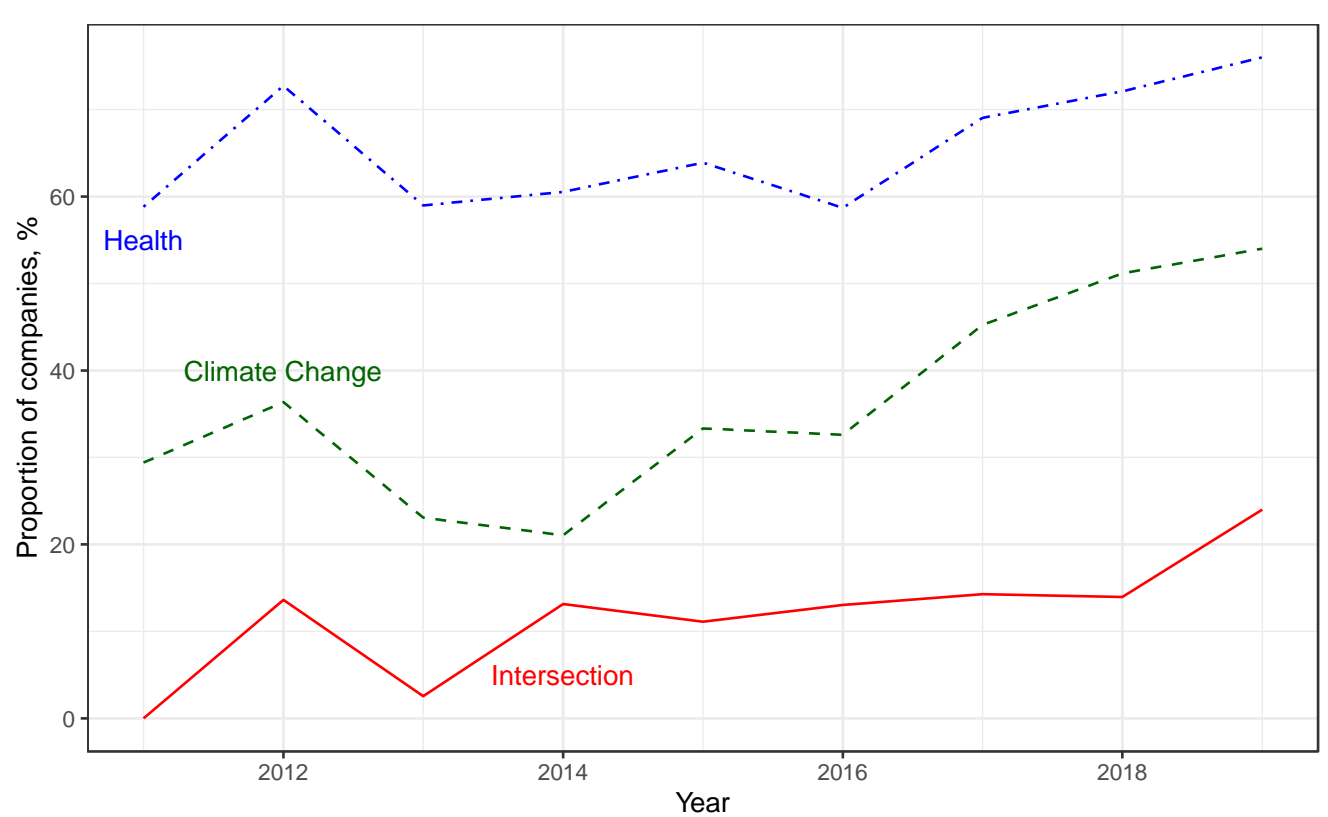


2058 Public and political engagement is essential to curb fossil fuel consumption and hold global 2059 temperature rise to below $1.5^{\circ} \mathrm{C} .{ }^{259}$ Section Five has examined indicators of engagement 2060 relating to the media, the public, the scientific community, national government and the 2061 corporate sector. Taken together, the analyses point to two broad trends.

2062 Firstly, engagement with health and climate change continues to increase. Between 2007 2063 and 2019, newspaper coverage increased by over $50 \%$ and scientific journal output by over 2064 $500 \%$. Across 2018 and 2019, the proportion of Wikipedia users searching for articles that linked health and climate change also increased. There is evidence of dynamic and reinforcing relationships between these domains. Media coverage increased at times of heightened political engagement and public engagement. September 2019, and Greta Thunberg's speech at the UN Climate Action Summit in particular, also saw a spike in individual engagement in health and climate change, as captured by Wikipedia use.

2070 However, beneath these trends are persisting inequalities in wealth and political influence. 2071 In both the UNGD and the NDCs, engagement in health and climate change is led by 2072 countries and regions that are suffering most from a changing climate to which they have 2073 contributed least. At the same time, the science of health and climate change continues to be led by higher-income, high-emitting countries, which are the most responsible for climate change. ${ }^{218,260}$

Secondly, in absolute terms, climate change continues to be framed in ways that pay little attention to its health dimensions. One in six newspaper articles on climate change discuss its health dimensions; less than one in ten scientific articles do so; as do less than one in four healthcare companies signed up to sustainable business practices. In the political domain, health and climate change are rarely connected by government leaders in their speeches at the UN's major global forum and, while most NDCs refer to health, countries with high per capita carbon emissions - including EU countries and the USA - do not. Nonetheless, in key domains of engagement, the health dimensions of climate change are increasingly recognised, with media and scientific coverage increasing more rapidly than for climate change as a whole. climate change remain, there is evidence that health is becoming increasingly central to public and political engagement. 
2090 With global average temperature rise having reached $1.2^{\circ} \mathrm{C}$ above pre-industrial times, the

2091

2092

2093

2094

2095

2096

2097

2098

2099

2100

2101

2102

2103

2104

2105

2106

2107

2108

2109

2110

2111

2112

2113

2114

2115

2116

2117

2118

2119

2120

2121

2122

2123

2124 indicators contained in the 2020 report provide insights into the health impacts of climate change today, and in the future. Extremes of heat hit vulnerable populations the hardest, with some 296,000 deaths occurring as a result of high temperatures in 2018 (Indicator 1.1.3)

The climate suitability for the transmission of a range of infectious diseases - dengue fever, malaria, and Vibrio bacteria- have demonstrated sustained rises across the world (Indicator 1.3.1). This is occurring at the same time as crop yield potential is falling for each of the major crops tracked, with dire consequences anticipated for food-insecure populations (Indicator 1.4.1).

And yet, the global response has remained muted. The carbon intensity of the global energy system has remained flat over the past three decades, and global coal use for energy has increased by $74 \%$ over the same period (Indicators 3.1.1 and 3.1.2). This has resulted in an estimated 390,000 deaths from particulate air pollution generated by coal fired power, with total global deaths for all ambient sources exceeding 3.01 million in 2018 (Indicator 3.3). In the agricultural sector, emissions from livestock grew by 16\% from 2000 to 2017, with some 990,000 deaths occurring globally from excess red meat consumption in 2017 (Indicators 3.5.1 and 3.5.2).

In the face of this, the response from the health profession continues to gain momentum. Spending on health system adaptation continued its previous upward trend, rising by $5.3 \%$ in 2019 , to $\$ 18.4$ billion (Indicator 2.4). A nine-fold increase in original research on health and climate change has occurred in just over 10 years, and, in half that time, health institutions with total assets of $\$ 42$ billion have divested their holdings from fossil fuel industries (Indicators 5.3 and 4.2.3). Led by low-income countries, more governments are linking health and climate change in their annual UN General Debate speeches and their NDCs under the Paris Agreement.

The public health and financial effects of COVID-19 will be felt for years to come, and efforts to protect and rebuild local communities and national economies will need to be robust and sustained. Despite concerning indicators across each section of this report, the 2021 UN climate change conference presents an opportunity for course correction, and revitalised Nationally Determined Contributions. The window of opportunity is narrow, and if the response to COVID-19 is not fully and directly aligned with countries' national climate change strategies, the world will be unable to meet its commitments under the Paris Agreement, damaging health and health systems today, and in the future. 
2126 1. McMichael AJ, Haines JA, Slooff R, et al. Climate change and human health: an assessment / 2127 prepared by a Task Group on behalf of the World Health Organization, the World Meteorological 2128 Association and the United Nations Environment Programme; editors: A. J. McMichael ... [et al.]. 2129 Geneva: World Health Organization; 1996.

21302 2. NASA Goddard Institute for Space Studies. GISS Surface Temperature Analysis (GISTEMP v4). 2020. https://data.giss.nasa.gov/gistemp/ (accessed 28 April 2020).

3. Smith KR, Woodward A, Campbell - Lendrum D, et al. Human Health: Impacts, Adaptation, and Co-Benefits. Climate Change 2014: Impacts, Adaptation, and Vulnerability Part A: Global and Sectoral Aspects Contribution of Working Group II to the Fifth Assessment Report of the Intergovernmental Panel on Climate Change. Cambridge, United Kingdom and New York, New York: Cambridge University Press; 2014: 709-54.

4. United Nations Framework Convention on Climate Change. Decision1/CP.21, Adoption of the Paris Agreement, FCCC/CP/2015/10/Add.1 (January 29, 2016), paras 23 and 24. 2016. http://unfccc.int/resource/docs/2015/cop21/eng/10a01.pdf (accessed April 6, 2020.

5. Herring SC, Christidis N, Hoell A, Hoerling MP, Stott PA. Explaining Extreme Events of 2017 from a Climate Perspective. Bulletin of the American Meteorological Society 2019; 100(1): S1-S117.

6. Herring SC, Christidis N, Hoell A, Hoerling MP, Stott PA. Explaining Extreme Events of 2018 from a Climate Perspective. Bulletin of the American Meteorological Society 2020; 101(1): S1-S128.

7. Herring SC, Christidis N, Hoell A, Kossin JP, III CJS, Stott PA. Explaining Extreme Events of 2016 from a Climate Perspective. Bulletin of the American Meteorological Society 2018; 99(1): S1-S157.

8. Herring SC, Hoell A, Hoerling MP, Kossin JP, III CJS, Stott PA. Explaining Extreme Events of 2015 from a Climate Perspective. Bulletin of the American Meteorological Society 2016; 97(12): S1-S145.

9. World Economic Forum. The Global Risks Report 2020. Cologny, Switzerland: World Economic Forum, 2020.

10. Ecosystems and Human Well-being: Current State and Trends, Volume 1. In: Hassan R, Scholes $\mathrm{R}$, Ash N, eds. The Millennium Ecosystem Assessment Series. Washington, DC and Covelo, CA, USA, and London, UK: Island Press; 2005.

11. United Nations General Assembly. Resolution adopted by the General Assembly on 25 September 2015 Transforming our world: the 2030 Agenda forSustainable Development New York, NY, USA: United Nations; 2015.

12. Wei $\mathrm{Y}-\mathrm{M}$, Han $\mathrm{R}$, Wang $\mathrm{C}$, et al. Self-preservation strategy for approaching global warming targets in the post-Paris Agreement era. Nature communications 2020; 11(1): 1-13.

13. Kjellstrom T, Briggs D, Freyberg C, Lemke B, Otto M, Hyatt O. Heat, Human Performance, and Occupational Health: A Key Issue for the Assessment of Global Climate Change Impacts. Annu Rev Public Health 2016; 37: 97-112.

14. Sampedro J, Smith SJ, Arto I, et al. Health co-benefits and mitigation costs as per the Paris Agreement under different technological pathways for energy supply. Environ Int 2020; 136: 105513. 15. Vandyck T, Keramidas K, Kitous A, et al. Air quality co-benefits for human health and agriculture counterbalance costs to meet Paris Agreement pledges. Nat Commun 2018; 9(1): 4939.

16. Watts N, Adger WN, Ayeb-Karlsson S, et al. The Lancet Countdown: tracking progress on health and climate change. The Lancet 2017; 389(10074): 1151-64.

17. Johns Hopkins Center for Systems Science and Engineering. COVID-19 Dashboard. 2020. https://coronavirus.jhu.edu/map.html (accessed 31 July 2020).

18. Strauss D. BoE is financing UK's coronavirus measures, Bailey acknowledges. Financial Times. 2020.

19. Hopman J, Allegranzi B, Mehtar S. Managing COVID-19 in Low- and Middle-Income Countries. JAMA 2020; 323(16): 1549-50. 
2173

2174

2175

2176

2177

2178

2179

2180

2181

2182

2183

2184

2185

2186

2187

2188

2189

2190

2191

2192

2193

2194

2195

2196

2197

2198

2199

2200

2201

2202

2203

2204

2205

2206

2207

2208

2209

2210

2211

2212

2213

2214

2215

2216

2217

2218

2219

20. Ji Y, Ma Z, Peppelenbosch MP, Pan Q. Potential association between COVID-19 mortality and health-care resource availability. The Lancet Global Health 2020; 8(4): e480.

21. Raju E, Ayeb-Karlsson S. COVID-19: How do you self-isolate in a refugee camp? International Journal of Public Health 2020.

22. IEA. Global Energy Review 2020. Paris, France: International Energy Agency, 2020.

23. Hallegatte S, Hammer S. Thinking ahead: For a sustainable recovery from COVID-19. 2020. https://www.preventionweb.net/news/view/71103 (accessed 23 May 2020).

24. WHO. Operational framework for building climate resilient health systems. Geneva, Switzerland: World Health Organization, 2015.

25. Audia C, Visman E, Fox G, et al. Decision-making heuristics for managing climate-related risks: The FREE framework. In: Conway D, ed. Climate Risk in Africa: Adaptation and Resilience. London, UK: Palgrave Macmillan; 2020.

26. Ranger N, Reeder T, Lowe J. Addressing 'deep'uncertainty over long-term climate in major infrastructure projects: four innovations of the Thames Estuary 2100 Project. EURO Journal on Decision Processes 2013; 1(3-4): 233-62.

27. IPCC. Climate Change 2014. Impacts, Adaptation, and Vulnerability. Working Group II Contribution to the Fifth Assessment Report of the Intergovernmental Panel on Climate Change. Cambridge and New York, 2014.

28. Lord Deben, Baroness Brown of Cambridge. Building a resilient recovery from the COVID-19 crisis. 2020 (accessed 23 March 2020).

29. NHS. GP online consultations. 2020. https://www.nhs.uk/using-the-nhs/nhs-services/gps/gponline-and-video-consultations/ (accessed 23 May 2020).

30. Watts N, Amann M, Arnell N, et al. The 2019 report of The Lancet Countdown on health and climate change: ensuring that the health of a child born today is not defined by a changing climate. The Lancet 2019; 394(10211): 1836-78.

31. Szekely M, Carletto L, Garami A. The pathophysiology of heat exposure. Temperature (Austin, Tex) 2015; 2(4): 452.

32. Xu Z, FitzGerald G, Guo Y, Jalaludin B, Tong S. Impact of heatwave on mortality under different heatwave definitions: A systematic review and meta-analysis. Environment International 2016; 89-90: 193-203.

33. Campbell S, Remenyi TA, White CJ, Johnston FH. Heatwave and health impact research: A global review. Health \& place 2018; 53: 210-8.

34. NASA Socioeconomic Data and Applications Center (SEDAC) Gridded Population of the World (GPWv4). Available at https://beta.sedac.ciesin.columbia.edu/data/collection/gpw-v4. 2020.

35. The Inter-Sectoral Impact Model Intercomparison Project (ISIMP). Input data set: Historical, gridded population. Available at https://www.isimip.org/gettingstarted/input-data-biascorrection/details/31/. 2020.

36. Copernicus Climate Change Service (C3S). ERA5 hourly data on single levels from 1979 to present. Available at https://doi.org/10.24381/cds.adbb2d47. 2020.

37. Honda $\mathrm{Y}$, Kondo $\mathrm{M}, \mathrm{McGregor} \mathrm{G}$, et al. Heat-related mortality risk model for climate change impact projection. Environ Health Prev Med 2014; 19(1): 56-63.

38. WHO. Quantitative risk assessment of the effects of climate change on selected causes of death, 2030s and 2050s. 2014.

39. Guo Y, Gasparrini A, Armstrong BG, et al. Temperature Variability and Mortality: A MultiCountry Study. Environ Health Perspect 2016; 124(10): 1554-9.

40. Sera F, Armstrong B, Tobias A, et al. How urban characteristics affect vulnerability to heat and cold: a multi-country analysis. International Journal of Epidemiology 2019; 48(4): 1101-12. 
41. Kjellstrom T, Freyberg C, Lemke B, Otto M, Briggs D. Estimating population heat exposure and impacts on working people in conjunction with climate change. International Journal of Biometeorology 2018; 62(3): 291-306.

42. ILO. ILOSTAT database. Geneva, Switzerland: International Labour Organization; 2020.

43. Hempel S, Frieler K, Warszawski L, Schewe J, Piontek F. A trend-preserving bias correctionthe ISI-MIP approach. 2013.

44. Lange S. EartH2Observe, WFDEI and ERA-Interim data Merged and Bias-corrected for ISIMIP (EWEMBI). GFZ Data Services 2016.

45. Lange S. Bias correction of surface downwelling longwave and shortwave radiation for the EWEMBI dataset. 2018.

46. Black C, Tesfaigzi $Y$, Bassein JA, Miller LA. Wildfire smoke exposure and human health: Significant gaps in research for a growing public health issue. Environmental toxicology and pharmacology 2017; 55: 186-95.

47. Copernicus Climate Change Service (C3S). Fire danger indices historical data from the Copernicus Emergency Management Service. Available at https://doi.org/10.24381/cds.0e89c522. 2020.

48. NASA EarthData. Active Fire Data. Available at https://earthdata.nasa.gov/earth-observationdata/near-real-time/firms/active-fire-data. 2020.

49. Dai A. Drought under global warming: a review. WIREs Climate Change 2011; 2(1): 45-65.

50. Stanke C, Kerac M, Prudhomme C, Medlock J, Murray V. Health effects of drought: a systematic review of the evidence. PLoS currents 2013; 5.

51. Du W, FitzGerald GJ, Clark M, Hou X-Y. Health Impacts of Floods. Prehospital and Disaster Medicine 2010; 25(3): 265-72.

52. Mukherjee S, Mishra A, Trenberth KE. Climate Change and Drought: a Perspective on Drought Indices. Current Climate Change Reports 2018; 4(2): 145-63.

53. Centre for Research on the Epidemiology of Disasters. EM-DAT The International Disaster Database. Available at https://emdat.be/. 2020.

54. World Health Organization. Global Health Observatory. Available at https://apps.who.int/nha/database/Select/Indicators/en. 2020.

55. World Weather Attribution. European heatwave, July 2015. 2015. https://www.worldweatherattribution.org/european-heat-wave-july-2015/ (accessed 27 April 2020). 56. World Weather Attribution. 2015 - a record breaking hot year. 2015. https://www.worldweatherattribution.org/record-hot-year-2015/ (accessed 27 April 2020).

57. King A, Kirkpatrick S, Oldenborgh GJv. Extreme heat in southeast Australia, February 2017. 2017. https://www.worldweatherattribution.org/extreme-heat-australia-february-2017/ (accessed 16 April 2020).

58. Otto F, Oldenborgh GJv, Vautard R, Schwierz C. Record June temperatures in western Europe. 2017. https://www.worldweatherattribution.org/european-heat-june-2017/ (accessed 2020 2020).

59. Oldenborgh GJv, Philip S, Kew S, et al. Human contribution to record-breaking June 2019 heatwave in France. 2019. https://www.worldweatherattribution.org/human-contribution-torecord-breaking-june-2019-heatwave-in-france/ (accessed 16 April 2020).

60. Vautard R, Boucher O, Oldenborgh GJv, et al. Human contribution to the record-breaking July 2019 heatwave in Western Europe. 2019. https://www.worldweatherattribution.org/humancontribution-to-the-record-breaking-july-2019-heat-wave-in-western-europe/ (accessed 16 April 2020).

61. van Oldenborgh GJ, Krikken F, Lewis $S$, et al. Attribution of the Australian bushfire risk to anthropogenic climate change. Nat Hazards Earth Syst Sci Discuss 2020; 2020: 1-46. 
62. World Weather Attribution. Record high temperatures in India, 2016. 2016. https://www.worldweatherattribution.org/india-heat-wave-2016/ (accessed 27 April 2020). 63. Oldenborgh GJv, Vries Hd, Vecchi G, Otto F, Tebaldi C. A cold winter in North America, December 2017 to January 2018. 2018. https://www.worldweatherattribution.org/winter-in-northamerica-is-cold-dec-2017-jan-2018/ (accessed 16 April 2020). 64. Otto FEL, Wolski P, Lehner F, et al. Likelihood of Cape Town water crisis tripled by climate change. 2018. https://www.worldweatherattribution.org/the-role-of-climate-change-in-the-20152017-drought-in-the-western-cape-of-south-africa/ (accessed 16 April 2020). 2014/15 Water Shortage in Southeast Brazil. Bulletin of the American Meteorological Society 2015; 96(12): S35-S40.

66. World Weather Attribution. Ethiopia drought, 2015 - a livelihood crisis. 2015. https://www.worldweatherattribution.org/ethiopia-drought-2015/ (accessed 27 April 2020).

67. Oldenborgh GJv, Wiel Kvd, Philip S, et al. Rapid analysis of drought in Somalia, 2016. 2017. https://www.worldweatherattribution.org/somalia-drought-2016-2017/ (accessed 27 April 2020).

68. Uhe $\mathrm{P}$, Philip S, Kew S, et al. Attributing drivers of the 2016 Kenyan drought. International Journal of Climatology 2018; 38(S1): e554-e68.

69. van Oldenborgh GJ, Philip S, Aalbers E, et al. Rapid attribution of the May/June 2016 floodinducing precipitation in France and Germany to climate change. Hydrol Earth Syst Sci Discuss 2016; 2016: 1-23.

70. van der Wiel K, Kapnick SB, van Oldenborgh GJ, et al. Rapid attribution of the August 2016 flood-inducing extreme precipitation in south Louisiana to climate change. Hydrol Earth Syst Sci 2017; 21(2): 897-921.

71. Oldenborgh GJv, Otto F, Singh R, Tebaldi C, Kew S, Philip S. Extreme rainfall in Japan, 2018 - a quick look. 2018. https://www.worldweatherattribution.org/a-quick-look-at-the-extreme-rainfall-injapan/ (accessed 16 April 2020).

72. Philip S, Sparrow S, Kew SF, et al. Attributing the 2017 Bangladesh floods from meteorological and hydrological perspectives. Hydrol Earth Syst Sci 2019; 23(3): 1409-29.

73. Mishra V, Shah HL. Hydroclimatological Perspective of the Kerala Flood of 2018. Journal of the Geological Society of India 2018; 92(5): 645-50.

74. Otto FEL, Wiel Kvd, Oldenborgh GJv, et al. Climate change increases the probability of heavy rains in Northern England/Southern Scotland like those of storm Desmond-a real-time event attribution revisited. Environmental Research Letters 2018; 13.

75. Zhang W, Vecchi GA, Murakami H, et al. Influences of Natural Variability and Anthropogenic Forcing on the Extreme 2015 Accumulated Cyclone Energy in the Western North Pacific. Bulletin of the American Meteorological Society 2016; 97(12): S131-S5.

76. van Oldenborgh GJ, van der Wiel K, Sebastian A, et al. Attribution of extreme rainfall from Hurricane Harvey. Environmental Research Letters 2017; 12.

77. Reed KA, Stansfield AM, Wehner MF, Zarzycki CM. Forecasted attribution of the human influence on Hurricane Florence. Science Advances 2020; 6(1): eaaw9253.

78. Oldenborgh GJv, Wiel Kvd, Philip S, et al. Rapid attribution of the extreme rainfall in Texas from Tropical Storm Imelda. 2019. https://www.worldweatherattribution.org/rapid-attribution-ofthe-extreme-rainfall-in-texas-from-tropical-storm-imelda/ (accessed 16 April 2020).

79. Vautard R, Oldenborgh GJv, Otto F, et al. Stormy January over western Europe, 2018. 2018. https://www.worldweatherattribution.org/the-stormy-month-of-january-2018-over-westerneurope/ (accessed 16 April 2020). 
2313 80. World Weather Attribution. Great Barrier Reef bleaching, 2016.2016. https://www.worldweatherattribution.org/great-barrier-reef-bleaching-march-2016/ (accessed 18 2315 May 2020).

2316 81. Oldenborgh GJv, Macias-Fauria M, King A, et al. Unusually high temperatures at the North Pole, winter 2016. 2016. https://www.worldweatherattribution.org/north-pole-nov-dec-2016/ (accessed 28 April 2020). 82. Bindoff N, PA S, AchutaRao KM ea. Detection and Attribution of Climate Change: from Global to Regional. Climate Change 2013: The Physical Science Basis Contribution of Working Group I to the Fifth Assessment Report of the Intergovernmental Panel on Climate Change; 2013.

83. Ebi KL, Ogden NH, Semenza JC, Woodward A. Detecting and attributing health burdens to climate change. Environmental health perspectives 2017; 125(8): 085004.

84. Stone $D$, Auffhammer $M$, Carey $M$, et al. The challenge to detect and attribute effects of climate change on human and natural systems. Climatic Change 2013; 121(2): 381-95.

85. IPCC. Global warming of $1.5^{\circ} \mathrm{C}$. An IPCC Special Report on the impacts of global warming of $1.5^{\circ} \mathrm{C}$ above pre-industrial levels and related global greenhouse gas emission pathways, in the context of strengthening the global response to the threat of climate change. Geneva, Switzerland: World Meteorological Organization, 2018.

86. Stabeno PJ, Bell SW. Extreme Conditions in the Bering Sea (2017-2018): Record-Breaking Low Sea-Ice Extent. Geophysical Research Letters 2019; 46(15): 8952-9.

87. Thoman RL, Bhatt US, Bieniek PA, et al. The Record Low Bering Sea Ice Extent in 2018: Context, Impacts, and an Assessment of the Role of Anthropogenic Climate Change. Bulletin of the American Meteorological Society 2020; 101(1): S53-S8.

88. Bethel Search and Rescue Report. 2017.

89. Macarthur A. Father's body recovered, five rescued after family falls through Kuskokwim on New Year's Eve. 2018.

90. Waldholz R. In western Alaska, there's water where there should be ice. 2018.

91. World Weather Attribution. Heatwave in northern Europe, summer 2018. 2018.

92. Åström C, Bjelkmar P, Forsberg B. High mortality during the 2018 heatwave in Sweden. Lakartidningen 2019; 116.

93. BBC. Summer heat killed nearly 1,500 in France, officials say. 2019. https://www.bbc.co.uk/news/world-europe-49628275 (accessed 20 May 2020).

94. Meijer B. Heatwave caused nearly 400 more deaths in Netherlands: stats agency. 2019. https://www.reuters.com/article/us-weather-netherlands/heatwave-caused-nearly-400-moredeaths-in-netherlands-stats-agency-idUSKCN1UZOGA?il=0 (accessed 20 May 2020).

95. Imada Y, Watanabe M, Kawase H, Shiogama H, Arai M. The July 2018 high temperature event in Japan could not have happened without human-induced global warming. SOLA 2019: 15A-002.

96. Shimpo A, Takemura K, Wakamatsu S, et al. Primary factors behind the heavy rain event of July 2018 and the subsequent heat wave in Japan. SOLA 2019: 15A-003.

97. Harris I, Osborn TJ, Jones P, Lister D. Version 4 of the CRU TS monthly high-resolution gridded multivariate climate dataset. Scientific Data 2020; 7(1): 109.

98. Koninklijk Nederlands Meteorologisch Instituut. KNMI Climate Explorer. Available at https://climexp.knmi.nl/. 2020.

99. Lyon B, Dinku T, Raman A, Thomson MC. Temperature suitability for malaria climbing the Ethiopian Highlands. Environmental Research Letters 2017; 12(6): 064015.

100. Martinez-Urtaza J, Trinanes J, Abanto M, et al. Epidemic Dynamics of Vibrio parahaemolyticus Illness in a Hotspot of Disease Emergence, Galicia, Spain. Emerging Infectious Diseases 2018; 24(5): 852-9. 
101. Martinez-Urtaza J, van Aerle R, Abanto M, et al. Genomic Variation and Evolution of Vibrio parahaemolyticus ST36 over the Course of a Transcontinental Epidemic Expansion. mBio 2017; 8(6). 102. Wang H, Tang X, Su YC, Chen J, Yan J. Characterization of clinical Vibrio parahaemolyticus strains in Zhoushan, China, from 2013 to 2014. PLoS One 2017; 12(7): e0180335.

104. Semenza JC, Sewe MO, Lindgren E, et al. Systemic Resilience to Cross-border Infectious Disease Threat Events in Europe. Transboundary and emerging diseases 2019.

105. WHO. International Health Regulations (2005): implementation status of IHR core capacities, 2010-2017. Geneva, Switzerland: World Health Organization, 2018. Organization of the United Nations, 2020.

107. Porter JR, Xie L, Challinor AJ, et al. Food Security and Food Production Systems. Climate Change 2014: Impacts, Adaptation, and Vulnerability Part A: Global and Sectoral Aspects Contribution of Working Group II to the Fifth Assessment Report of the Intergovernmental Panel on Climate Change. Cambridge, United Kingdom and New York, NY, USA; 2014.

108. Craufurd PQ, Wheeler TR. Climate change and the flowering time of annual crops. Journal of Experimental Botany 2009; 60(9): 2529-39.

109. FAO. The State of World Fisheries and Aquaculture 2018 - Meeting the sustainable development goals. Rome: Food and Agriculture Organization of the United Nations, 2018.

110. GBD 2017 Diet Collaborators, Afshin A, Sur PJ, et al. Health effects of dietary risks in 195 countries, 1990-2017: a systematic analysis for the Global Burden of Disease Study 2017. Lancet (London, England) 2019; 0(0).

111. FAO. Impact of climate change on fisheries and aquaculture: synthesis of current knowledge, adaptation and mitigation options. Rome, Italy: Food and Agriculture Organization of the United Nations, 2018.

112. FAO. New Food Balance Sheets. 2020. http://www.fao.org/faostat/en/\#data/FBS (accessed 19 February 2020).

113. NASA NEO NEO. Sea surface temperature (1 month - AQUA/MODIS). 2017. https://neo.sci.gsfc.nasa.gov/view.php?datasetld=MYD28M (accessed 23 September 2019).

114. NOAA. NOAA Coral Reef Watch Version 3.1 Daily Global 5-km Satellite Coral Bleaching Degree Heating Week Product. Washington DC: National Oceanic and Atmospheric Administration; 201.

115. McMichael C. Climate change-related migration and infectious disease. Virulence 2015; 6(6): 548-53.

116. Schwerdtle $\mathrm{P}$, Bowen $\mathrm{K}, \mathrm{McMichael} \mathrm{C}$. The health impacts of climate-related migration. $B M C$ medicine 2018; 16(1): 1.

117. Kulp SA, Strauss BH. New elevation data triple estimates of global vulnerability to sea-level rise and coastal flooding. Nature communications 2019; 10(1): 1-12.

118. Lindsey R. Climate Change: Global Sea Level. 2019.

119. Bright EA, Rose AN, Urban ML, McKee J. LandScan 2017 High-Resolution Global Population Data Set: Oak Ridge National Lab.(ORNL), Oak Ridge, TN (United States), 2018.

120. Kulp SA, Strauss BH. CoastalDEM: a global coastal digital elevation model improved from SRTM using a neural network. Remote sensing of environment 2018; 206: 231-9.

121. Hauer ME, Fussell E, Mueller V, et al. Sea-level rise and human migration. Nature Reviews Earth \& Environment 2019: 1-12.

122. Luber G, Knowlton K, Balbus J, et al. Human health. Climate change impacts in the United States: the third National Climate Assessment 2014: 220-56. 
123. Ayeb-Karlsson S, Kniveton D, Cannon T. Trapped in the prison of the mind: Notions of climateinduced (im)mobility decision-making and wellbeing from an urban informal settlement in Bangladesh. Palgrave Communications 2020: forthcoming.

124. Dannenberg AL, Frumkin H, Hess JJ, Ebi KL. Managed retreat as a strategy for climate change adaptation in small communities: public health implications. Climatic change 2019; 153(1-2): 1-14.

125. Schütte S, Gemenne F, Zaman M, Flahault A, Depoux A. Connecting planetary health, climate change, and migration. The Lancet Planetary Health 2018; 2(2): e58-e9.

126. Page LA, Hajat $S$, Kovats RS. Relationship between daily suicide counts and temperature in England and Wales. The British Journal of Psychiatry 2007; 191(2): 106-12.

127. Thompson R, Hornigold R, Page L, Waite T. Associations between high ambient temperatures and heat waves with mental health outcomes: a systematic review. Public health 2018; 161: 171-91.

128. Cunsolo A, Ellis NR. Ecological grief as a mental health response to climate change-related loss. Nature Climate Change 2018; 8(4): 275.

129. Legido-Quigley $\mathrm{H}$, Asgari $\mathrm{N}$, Teo YY, et al. Are high-performing health systems resilient against the COVID-19 epidemic? The Lancet 2020; 395(10227): 848-50.

130. Phillips CA, Caldas A, Cleetus R, et al. Compound climate risks in the COVID-19 pandemic. Nature Climate Change 2020; 10(7): 586-8.

131. UNEP. The Adaptation Gap Report 2018. Health Report. Nairobi: United Nations Environment Program, 2018.

132. Mimura N, Pulwarty RS, Duc DM, et al. 2014:Adaptation planning and implementation. In: Field CB, Barros VR, Dokken DJ, et al., eds. Climate Change 2014: Impacts,Adaptation, and Vulnerability Part A: Global and Sectoral Aspects Contribution of Working Group II to the Fifth Assessment Report of the Intergovernmental Panel on Climate Change

Cambridge, United Kingdom and New York, NY, USA: Cambridge University Press; 2014: 869-98.

133. CDP. Annual Cities Survey Data. In: CDP, editor. London, UK; 2020.

134. WHO. WHO Health and Climate Change Survey Report: Tracking Global Progress. Geneva, Switzerland: World Health Organization, 2019.

135. WBG. Urban 2020. https://www.worldbank.org/en/topic/urbandevelopment/overview (accessed 28 April 2020).

136. Watts N, Amann M, Arnell N, et al. The 2018 report of the Lancet Countdown on health and climate change: shaping the health of nations for centuries to come. The Lancet 2018; 392(10163): 2479-514.

137. WMO. Country Profile Database. 2019.

138. Kandel N, Chungong S, Omaar A, Xing J. Health security capacities in the context of COVID-19 outbreak: an analysis of International Health Regulations annual report data from 182 countries. The Lancet 2020; 395(10229): 1047-53.

139. Bouchama A, Dehbi M, Mohamed G, Matthies F, Shoukri M, Menne B. Prognostic factors in heat wave related deaths: a meta-analysis. Archives of internal medicine 2007; 167(20): 2170-6.

140. Salamanca F, Georgescu M, Mahalov A, Moustaoui M, Wang M. Anthropogenic heating of the urban environment due to air conditioning. Journal of Geophysical Research: Atmospheres 2014; 119(10): 5949-65.

141. Waite M, Cohen E, Torbey H, Piccirilli M, Tian Y, Modi V. Global trends in urban electricity demands for cooling and heating. Energy 2017; (127): 786-802.

142. Abel DW, Holloway $T$, Harkey $M$, et al. Air-quality-related health impacts from climate change and from adaptation of cooling demand for buildings in the eastern United States: An interdisciplinary modeling study. PLOS Medicine 2018; 15(7): e1002599. 
2452

2453

2454

2455

2456

2457

2458

2459

2460

2461

2462

2463

2464

2465

2466

2467

2468

2469

2470

2471

2472

2473

2474

2475

2476

2477

2478

2479

2480

2481

2482

2483

2484

2485

2486

2487

2488

2489

2490

2491

2492

2493

2494

2495

2496

2497

143. Hospers L, Smallcombe JW, Morris NB, Capon A, Jay O. Electric fans: A potential stay-at-home cooling strategy during the COVID-19 pandemic this summer? Science of The Total Environment 2020: 141180.

144. Miettinen OS. Proportion of disease caused or prevented by a given exposure, trait or intervention. American journal of epidemiology 1974; 99(5): 325-32.

145. Markevych I, Schoierer J, Hartig T, et al. Exploring pathways linking greenspace to health: Theoretical and methodological guidance. Environmental Research 2017; 158: 301-17.

146. Fong KC, Hart JE, James P. A Review of Epidemiologic Studies on Greenness and Health: Updated Literature Through 2017. Current Environmental Health Reports 2018; 5(1): 77-87.

147. Sreetheran M, Van Den Bosch CCK. A socio-ecological exploration of fear of crime in urban green spaces-A systematic review. Urban Forestry \& Urban Greening 2014; 13(1): 1-18.

148. Wolch JR, Byrne J, Newell JP. Urban green space, public health, and environmental justice: The challenge of making cities 'just green enough'. Landscape and urban planning 2014; 125: 234-44.

149. NASA LP DAAC. MOD13Q1.006 Terra Vegetation Indices 16-Day Global 250m.

150. Florczyk AJ, Melchiorri M, Corbane C, et al. Description of the GHS Urban Centre Database 2015. Brussels, Belgium: European Commission - DG Joint Research Centre, 2019.

151. kMatrix Ltd. Adaptation and Resilience to Climate Change dataset. 2020.

152. Fisk M, Livingstone A, Pit SW. Telehealth in the Context of COVID-19: Changing Perspectives in Australia, the United Kingdom, and the United States. J Med Internet Res 2020; 22(6): e19264.

153. UNEP. Emissions Gap Report 2019. Nairobi: United Nations Environment Programme, 2019.

154. WBG. Global Economic Prospects: Slow Growth, Policy Challenges. Washington, DC, USA: World Bank Group; 2020.

155. Le Quéré $\mathrm{C}$, Jackson $\mathrm{RB}$, Jones $\mathrm{MW}$, et al. Temporary reduction in daily global $\mathrm{CO} 2$ emissions during the COVID-19 forced confinement. Nature Climate Change 2020.

156. Lelieveld J, Evans JS, Fnais M, Giannadaki D, Pozzer A. The contribution of outdoor air pollution sources to premature mortality on a global scale. Nature 2015; 525(7569): 367.

157. Sellers S, Ebi KL, Hess J. Climate change, human health, and social stability: addressing interlinkages. Environmental health perspectives 2019; 127(04): 045002.

158. IEA. World Energy Outlook 2019. Paris: IEA, 2019.

159. IEA. IEA Statistical Report. Paris: IEA, 2020.

160. Peters GP, Marland G, Le Quéré C, Boden T, Canadell JG, Raupach MR. Rapid growth in CO2 emissions after the 2008-2009 global financial crisis. Nature Climate Change 2012; 2(1): 2-4.

161. IEA. World Extended Energy Balances. UK Data Service; 2020.

162. Bergen T. Sweden and Austria close their last coal plants. 2020. https://inhabitat.com/sweden-and-austria-close-their-last-coal-plants/.

163. IEA. Sustainable Recovery: World Energy Outlook Special Report. Paris, France: International Energy Agency, 2020.

164. Roth GA, Abate D, Abate KH, et al. Global, regional, and national age-sex-specific mortality for 282 causes of death in 195 countries and territories, 1980-2017: a systematic analysis for the Global Burden of Disease Study 2017. The Lancet 2018; 392(10159): 1736-88.

165. WHO. Burden of disease from Household Air Pollution for 2016. Geneva, Switzerland: World Health Organization, 2018.

166. Hajat A, Hsia C, O'Neill MS. Socioeconomic Disparities and Air Pollution Exposure: a Global Review. Current environmental health reports 2015; 2(4): 440-50.

167. WHO. Ambient air pollution database, 2018 update. Geneva, Switzerland: World Health Organization, 2018. 
168. Amann M, Bertok I, Borken-Kleefeld J, et al. Cost-effective control of air quality and greenhouse gases in Europe: Modeling and policy applications. Environmental Modelling \& Software 2500 2011; 26(12): 1489-501.

2501 169. IEA. World Energy Outlook 2018. Paris, France: International Energy Agency, 2018.

2502 170. Zhang $Q$, Zheng $Y$, Tong $D$, et al. Drivers of improved $P_{2.5}$ air quality in China from 2013 to 2017. Proceedings of the National Academy of Sciences 2019; 116(49): 24463-9.

2504

2505

172. Milner J, Hamilton I, Woodcock J, et al. Health benefits of policies to reduce carbon emissions. BMJ 2020; 368: 16758.

173. International Transport Forum. Income Inequality, Social Inclusion and Mobility. Paris, France: Organisation for Economic Co-operation and Development, 2017.

174. IEA. Global EV Outlook. Paris: International Energy Institute, 2019.

175. Food Climate Research Network Foodsource: Food systems and greenhouse gas emissions. 2020. https://foodsource.org.uk/31-what-food-system\%E2\%80\%99s-contribution-global-ghgemissions-total (accessed 30 April 2020).

176. Carlson KM, Gerber JS, Mueller ND, et al. Greenhouse gas emissions intensity of global croplands. Nature Climate Change 2017; 7(1): 63-8.

177. FAO. FAOSTAT. 2020.

178. Herrero M, Havlík $\mathrm{P}$, Valin $\mathrm{H}$, et al. Biomass use, production, feed efficiencies, and greenhouse gas emissions from global livestock systems. Proceedings of the National Academy of Sciences 2013; 110(52): 20888-93.

179. Global Alliance for Improved Nutrition. GAIN Briefing Paper Series 2 - Animal-source foods for human and planetary health. Geneva, Switzerland: Global Alliance for Improved Nutrition (GAIN), 2020.

180. Springmann $M$, Clark $M$, Mason- $D^{\prime} C r o z ~ D$, et al. Options for keeping the food system within environmental limits. Nature 2018; 562(7728): 519-25.

181. Willett W, Rockstrom J, Loken B, et al. Food in the Anthropocene: the EAT-Lancet Commission on healthy diets from sustainable food systems. The Lancet 2019; 393(10170): 447-92.

182. FAO. Food balance sheets: a handbook. Rome, Italy: Food and Agriculture Organization of the United Nations; 2001.

183. Dietzenbacher E, Los B, Stehrer R, Timmer M, De Vries G. The construction of world inputoutput tables in the WIOD project. Economic Systems Research 2013; 25(1): 71-98.

184. Fullman N, Yearwood J, Abay SM, et al. Measuring performance on the Healthcare Access and Quality Index for 195 countries and territories and selected subnational locations: a systematic analysis from the Global Burden of Disease Study 2016. The Lancet 2018; 391(10136): 2236-71.

185. Stadler K, Wood R, Bulavskaya T, et al. EXIOBASE 3: Developing a time series of detailed environmentally extended multi-regional input-output tables. Journal of Industrial Ecology 2018; 22(3): 502-15.

186. WBG. Consumer price index $(2010=100) .2020$. https://data.worldbank.org/indicator/FP.CPI.TOTL?end=2017\&locations=US\&start=2000.

187. WHO. Current health expenditure by financing schemes, in Global Health Expenditure Database. In: Organization WH, editor.; 2020.

188. NHS England, Public Health England. Reducing the use of natural resources in health and social care. London: NHS England, 2018.

189. NHS England. Greener NHS campaign to tackle climate 'health emergency'. 2020. https://www.england.nhs.uk/2020/01/greener-nhs-campaign-to-tackle-climate-health-emergency/ (accessed 26 April 2020).

190. Swiss Re Institute. Sigma explorer. Zurich, Switzerland: Swiss Re; 2020. 
2546 191. WBG. World Development Indicators. Washington, DC, USA: World Bank Group, 2020.

2547 192. NatCatSERVICE. Relevant weather-related loss events worldwide 1990-2018. Munich, 2548 Germany: Munich Re, 2020.

2549 193. OECD. Mortality Risk Valuation in Environment, Health and Transport Policies. OECD 2550 Publishing; 2012.

2551 194. WBG. GNI (current US\$̦). Washington, DC, USA: World Bank Group; 2020.

2552 195. European Commission. Part III: Annexes to Impact Assessment Guidelines. Brussels, Belgium: 2553 European Commission, 2009.

2554 196. IEA. World Energy Investment 2020. In: IEA, editor. Paris, France; 2020.

2555 197. IRENA. Transforming the energy system. Abu Dhabi: International Renewable Energy Agency,

2556

2557

2558

2559

2560

2561

2562

2563

2564

2565

2566

2567

2568

2569

2570 2019.

198. Balise VD, Meng C-X, Cornelius-Green JN, Kassotis CD, Kennedy R, Nagel SC. Systematic review of the association between oil and natural gas extraction processes and human reproduction. Fertility and Sterility 2016; 106(4): 795-819.

199. Cortes-Ramirez J, Naish S, Sly PD, Jagals P. Mortality and morbidity in populations in the vicinity of coal mining: a systematic review. BMC public health 2018; 18(1): 721.

200. IBISWorld. IBISWorld Industry Report: Global Coal Mining. Los Angeles, CA: IBISWorld, 2019.

201. IBISWorld. IBISWorld Industry Report: Global Oil \& Gas Exploration \& Production. Los Angeles, CA: IBISWorld, 2020.

202. IRENA. Renewable Energy and Jobs: Annual Review 2020. Abu Dhabi, United Arab Emirates: International Renewable Energy Agency, 2020.

203. Halcoussis D, Lowenberg AD. The effects of the fossil fuel divestment campaign on stock returns. The North American Journal of Economics and Finance 2019; 47: 669-74.

204. Hunt C, Weber O. Fossil fuel divestment strategies: Financial and carbon-related consequences. Organization \& Environment 2019; 32(1): 41-61.

2571

205. 350.org.

Divestment

Commitments.

2020.

2572 https://gofossilfree.org/divestment/commitments/ (accessed 14 April 2019).

2573 206. Stiglitz JE. Addressing climate change through price and non-price interventions. European

2574 Economic Review 2019; 119: 594-612.

2575 207. Zapf M, Pengg H, Weindl C. How to Comply with the Paris Agreement Temperature Goal: Global Carbon Pricing According to Carbon Budgets. Energies 2019; 12(15): 2983.

208. Coady D, Parry I, Le N, Shang B. Global fossil fuel subsidies remain large: an update based on country-level estimates: International Monetary Fund, 2019.

209. Gençsü I, McLynn M, Runkel M, et al. Phase-out 2020: Monitoring Europe's fossil fuel subsidies: ODI and Climate Action Network,, 2017.

210. IEA. Fossil fuel subsidies. 2019. https://www.iea.org/weo/energysubsidies/ (accessed 25th November 2019).

211. OECD. OECD Companion to the Inventory of Support Measures for Fossil Fuels 2018. Paris, France: OECD Publishing; 2018.

212. WBG. Carbon Pricing Dashboard. 2019. https://carbonpricingdashboard.worldbank.org/ (accessed 25th November 2019).

213. Berkes F. Sacred ecology. New York, NY: Routledge; 2008.

214. Duyck S, Lennon E. National Human Rights Institutions and the 2018 Talanoa Dialogue: showcasing that climate action should be human rights-based. 2018 . https://nbnresolving.org/urn:nbn:de:0168-ssoar-59529-7 (accessed April 5, 2020.

215. Jamison A. Climate change knowledge and social movement theory. Wiley Interdisciplinary Reviews: Climate Change 2010; 1(6): 811-23. 
216. Pew Research Center. Climate change still seen as the top global threat, but cyberattacks a rising concern. 2019. https://www.pewresearch.org/global/2019/02/10/climate-change-still-seen-asthe-top-global-threat-but-cyberattacks-a-rising-concern/ (accessed April 5, 2020. 217. Poortinga W, Whitmarsh L, Steg L, Böhm G, Fisher S. Climate change perceptions and their individual-level determinants: A cross-European analysis. Global environmental change 2019; 55: 2535. climate emergency. BioScience 2019; 70(1): 8-12.

219. Thackeray SJ, Robinson SA, Smith P, et al. Civil disobedience movements such as School Strike for the Climate are raising public awareness of the climate change emergency. Global Change Biology, 2020; 26: 1042-4.

220. United Nations Framework Convention on Climate Change. Local communities and indigenous peoples platform: Proposals on operationalization based on the open multi-stakeholder dialogue and submissions [online]. 2017. http://unfccc.int/resource/docs/2017/sbsta/eng/06.pdf (accessed April 5, 2020.

221. Boykoff MT. Who speaks for the climate?: Making sense of media reporting on climate change. Cambridge: Cambridge University Press; 2011.

222. Carvalho A, Burgess J. Cultural circuits of climate change in UK broadsheet newspapers, 19852003. Risk Analysis: An International Journal 2005; 25(6): 1457-69.

223. Gavin NT. Addressing climate change: a media perspective. Environmental Politics 2009; 18(5): 765-80.

224. Happer C, Philo G. The role of the media in the construction of public belief and social change. Journal of social and political psychology 2013; 1(1): 321-36.

225. Hassid J. Controlling the Chinese Media: An Uncertain Business. Asian Survey 2008; 48(3): 41430.

226. Wang H, Sparks C, Huang Y. Measuring differences in the Chinese press: A study of People's Daily and Southern Metropolitan Daily. Global Media and China 2018; 3(3): 125-40.

227. Alexander DD. The top 500 sites on the Web. 2018. https://www.alexa.com/topsites.

228. Bornmann L. Scientific peer review. Annual review of information science and technology 2011; 45(1): 197-245.

229. Mesgari M, Okoli C, Mehdi M, Nielsen FÅ, Lanamäki A. "The sum of all human knowledge": A systematic review of scholarly research on the content of Wikipedia. Journal of the Association for Information Science and Technology 2015; 66(2): 219-45.

230. Schroeder R, Taylor L. Big data and Wikipedia research: social science knowledge across disciplinary divides. Information, Communication \& Society 2015; 18(9): 1039-56.

231. Wikimedia Statistics. https://stats.wikimedia.org/v2/\#/all-projects (accessed April 5, 2020.

232. Lewis J, Williams A, Franklin B. A compromised fourth estate? UK news journalism, public relations and news sources. Journalism studies 2008; 9(1): 1-20.

233. Molek-Kozakowska K. Popularity-driven science journalism and climate change: A critical discourse analysis of the unsaid. Discourse, Context \& Media 2018; 21: 73-81.

234. General Assembly of the United Nations. United Nations General Debate of the 74th session of the General Assembly 24-27 September 2019. 2019. https://gadebate.un.org/generaldebate74/en/ (accessed April 7, 2020.

235. Peterson MJ. General Assembly. In: Weiss TG, Daws S, eds. The Oxford Handbook on the United Nations. Oxford, UK: Oxford University Press; 2018.

236. Brandi C, Dzebo A, Janetschek H, Lambert C, Savvidou G. NDC-SDG Connections. 2017. https://klimalog.die-gdi.de/ndc-sdg (accessed April 5, 2020. 

https://www.researchgate.net/publication/289451213 health_in intended_nationally_determined contributions_indcs_executive_summary/citation/download (accessed April 5, 2020.

238. Jeswani HK, Wehrmeyer W, Mulugetta Y. How warm is the corporate response to climate change? Evidence from Pakistan and the UK. Business Strategy and the Environment 2008; 17(1): 4660.

239. World Economic Forum. Two Degrees of Transformation. Businesses are coming together to lead on climate change. Will you join them? 2019. https://www.weforum.org/reports/two-degreesof-transformation-businesses-are-coming-together-to-lead-on-climate-change-will-you-join-them. Press; 2015.

241. United Nations Global Compact. https://www.unglobalcompact.org/ (accessed 13.04.19.

242. State Council of China. Air pollution prevention and control action plan. 2013. http://www.gov.cn/jrzg/2013-09/12/content_2486918.htm (accessed April 1, 2020.

243. Auerbach Y, Bloch-Elkon Y. Media framing and foreign policy: The elite press vis-a-vis US policy in Bosnia, 1992-95. Journal of Peace Research 2005; 42(1): 83-99.

244. Billett S. Dividing climate change: global warming in the Indian mass media. Climatic change 2010; 99(1-2): 1-16.

245. Boykoff MT, Boykoff JM. Balance as bias: global warming and the US prestige press. Global environmental change 2004; 14(2): 125-36.

246. Nagarathinam S, Bhatta A. Coverage of climate change issues in Indian newspapers and policy implications. Current Science 2015; 108(11): 1972-3.

247. Schäfer MS, Ivanova A, Schmidt A. What drives media attention for climate change? Explaining issue attention in Australian, German and Indian print media from 1996 to 2010. International Communication Gazette 2014; 76(2): 152-76.

248. Shehata A, Hopmann DN. Framing Climate Change. Journalism Studies 2012; 13(2): 175-92.

249. Brooks J, McCluskey S, Turley E, King N. The Utility of Template Analysis in Qualitative Psychology Research. Qualitative Research in Psychology 2015; 12(2): 202-22.

250. Segev E, Sharon AJ. Temporal patterns of scientific information-seeking on Google and Wikipedia. Public Understanding of Science 2017; 26(8): 969-85.

251. Yoshida M, Arase Y, Tsunoda T, Yamamoto M. Wikipedia page view reflects web search trend. Proceedings of the ACM Web Science Conference; 2015; 2015. p. 1-2.

252. Wulczyn E, Taraborelli D. Wikipedia clickstream. figshare. 2015.

253. Zachte E. WikiStats. Page Views for Wikipedia, Both Sites, Normalized. 2019. https://stats.wikimedia.org/EN/TablesPageViewsMonthlyCombined.htm. (accessed April 5, 2020.

254. United Nations. UN Climate Action Summit 2019.2019. https://www.un.org/en/climatechange/un-climate-summit-2019.shtml (accessed April 5, 2020.

255. Baturo A, Dasandi N, Mikhaylov SJ. Understanding state preferences with text as data: Introducing the UN General Debate corpus. Research \& Politics 2017; 4(2): 2053168017712821.

256. Jankin Mikhaylov S, Baturo A, Dasandi N. United Nations General Debate Corpus. In: Jankin Mikhaylov S, editor. V5 ed: Harvard Dataverse; 2017.

257. World Health Organization. Health in the NDCs. Geneva, Switzerland: World Health Organization, 2019.

258. United Nations Global Compact. Corporate sustainability in the world economy. New York: UN Global Compact, 2008. 
2686 259. Institute for Global Environmental Strategies Allto University, D-mat Ltd. 1.5-Degree 2687 Lifestyles: Targets and options for reducing lifestyle carbon footprints. Technical Report. 2019. 2688 https://www.iges.or.jp/en/pub/15-degrees-lifestyles-2019/en (accessed April 5, 2020.

2689 260. Pretty J. The consumption of a finite planet: well-being, convergence, divergence and the 2690 nascent green economy. Environmental and Resource Economics 2013; 55(4): 475-99.

2691 